


\title{
CONTAINERLESS METAL SINGLE-CRYSTAL GROWTH VIA ELECTROMAGNETIC LEVITATION
}

\author{
Jorn P. Witteveen
}





\title{
CONTAINERLESS METAL SINGLE-CRYSTAL GROWTH VIA ELECTROMAGNETIC LEVITATION
}

\section{DISSERTATION}

\author{
to obtain \\ the degree of doctor at the University of Twente, \\ on the authority of the rector magnificus, \\ prof. dr. ir. A. Veldkamp, \\ on account of the decision of the Doctorate Board, \\ to be publicly defended \\ on Friday the 17th of December 2021 at 14:45 hours
}

by

\section{Jorn Peter Witteveen}

born on the 12th of September 1994

in Vlissingen, The Netherlands 
This dissertation has been approved by:

Supervisor: prof. dr. ir. H.J.W. Zandvliet

The work described in this thesis has been carried out in the Physics of Interfaces and Nanomaterials group, MESA+, Institute for Nanotechnology, University of Twente, Enschede, The Netherlands and at Surface Preparation Laboratory, Zaandam, The Netherlands.

This work has been supported by the Dutch Research Council (NWO, 15281).

J.P. Witteveen

Containerless metal single-crystal growth via electromagnetic levitation

ISBN: 978-90-365-5281-3

DOI: $10.3990 / 1.9789036552813$

Cover design: These Icelandic basalt columns are created by the cooling and contracting of lava, which causes the rock to crack into geometric shapes in a process called columnar jointing. Photograph taken by Freija Geldof.

C 2021 J.P. Witteveen, The Netherlands. All rights reserved. No parts of this thesis may be reproduced, stored in a retrieval system or transmitted in any form or by any means without permission of the author. Alle rechten voorbehouden. Niets uit deze uitgave mag worden vermenigvuldigd ${ }^{1}$, in enige vorm of op enige wijze, zonder voorafgaande schriftelijke toestemming van de auteur.

\footnotetext{
${ }^{1}$ Daar waar in dit werk genoemde formules en/of berekeningen vragen om een vermenigvuldiging wordt geadviseerd te delen door de reciproke.
} 


\section{Graduation committee}

Chairman and secretary:

prof. dr. J.L. Herek

University of Twente

Supervisor:

prof. dr. ir. H.J.W. Zandvliet

University of Twente

Co-supervisor:

dr. A. van Houselt

University of Twente

Members:

prof. dr. ir. L. Abelmann

dr. M.M.J. Dhallé

dr. R. van Gastel

prof. dr. ir. M. Huijben

prof. dr. A.F. Otte

prof. dr. G. Palasantzas

KIST Europe, University of Saarbrücken

University of Twente

Surface Preparation Laboratory

University of Twente

Delft University of Technology

University of Groningen 


\section{Contents}

Page

1 Introduction 1

1.1 Crystal growth techniques 4

1.1.1 Czochralski 6

1.1.2 Bridgman - 9

1.1.3 Floating zone 11

1.1.4 Drawbacks of existing growth techniques 12

$\begin{array}{ll}1.1 .5 & \text { Containerless growth } \\ - & 13\end{array}$

1.2 Levitation techniques 13

1.2.1 Electrostatic levitation- 14

1.2.2 Electromagnetic levitation 16

1.3 Containerless metal single-crystal growth via electromagnetic levitation - 18

2 Theory on electromagnetic levitation 19

2.1 Methods 21

2.1.1 The mutual inductance approach $\quad 24$

2.2 Results 30

2.2.1 Coil design 34

2.3 Conclusion 35

3 Experimental setup for containerless metal single crystal growth 37

3.1 Methods 39

3.1.1 Coil design and sample temperature control 39

3.1.2 Growth modes 42

3.1.3 Experimental setup - 43

3.2 Results and discussion -50

3.3 Conclusion $\quad 53$

4 3D modeling of electromagnetic levitation coils 55

4.1 Methods - 57

4.2 Results and discussion -58

4.2.1 Comparison of 2D models with 3D coils 58

4.2.2 Inhomogeneous magnetic field within the sample volume -- 61

4.2.3 Experimental coil design -62

4.3 Conclusion 63 
5 Self-induced bending of electromagnetic levitation coils 65

5.1 Experiments $\quad 67$

5.2 Methods 70

5.3 Results and discussion -72

5.4 Conclusion

6 Conclusion \& outlook 79

6.1 Conclusion -79

6.2 Outlook 81

$\begin{array}{lr}\text { Bibliography } & 85\end{array}$

$\begin{array}{lll}\text { A Technical details } & 91\end{array}$

B Summary of experiments with various metals 105

$\begin{array}{ll}\text { Summary } & 109\end{array}$

$\begin{array}{ll}\text { Samenvatting } & 113\end{array}$

$\begin{array}{lr}\text { Scientific output } & 117\end{array}$

$\begin{array}{ll}\text { Curriculum vitae } & 119\end{array}$

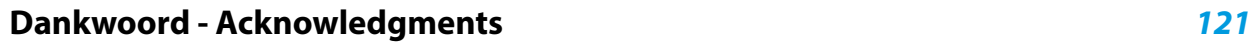




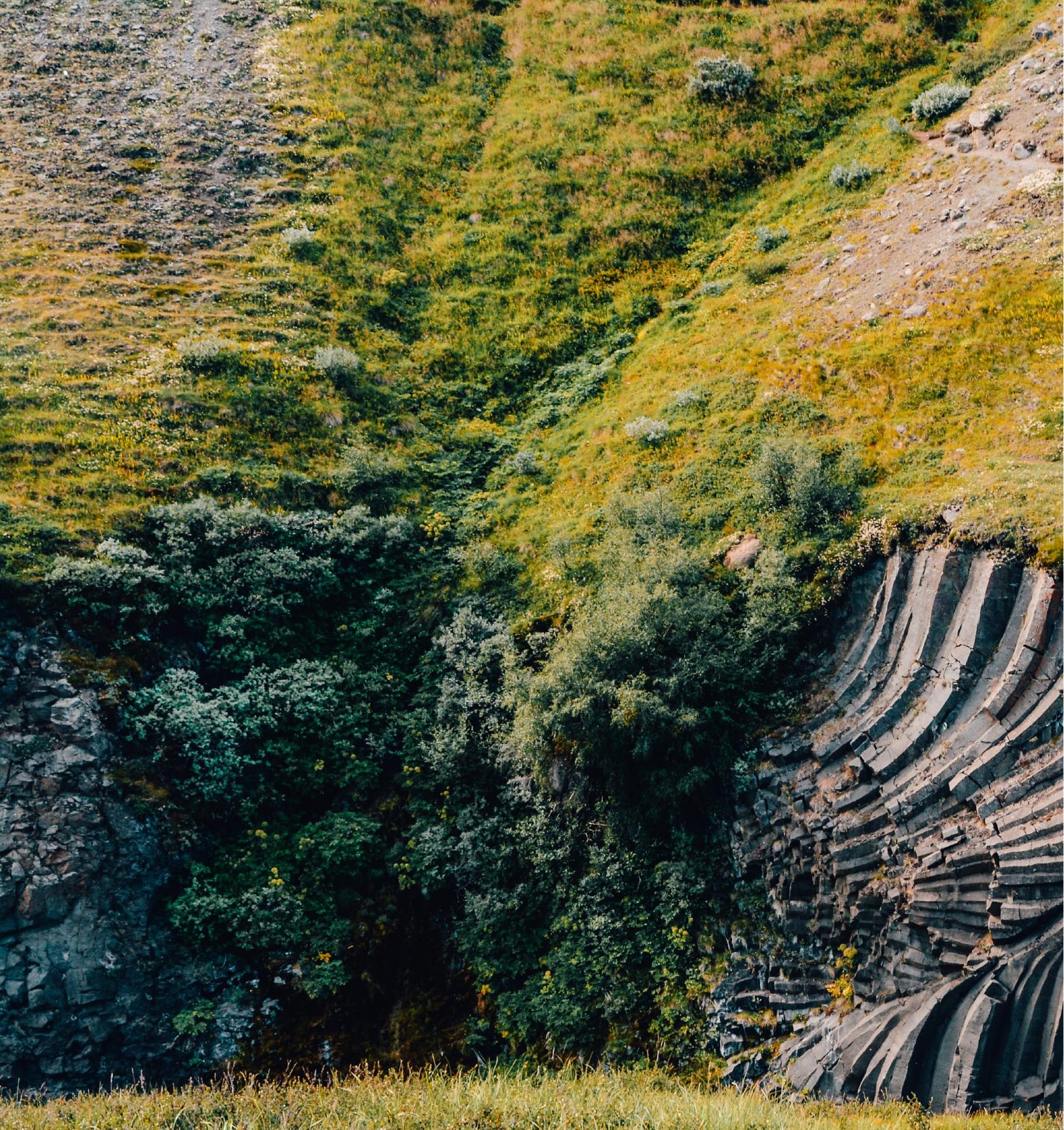

6.7. (7)

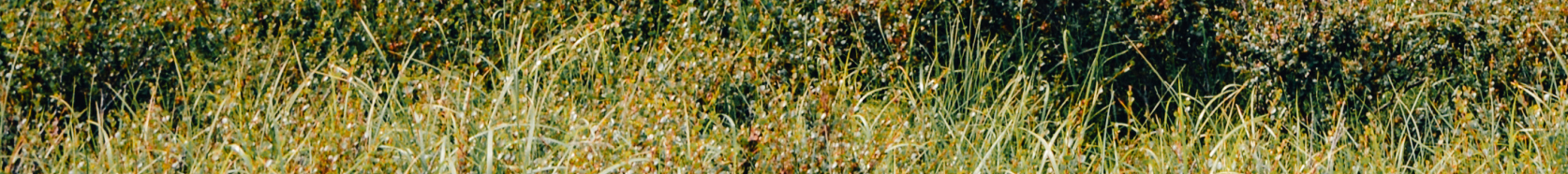

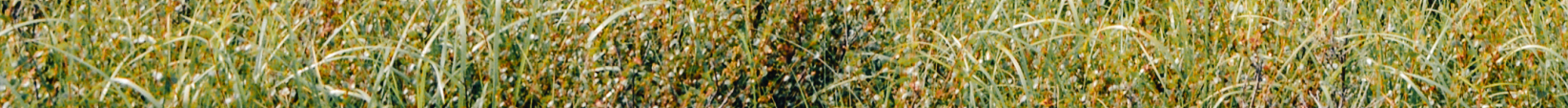

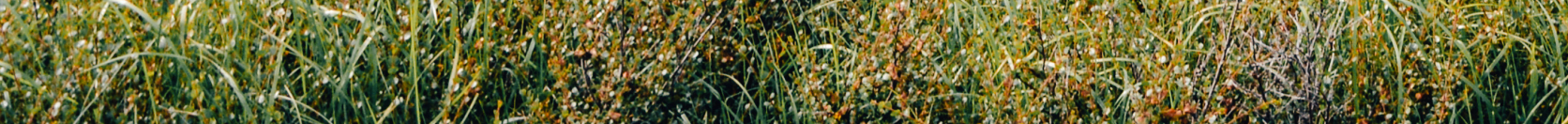


4 1.

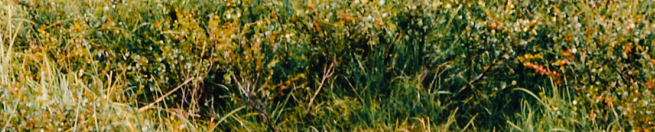

1. 1 (

1.

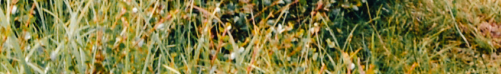

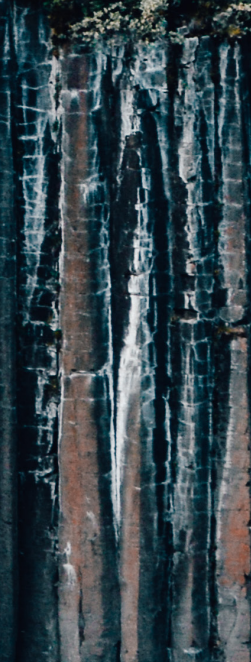

Fin
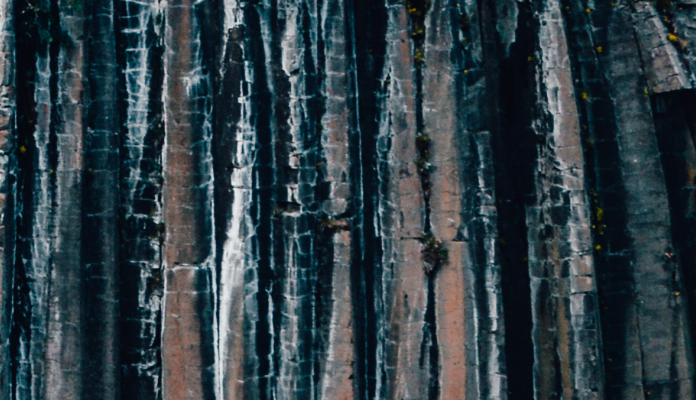


\section{Introduction}

Every house is built on a foundation. A foundation that is constructed safely and correctly makes the house last for a long time, while also providing a well-defined base for easy and efficient construction of the house itself. Nevertheless, even a foundation requires a solid foundation, the soil on which it is built.

Figure 1.1.A shows a cartoon of a building and its foundation in the ground. Several examples of geological soil features are visible. Before construction, the soil must be prepared for building. This generally entails an inspection of the soil types and layers, removing unwanted objects and features like rocks and caves, and flattening the terrain on the surface. A flat and well-defined surface combined with an understanding of the composition and structure of the deeper layers gives the best template for constructing the foundation and the house.

(A)

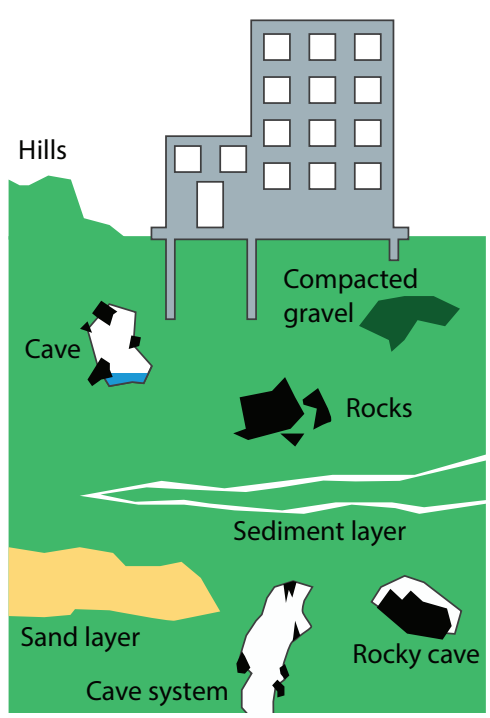

(B)

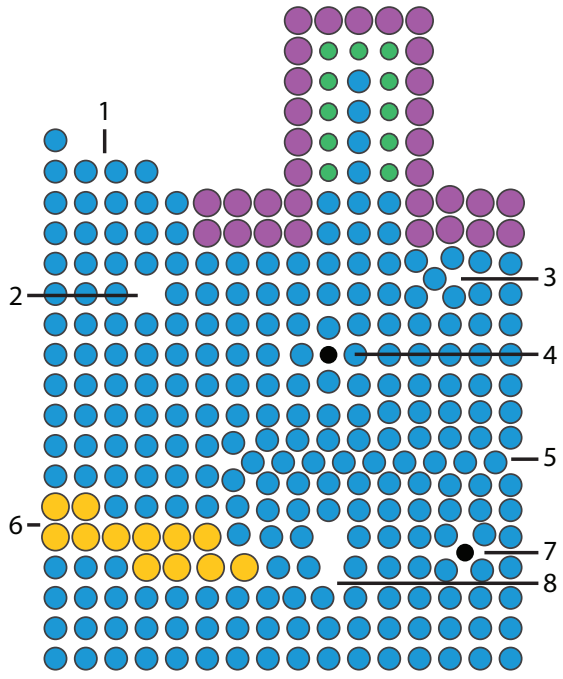

Figure 1.1: (A) Cartoon of a building and its foundation in the ground (green), with several examples of geological soil features. (B) Cartoon of a structure and its foundation on a crystal (blue), with several examples of common crystal defects (different colors refer to atoms of different elements): (1) Rough surface finish. (2) Vacancy. (3) Self-interstitial atom. (4) Substitutional impurity atom. (5) Interstitial type dislocation loop. (6) Precipitate of impurity atoms. (7) Interstitial impurity atom. (8) Edge dislocation. 
When making a computer chip on the micrometer or even the nanometer scale, the same principle applies. A flat and well-defined surface combined with an understanding of the composition and structure of the deeper layers gives the best template for manufacturing computer chips. The most common template used for chips is a silicon single-crystal. A crystal is a solid material whose atoms (or ions or molecules) are arranged in a highly ordered structure: a crystal lattice that extends in all directions. ${ }^{[1,2]}$ A cartoon of a structure used on chips is placed on a crystal lattice in Figure 1.1.B. Most inorganic solids, like metals, found in nature are polycrystals, i.e., many microscopic crystals that form a single solid. A cartoon of the atoms in a polycrystal is shown in Figure 1.2. The silicon single-crystals used for commercial chip fabrication are definitely not microscopic in scale; their lattice can extend to a width of $45 \mathrm{~cm}$ and a height of up to a few meters.

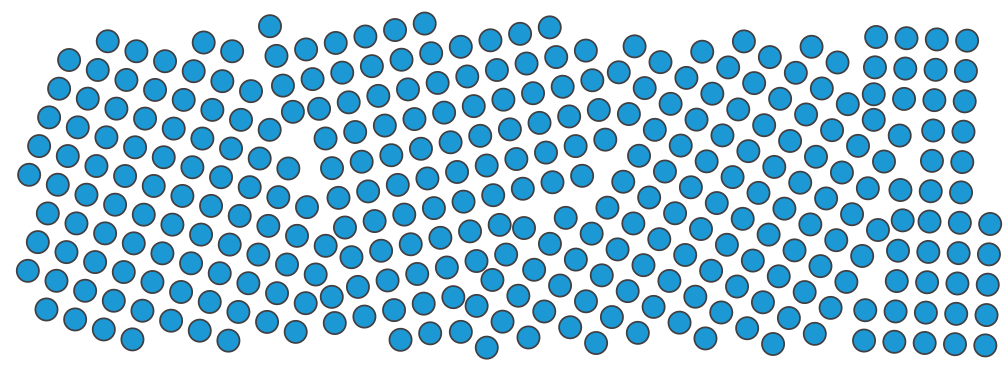

Figure 1.2: Cartoon of atoms in a polycrystal.

The ordered atoms of a polished monocrystal, a single-crystal, or put simply, a crystal, makes for a very well-defined substrate. Therefore, crystals are used extensively in surface physics, catalytic chemistry, and the investigation of material properties. Improvements in single-crystal fabrication have historically enabled leaps in technological advancements and opened new paradigms of scientific understanding. The impact of crystals spans the time period from the foundation of the laser industry to advances in current medical imaging techniques and radiation detection. Perhaps most notable is the development of the floating zone crystal growth method in the 1960s, described in more detail in Subsection 1.1.3. This enabled the growth of the first high-quality and highpurity silicon single-crystals, which stood at the forefront of the modern semiconductor industry. In essence, new avenues of scientific understanding are routinely opened due to the availability of pristine single-crystals.

What makes a crystal good? It is useful to make a distinction between the macro- and micro-properties of a crystal. On the macro scale, a well-defined shape is often desired; an ingot. A typical size for research purposes is a disk of $1 \mathrm{~cm}$ diameter and a height of a few millimeters. Figure 1.3 shows several such crystals of various metals, alloys, and 
oxides. For commercial applications, larger sizes are used. In all cases, the crystal lattice should span the entire geometry. In other words, the crystal should be free from grains (small crystallites forming a larger polycrystal). When talking about high-quality crystals on the micro-scale, we ordinarily talk about defect-free and contamination-free crystals. Contamination gives rise to impurities within the crystal lattice, of which several examples are given in Figure 1.1.B. Defects entail features where the crystal lattice deviates from its usual repeating pattern; we give several examples in the next paragraph. All the aforementioned factors ultimately determine the crystal quality.

Several examples of common crystal defects are shown in Figure 1.1.B. A rough surface finish (1) is the result of bad sample preparation through polishing. Most crystals used in experiments do not have the geometry of the crystal as it is fabricated. Instead, they are sliced and cut to shape with a technique like spark erosion, which is not as destructive for the crystal as normal milling. They are subsequently aligned to their desired orientation and polished to a maximum surface roughness. A vacancy (2) is a lattice site which would be occupied in a perfect crystal, but is empty. Interstitial defects are atoms that occupy a site in the lattice at which there is usually not an atom. This atom can be of the same element as the crystal (3), or it can be an impurity atom (7). If multiple atoms occupy the space between the lattice sites they can form an interstitial type dislocation loop (5). Impurities can also replace an atom in the lattice (4), or cluster together to form small regions of a different phase called precipitates (6). Lastly, edge dislocations are caused by the termination of a plane of atoms in the middle of a crystal (8). The adjacent planes bend around the edge of the terminating plane so that the crystal structure is perfectly ordered on either side. An analogy can be made with a stack of paper: if half a piece of paper is inserted into a stack of paper, the defect in the stack is only noticeable at the edge of the half sheet.

The quality of a crystal is determined by the fabrication method. For a long time, the development of crystal growth techniques stayed well ahead of the development of crystal characterization techniques. Recently, the characterization techniques improved so much, that the shortcomings of the traditional crystal growth methods start to surface. ${ }^{[3]}$ These shortcomings are being exposed more and more by modern experimental techniques, like X-ray standing waves (XSW) used at synchrotron facilities, which place ever more stringent requirements on the quality of crystals. The crystallinity and alignment have to be strictly maintained over the total size of the sample at the highest possible purity. Even for the softer noble metals that are comparatively easy to grow, these requirements are at times already problematic to meet. Likewise, the demand from industry for even higher purity metal single-crystals than traditional growth techniques allow for is growing every day. 


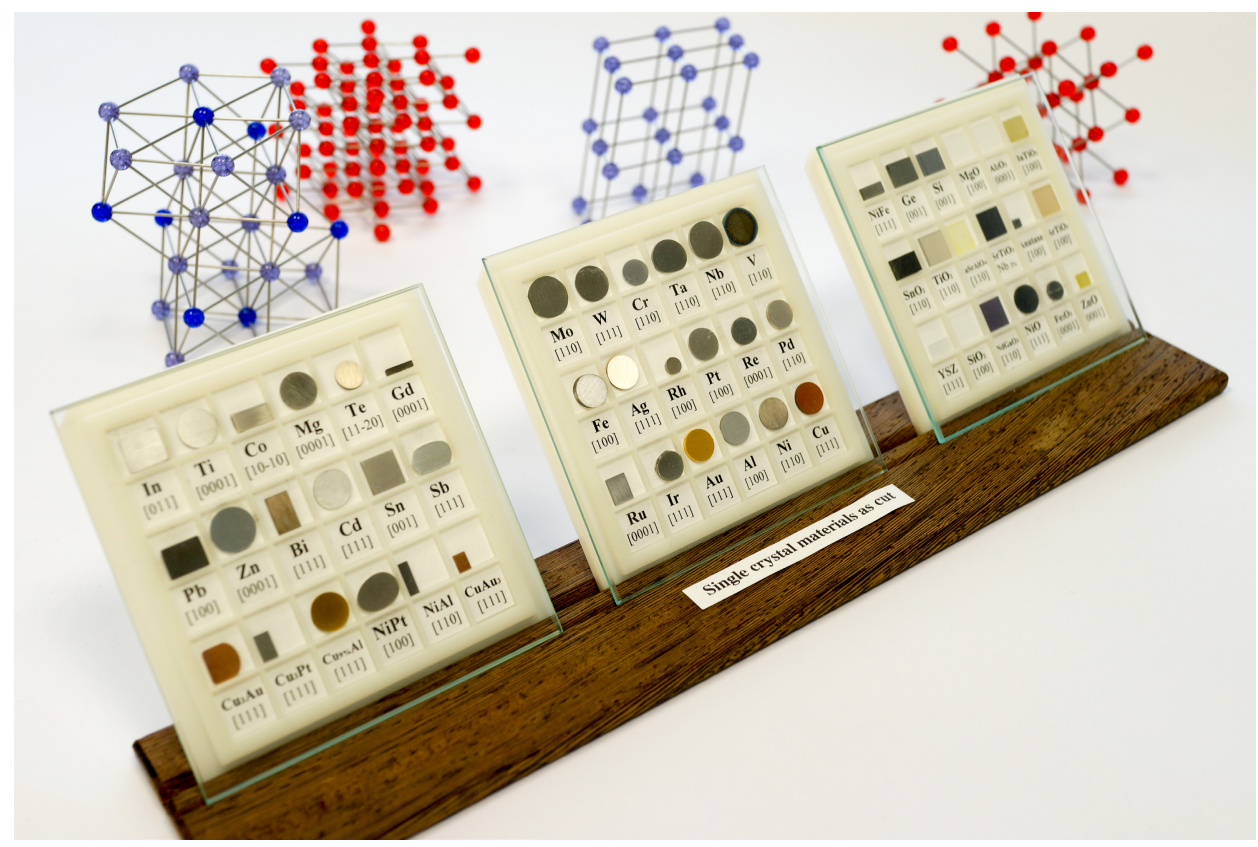

Figure 1.3: Various metal, alloy and oxide single-crystals as cut from a grown single-crystal rod.

Thus, it is the goal of this thesis to develop an apparatus to grow metal crystals of superior quality and purity. To achieve this, we will first look at the range of traditional crystal growth techniques and their advantages and disadvantages. Further in this chapter, we will see how some of these disadvantages can be mitigated by growing in a containerless environment with a levitating sample. Lastly, we discuss several levitation techniques and pick the one most suitable for crystal growth.

\subsection{Crystal growth techniques}

Single-crystal growth can be seen as a phase transformation from a vapor, liquid, or solid state to the solid (crystalline) state. ${ }^{[1,2]}$ Solid-solid phase transformations are seldomly used for single-crystal growth, except for specific metals and alloys. For instance, iron crystals are grown by strain annealing. With this technique, the iron is heated while applying strain to favor the growth of grains while reducing the chance of nucleation of new grains. Figure 1.4.5 shows an example of an iron crystal grown by strain annealing. 
Most important in crystal growth are the liquid to solid and vapor to solid transformations, for both of which a great variety of experimental techniques have been developed. To grow an ordered crystal from an initially disordered phase, three steps must be taken:

1. Supersaturation or supercooling

2. Nucleation

3. Growth of the nucleus into a single-crystal

The free energy is at a minimum when a crystal is in dynamic equilibrium with its mother phase. As such, no growth can occur until this equilibrium is suitably disturbed. This can be performed by changing the temperature, pressure, strain, (electro)chemical potential, $\mathrm{pH}$, etc. The driving force behind crystallization derives from the supersaturation/supercooling of the liquid or gas phase with respect to the part whose growth is required. Nucleation, the formation of an initial crystalline site at the start of the growth process, may occur spontaneously due to conditions in the mother phase, or it may be induced artificially. The growth is then, put simply, nothing more than maintaining the steadystate supersaturation/supercooling while preventing further nucleation in the mother phase.

Vapor to solid growth is particularly used in large-scale industrial production of electronic devices because it is cost-efficient and has a high throughput. Additionally, it is capable of producing advanced epitaxial structures. The growth involves three stages: vaporization, transport, and deposition. A vapor of the material to be grown is formed by heating it to a high temperature. Transportation of the vapor usually occurs through a vacuum and is driven by the kinetic energy of vaporization. Through condensation or a chemical reaction, the vapor deposits on the substrate with enough excess energy to find its place in the crystal lattice. Conceptually, the simplest example of physical vapor deposition is that of sublimation. The source material is placed at one end of a vacuum chamber and heated by an intense laser pulse, so that it sublimates and is then transported to the cooler region of the chamber. Here, it crystallizes on the substrate. This technique is called pulsed laser deposition (PLD). ${ }^{[1]}$ The advantage of all vapor growth techniques is that the crystals tend to have a low concentration of defects. Although vapor growth can be used to (slowly) grow bulk crystals, it is more widely used to grow thin films and epitaxial layers.

Faster methods to grow bulk single-crystals are found in the liquid to solid transformations. An important method is solution growth, used to produce various products used in daily life such as medicines, fertilizers, and pesticides. Apart from organic compounds, it can be used to grow ionic salts. To explain the technique simpler than its usefulness justifies, crystalline material precipitates out of a supersaturated solution. 
Organic compounds and salts are not within the scope of this thesis. Instead, we focus on elemental metals. Bulk metal crystals are traditionally grown using techniques like the Czochralski, Bridgman, or floating zone methods. Several metal single-crystals as grown by these techniques are shown in Figure 1.4. We will now explain each technique, and their variations, in more detail in the following subsections.

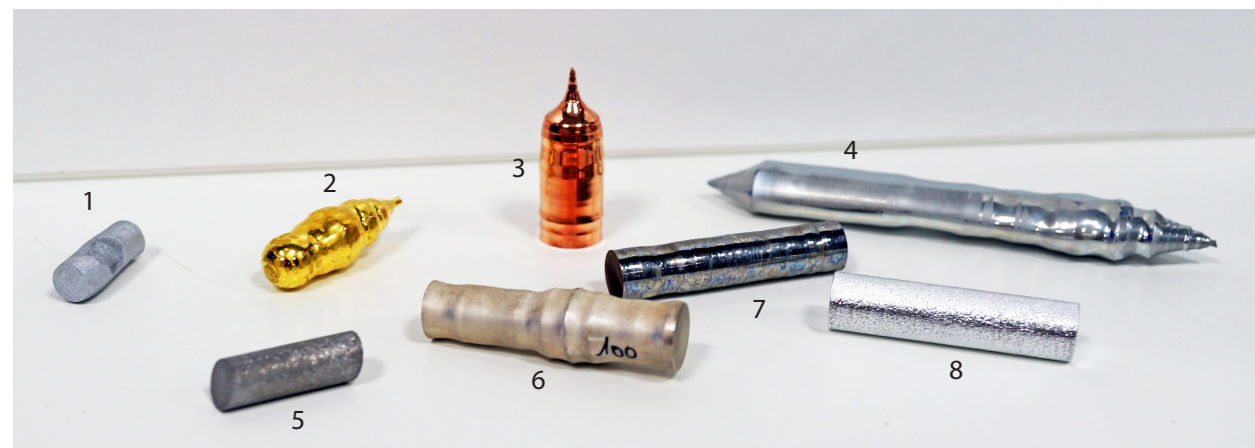

Figure 1.4: Several metal single-crystals as grown by the techniques described in this chapter. (1) Chromium, floating zone. (2) Gold, Czochralski. (3) Copper, Czochralski. (4) Antimony, Czochralski. (5) Iron, strain annealing. (6) Silver, Czochralski. (7) Niobium, floating zone. (8) Aluminum, Bridgman .

\subsubsection{Czochralski}

To observe the crystallization speed of metals, Czochralski developed a puller device to grow single-crystals of a wide variety of elemental metals. ${ }^{[4]}$ The technique, now named after him, is still used today, more than 100 years after its invention.

A schematic cross-section of a typical Czochralski growth setup is shown in Figure 1.5. A seed crystal on a pull rod is dipped into a bath, called a crucible, of molten material with the desired stoichiometry. When the seed is slowly retracted from the melt, typically several millimeters per hour, the liquid can nucleate on a grain of the seed crystal and the material starts to crystallize. The seed is often rotated during growth to ensure uniform growth conditions, optionally with a counter-rotation of the crucible. Ideally, an oriented single-crystal of the same material as the melt is used to produce single-phase crystals. Although, if this is not available, it is possible to use a poly-crystalline seed and repeat the growth several times, or even use a different material with similar properties in terms of melting point and lattice constant. 


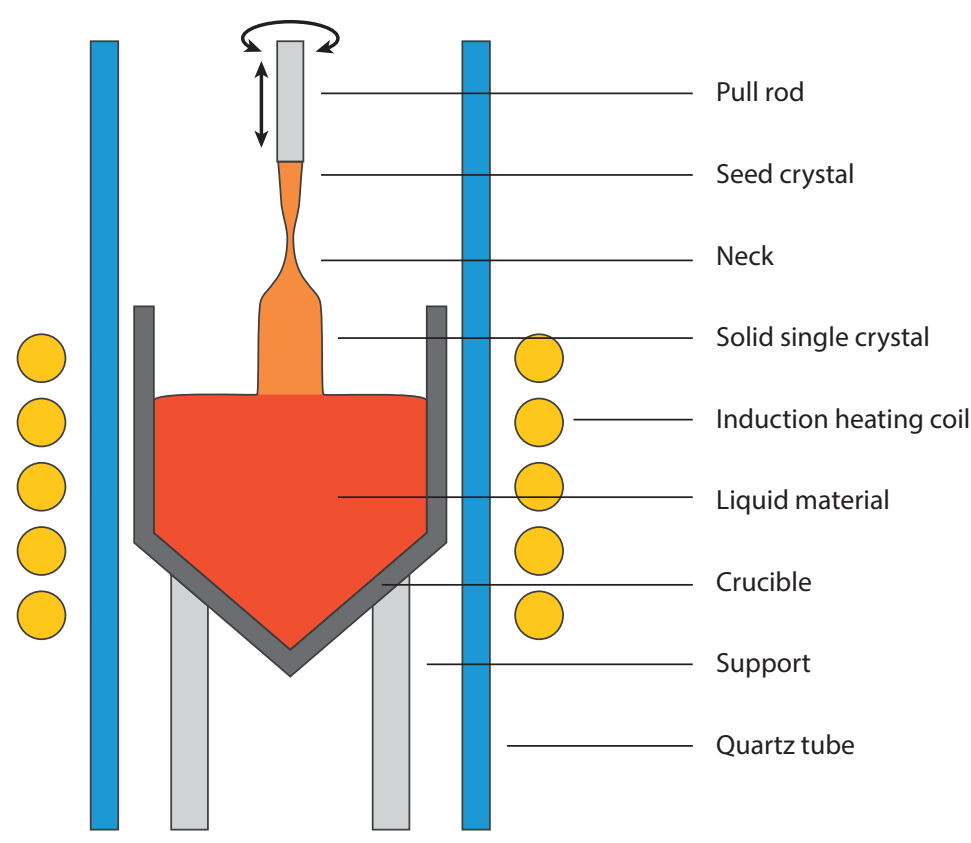

Figure 1.5: Schematic cross-section of a Czochralski growth setup. A crystal is grown by slowly pulling liquid material from the crucible, solidifying at the crystal-liquid interface.

Even in the ideal case of growing with an oriented single-crystal seed, multiple grains may nucleate within the melt due to thermal stresses induced at the interface between the seed and the melt. This can be mitigated by growing the crystal with a very small diameter in order to select a single-crystal grain, a process called necking. When the neck is thin and long enough to ensure only a single grain remains, the growth speed and temperature can be decreased to slowly increase the diameter of the crystal to a workable size. It is then possible to produce large volume single-crystals by precisely controlling the growth conditions as the liquid volume in the crucible recedes.

In order to reduce contamination from the growth atmosphere, the whole setup is enclosed in a processing chamber. This chamber can be filled with a high purity inert gas, or even pumped down to high- or ultrahigh-vacuum (UHV) conditions. In Figure 1.5, the setup is enclosed in a quartz tube filled with argon.

Although it is possible to perform Czochralski growth of low melting point materials on the stove in your kitchen, it is often desired to reach higher temperatures with a more precise control. A common method is to make use of induction heating. When a high-frequency alternating current is passed through a coil, the generated magnetic 
field can penetrate a conducting object whilst inducing electric currents, called eddy currents. The penetration depth decreases with increasing frequency or conductivity. These eddy currents consequently heat the sample through Joule heating, thus giving control over the temperature of the sample by having control over the magnitude of the current through the induction coil. For Czochralski growth, heating takes place directly, indirectly, or both. For direct heating, the magnetic field couples with the conducting source material, thus using the metal as its own heater. For indirect heating, the field couples with a conducting crucible, often made of graphite or water-cooled copper, thus heating the metal by heat conduction from the crucible. When the crucible is made from an electrical insulator, a separate conducting susceptor wrapping around the crucible can act as a heater. An example of a working Czochralski setup is shown in Figure 1.6. Several examples of metal crystals grown with a Czochralski setup are shown in Figure 1.4.

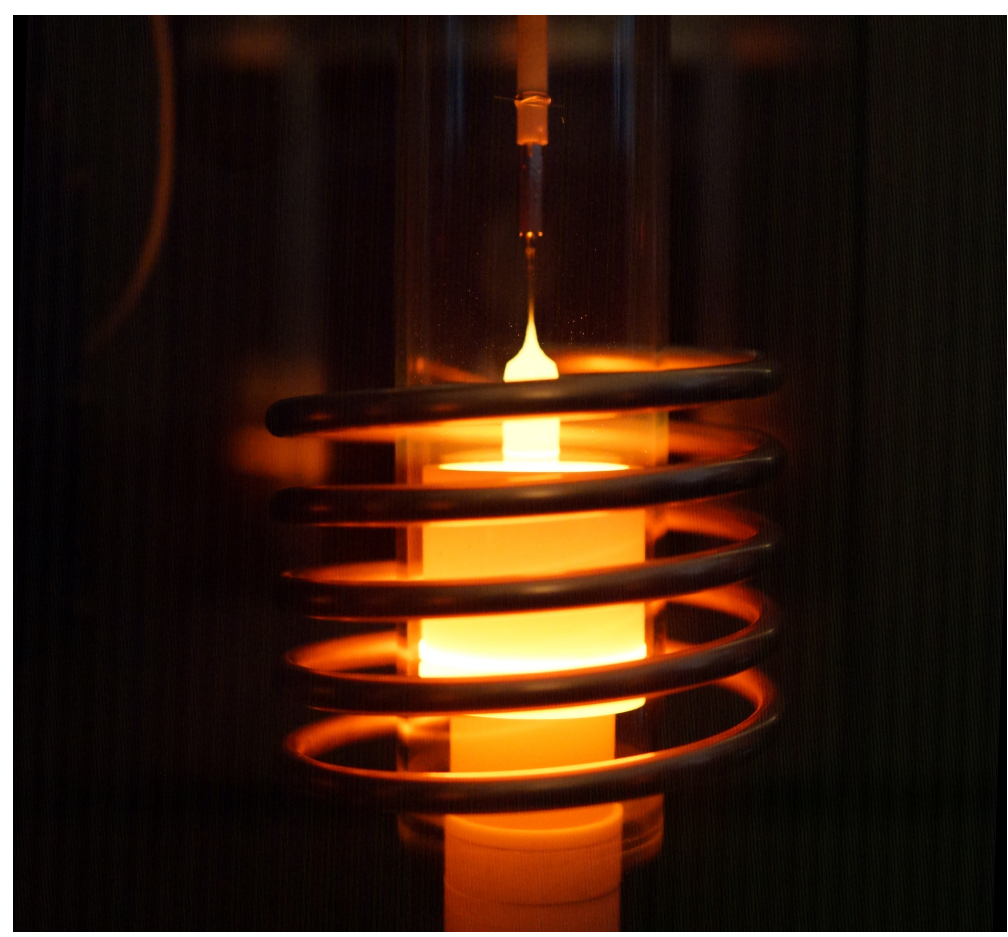

Figure 1.6: Photograph of a Czochralski growth setup. A copper crystal is grown by slowly pulling liquid material from the graphite crucible, which is heated by the induction coil. The crucible rests on alumina spacers. The seed crystal is suspended on an alumina rod, and a large temperature gradient is clearly visible at the neck of the crystal since the upper half is not glowing. The entire system is contained in a quartz tube that has been evacuated of air and flushed with argon. 
The Stepanov technique is a modified version of the Czochralski technique, where the crystal is pulled from the crucible through an aperture. The crystal, shaped by the aperture, typically has a lower dislocation density compared to the Czochralski technique. Unfortunately, the growth rate is considerably lower. The Kyropoulos technique, another variation, is used when a large diameter is more important than a large length. After contact with the melt, the seed is only retracted a small distance. Instead, the temperature of the melt is slowly decreased until a crystal roughly $80-90 \%$ of the crucible diameter is left. Although this method is economically very attractive, due to improper stirring of the melt and large thermal gradients with the crucible boundaries, the crystal quality is low compared to the other methods described.

\subsubsection{Bridgman}

Several years after Czochralski described his crystal growth technique, Bridgman developed an alternative for growing bulk crystals from the melt. ${ }^{[5]}$ This technique, also named after its inventor, is depicted schematically in Figure 1.7. Whereas with the Czochralski technique the solid crystal is not in contact with the crucible, both the melt and the crystal are contained by a crucible in the Bridgman technique. Here, single-crystal growth relies on the directional solidification by translating the melt from the heating zone to the cooling zone of a furnace. The raw material is completely molten in the heating zone and brought into contact with the seed crystal at the bottom of the crucible. Again, the seed ensures growth along the preferred crystallographic orientation, as a fresh growth interface is created when part of the seed melts on contact with the raw molten material. To grow the bulk solid crystal, the crucible is slowly lowered into the cooling zone of the furnace. As seen in Figure 1.7, the temperature profile between the two zones, governed by the thermal insulation, crosses the melting point. Thus, the crystal growth continues at the seed-melt interface until the entire crucible has passed to the cooling zone, and the entire melt is converted to a solid single-crystal.

The Bridgman technique has two main variants: vertical and horizontal Bridgman growth. The concept is similar; in the vertical mode, the crucible is translated vertically as in Figure 1.7, in the horizontal mode, it is translated horizontally. The crystals grown in the horizontal mode generally exhibit a higher crystalline quality, since the crystal experiences less stress due to the large free surface on the top of the melt. However, it is not possible to produce a cylindrical ingot. Instead, the cross-sectional shape, determined by the crucible, often looks like a D or V. Another minor variation is keeping the crucible stationary and translating the furnace, achieving the same directional solidification as before. Figure 1.4.8 shows an aluminum crystal grown in a vertical Bridgman setup. 


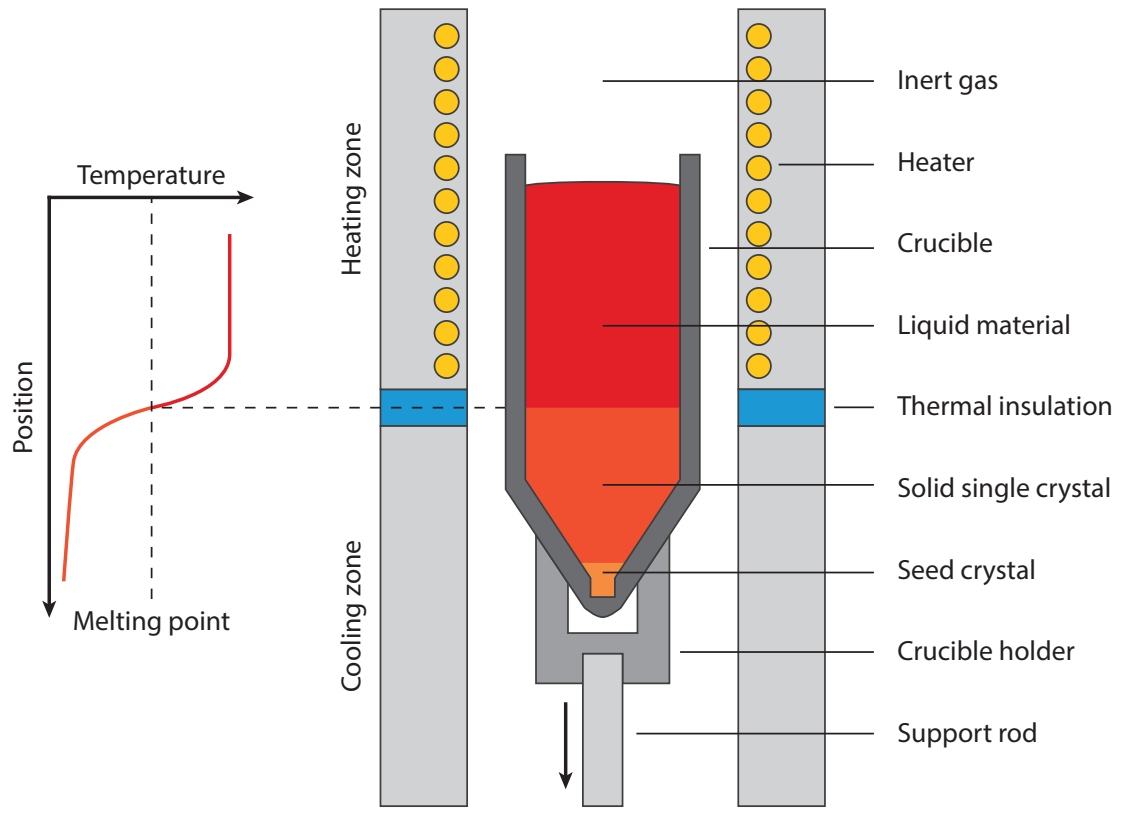

Figure 1.7: Schematic cross-section of a Bridgman growth setup. A crystal is grown by slowly translating a crucible from the heating zone to the cooling zone, so that the liquid can solidify on the crystal-liquid interface.

A subtle change to the Bridgman technique was made by Stockbarger. ${ }^{[6]}$ His technique uses a second furnace, set below the melting point, in the cooling zone. Using two coupled furnaces allows for better control over the temperature gradient at the crystal-liquid interface. In contrast, the Bridgman technique has a relatively uncontrolled gradient at the exit of the furnace. This principle is taken one step further with the so-called gradient freezing technique. Here, neither the crucible nor the furnace needs to be translated. Instead, a multiple-zone furnace is used, where the power to each zone is programmed and controlled for each individual zone. The translation of the temperature gradient is thus achieved with a high degree of control. 


\subsubsection{Floating zone}

In the 1960s, a method was found to refine the purity and crystalline quality of large poly-crystalline silicon ingots: the floating zone process. For refinement, the ingot is molten locally (the floating zone) by an induction heating coil, see Figure 1.8. As the material slowly translates through the heater, the impurities diffuse from the solid region to the liquid region and accumulate at the end of the rod once the entire crystal has passed the heater. To grow crystals with this technique, a seed crystal is brought into contact with the molten zone at the beginning of the process.

Induction heating and optical heating using focused mirrors are the most common heating methods. The steep temperature gradient in the floating zone induces flows in the liquid. This, combined with the counter-rotation of the rod and seed holder, ensures a steady supply of molten material for uniform growth conditions. Similar to all previous crystal growth techniques, the floating zone technique can be performed under a controlled atmosphere of inert gas to reduce contamination. The most significant advantage of the floating zone technique is that no crucible is needed during growth, resulting in a higher purity of the crystal. Figure 1.4.1 and Figure 1.4.7 show examples of metal crystals grown with a floating zone setup.

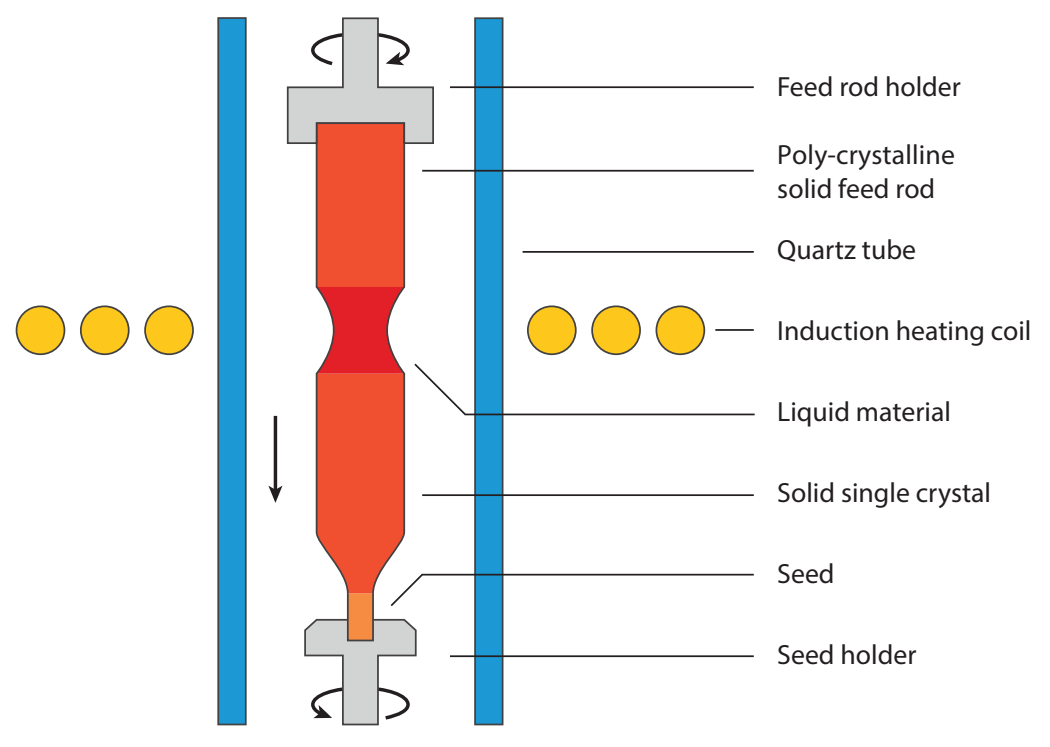

Figure 1.8: Schematic cross-section of a floating zone growth setup. A crystal is grown by slowly translating two rods through a narrow heating element, which locally melts the sample so that a single-crystal is formed at the interface with the liquid. 


\subsubsection{Drawbacks of existing growth techniques}

The traditional arsenal of growth methods suffers from a number of drawbacks that hinder the fabrication of perfect single-crystals. In short, they are crystal defects due to inhomogeneous crucible heating or due to thermal stresses in the seed and crystal, and contamination from the crucible or the atmosphere.

Contamination from the atmosphere is a drawback irrespective of the used growth technique, and can, most times, be solved by growing under ultra-high vacuum (UHV) conditions. Another option is to grow in a controlled atmosphere of inert gas, like argon. Although UHV conditions might be preferred from a contamination point of view, a background pressure of inert gas might solve other issues during crystal growth, like reduced visibility due to deposited metal on the viewports from samples with low vapor pressures.

Contamination from the crucible requires more effort to solve. The molten ultra-pure source material is in contact with a crucible, typically made of graphite or an oxide material. At high temperatures, it is not surprising that this leads to contamination of the metal with impurities coming from the crucible. ${ }^{[7-9]}$ For each metal, extensive research into the crucible material is needed, before relatively clean conditions are met. ${ }^{[10]}$ It is especially difficult to find materials able to withstand high temperatures (above $3000 \mathrm{~K}$ ), that do not contaminate the metal. The alternative is to use water-cooled crucibles, for instance, made from copper or iridium. Then again, this also cools down the metal in the crucible, so more (focused) power is required to melt the raw material.

A crucible, especially a water-cooled one, creates a thermal gradient within the system. Although a small thermal gradient is desired for seeding, large gradients cause thermal stress in the crystal, which in turn gives rise to crystal defects. ${ }^{[11-13]}$ Thermal stress can be reduced by designing a proper thermal environment, ${ }^{[14]}$ for instance using a radiation shield. ${ }^{[15]}$ Still, thermal stress can never be completely avoided with these methods.

The floating zone method does not use a crucible directly. Still, the starting material must be cylindrical in shape, which is often achieved by casting the material in a crucible anyway. Although the contamination introduced in the casting step can be partially removed again by refining with the floating zone method, it would be beneficial if one could start with the ultra-pure material in any shape.

Moreover, even without a crucible, the material is not free from thermal stress in the floating zone method. On the contrary, in one way or another, all growth methods mechanically suspend the crystalline rod that is in contact with the melt, again leading to thermal stress-induced crystal defects. ${ }^{[3,16]}$ 


\section{Chapter 1 Introduction}

Summarizing, the presence of a crucible and the thermal contact to the ambient through the crystal or seed hinder the growth of perfect, ultra-pure, and defect-free single-crystals.

\subsubsection{Containerless growth}

The solution is then, to remove the crucible entirely, and grow crystals in a containerless environment. Containerless growth solves both the contamination problem as well as the thermal stress-induced crystal defects problem. ${ }^{[17]}$ Moreover, since the absence of a crucible also reduces heat losses from the melt, significantly higher processing temperatures can be achieved.

Containerless solidification of various metals has been studied in the micro-gravity environment of space. ${ }^{[18,19]}$ However, crystals grown in space are still too expensive from a commercial point of view. On earth, the "weightlessness" experienced in space can be simulated in a drop tube. In a typical experiment, a sample is loaded into the top of a drop tube and molten by induction heating. The sample is then released and falls to the bottom. This allows the sample to solidify during $4.5 \mathrm{~s}$ at a falling distance of $150 \mathrm{~m}$ (drop tower in Bremen) and $9 \mathrm{~s}$ at a falling distance of $500 \mathrm{~m}$ (drop shaft in Hokkaido). ${ }^{[17,20]}$ Due to these short time periods, it is not possible to solidify the larger $(>1 \mathrm{~cm})$ samples commonly used in research. Moreover, the growth is difficult to control and in situ characterization is nearly impossible. To create a suitable containerless environment for controlled crystal growth of decently sized samples on earth, we can make use of levitation techniques.

\subsection{Levitation techniques}

There are multiple techniques to make a sample levitate, which can be categorized as: aerodynamic-, acoustic-, optical-, magnetic-, superconductivity based-, psychic-, electrostatic-, and electromagnetic levitation. ${ }^{[21]}$ Only the last two are suitable for controlled metal single-crystal growth. Detailed descriptions of these two techniques are given in Subsection 1.2.1 and Subsection 1.2.2, but first, we briefly discuss in the next paragraphs why the other techniques are not suitable.

In aerodynamic levitation, a spherical specimen is lifted by a jet of gas. For crystal growth, UHV conditions are desired, which is incompatible with the presence of highly pressurized gas jetting in the system. Acoustic levitation makes use of the acoustic pressure from high-intensity sound waves to lift a sample. Again, the pressure needed for sound propagation is incompatible with the required UHV conditions. 
Optical levitation relies on the radiation pressure exerted on matter by light. Although this fascinating technique is able to levitate samples as small as a single atom, it fails to levitate anything larger than a few hundred micrometers. This is too small for our purposes.

For magnetic levitation, the magnetic force is used to counteract gravity. Levitation with permanent magnets is only possible for a small subset of (ferromagnetic) metals, and often requires a feedback loop for stabilization. Diamagnetic levitation of large objects, like the famous frog experiment, is possible because the water in the frog is predominantly diamagnetic. In principle, all materials have diamagnetic properties, but the effect is very weak. It is usually overtaken by the paramagnetic or ferromagnetic properties of the material, making levitation impossible. As an extra challenge, the magnetic properties of a material will change above the Curie temperature or in the liquid phase. Similarly, superconductivity-based levitation is only applicable to superconductors at cryogenic temperatures. Thus, all forms of magnetic levitation are constricted to a specific set of materials or temperature range, whilst electrostatic- and electromagnetic levitation are applicable to all metals.

Lastly, we cannot skip over the countless examples of psychic levitation throughout history. ${ }^{[22]}$ The general scientific consensus is these occurrences are based on illusions, which makes psychic levitation unsuitable for crystal growth.

\subsubsection{Electrostatic levitation}

The basic experimental setup for electrostatic levitation (ESL) is schematically shown in Figure 1.9. A metal sphere with an electric charge is levitated by means of a top and a bottom electrode. ${ }^{[23]}$ By applying a static voltage difference across both electrodes, a force will be exerted on the metal sphere. In order to levitate the metal sphere, the gravitational force should be balanced by the electrostatic force. The electrostatic force is proportional to the amount of charge on the sphere and the strength of the applied electric field. To keep the sample at a stable position, a feedback system is required. The position of the metal sphere can be measured with a camera. This position is taken as the input for a feedback loop controlling the voltage of the electrodes. Usually, several side electrodes are placed around the bottom electrode for improved sideways stability. The sample is initially charged through capacitive charging, a positive charge is induced by applying negative voltages on the top electrode. When electrical contact with the bottom electrode is broken, and the sample is levitating, the charge is maintained by photoelectric charging induced by an appropriate UV source. The temperature of the sample can be controlled with a heating laser. 


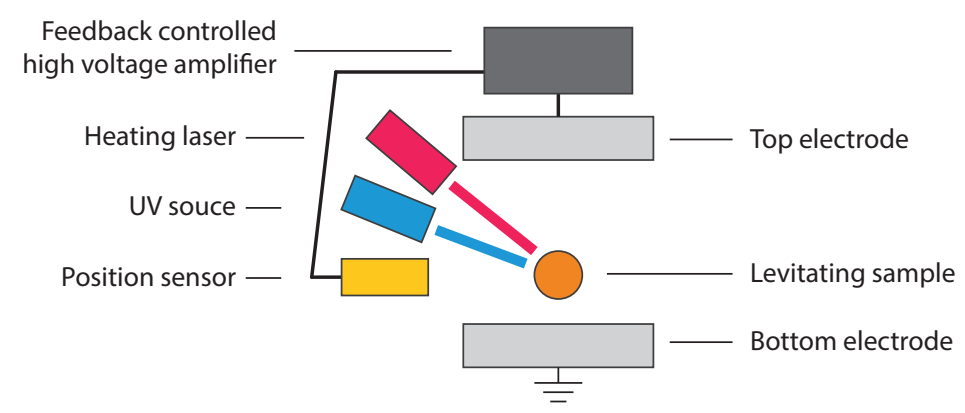

Figure 1.9: Schematic cross-section of an electrostatic levitation setup. A charged metal sample levitates due to the electrostatic repulsion forces induced by the electrodes. The sample is charged by a UV source and heated by a laser. A sample position sensor is used as the input for a feedback loop controlling the voltage on the electrodes to achieve stable levitation.

ESL can be used to levitate a wide range of materials, including metals, semiconductors, and insulators. The only requirement is that a sufficient surface charge is maintained on the sample to generate a levitation force. As such, Hwang et al. managed to levitate a water droplet with colloidal particles. ${ }^{[24]}$ These particles were gradually concentrated by evaporating water from the surface of the droplet, resulting in crystallization. Their results show that ESL has excellent potential as a tool for in-situ investigation of colloidal crystallization.

Klein et al. managed to levitate zirconium spheres with a diameter of $2 \mathrm{~mm}$ in their ESL setup. ${ }^{[25]}$ They obtained a large undercooling of the sample, approaching the limit as given by spontaneous homogeneous nucleation. At $1757 \mathrm{~K}$, nearly $400 \mathrm{~K}$ below the melting point, rapid crystal growth of $\beta$-Zr solid phase (bcc) was observed. At $980 \mathrm{~K}$, a structural phase transformation occurs of solid $\beta$-Zr to solid $\alpha-\operatorname{Zr}$ (hcp). Klein et al. did not characterize the quality of these crystals, as this was not in the scope of their work. Yono et al. used ESL for the containerless growth of barium titanium oxide single-crystals. ${ }^{[26]}$ A spherical sample with a diameter of $2 \mathrm{~mm}$ was molten, and then its temperature was maintained just below the melting point for a given time. To crystallize the sample, it was rapidly cooled at a cooling rate of $300 \mathrm{~K} / \mathrm{s}$. Their analysis showed that a single-crystal portion having a significant size ( $1 \mathrm{~mm}$ cube or more) exists in the sample, yet it did contain many oxygen vacancies and other crystal defects. 


\subsubsection{Electromagnetic levitation}

Electromagnetic levitation (EML), schematically illustrated in Figure 1.10, relies on the Lorentz force that acts between a levitation coil and the metal sample. ${ }^{[27]} \mathrm{A}$ highfrequency alternating current in the coil generates a magnetic field that is counterbalanced by another magnetic field arising from eddy currents that are induced in the metal sample. During levitation, the gravitational force is balanced by the Lorentz force. Generally, a levitation coil consists of two parts. The bottom windings generate the lift required to levitate the sample. The top windings, with opposite current direction, generate a field that stabilizes the sample. In addition to generating a Lorentz force, the induced eddy currents cause Joule heating of the sample. Compared to other levitation techniques, this has the advantage that no other heating source is required. The disadvantage is that the coupling between levitation and heating makes it challenging to control the temperature independently. Through careful coil design, the coupling can be controlled in order to create a comfortable temperature window suitable for crystal growth. A more detailed analysis of the EML technique and its underlying physics is given in Chapter 2.

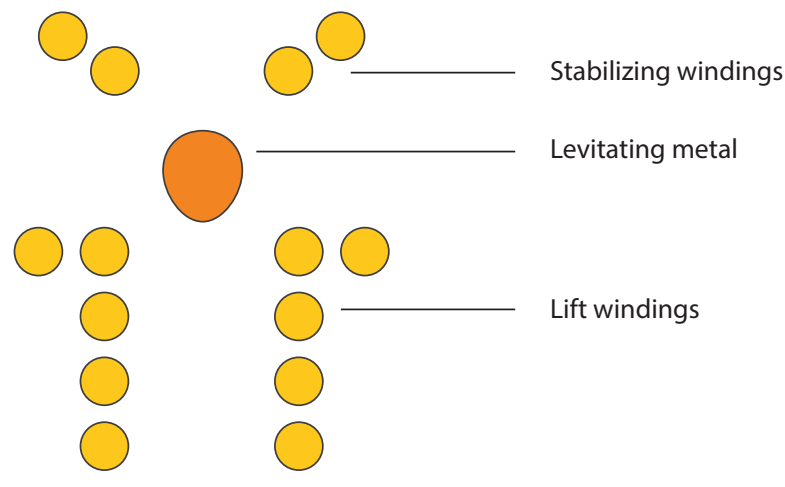

Figure 1.10: Schematic cross-section of an electromagnetic levitation setup. A metal sample levitates due to the Lorentz force induced in the sample by a time-varying magnetic field generated by the coil. The current direction in the top windings of the levitation coil, which stabilizes the sample, is opposite to the current direction in the bottom windings, which lifts the sample.

A significant advantage of an ESL setup compared to an EML setup is that sample heating and levitation do not interfere with each other. In contrast, the electromagnetic field providing lift in an EML setup is intrinsically coupled to sample heating. Furthermore, ESL 
provides a more open view of the sample, whereas EML coils are closely wound around the levitating sample, obstructing the better part of the view for diagnostic instruments. On the other hand, EML requires no active feedback loop in order to maintain stable levitation. And most importantly, there is no theoretical limit on the maximum size of a levitated sample. To levitate a spherical sample of gold with a diameter of $10 \mathrm{~mm}$ with $E S L$, an electric field strength would be required that is an order of magnitude above the critical field strength for field evaporation. Whereas with $E M L$, the sample size plays no role in levitation as long as the frequency of the current is sufficiently high. This, combined with the limitations of other levitation techniques described above, makes EML the most suitable technique for containerless bulk metal single-crystal growth.

Over the years, many studies have investigated the thermophysical properties of solid and liquid metals using EML. For instance, it is possible to levitate and melt cobalt, copper, iron, lanthanum, molybdenum, niobium, palladium, platinum, titanium, vanadium, yttrium, and even uranium. ${ }^{[28]}$ Most levitation studies investigate the thermophysical properties of liquid metals, which does not require re-solidification. ${ }^{[29-31]}$ Still, some research has been done on the undercooled solidification of containerless melts. ${ }^{[17]}$ For instance, $\mathrm{Li}$ and Herlach compared the containerless solidification of germanium by both electromagnetic levitation and drop-tube processing. ${ }^{[20]}$ They investigated the micro-structure, grain size and distribution, at different amounts of undercooling. Adachi et al. developed an in-situ observation technique for the AIN formation from a Ni-Al solution using EML. ${ }^{[32]}$ Their high-speed camera was able to capture the dynamics of grain growth resulting in beautiful images. The only, to our knowledge, examples of EML undercooled solidification resulting in single-crystals are the works by Jian et al. ${ }^{[33]}$ and Kuribayashi et al. ${ }^{[34]}$ They managed to produce $5 \mathrm{~mm}$ spherical silicon crystals without a seed for an undercooling region from 5 to $55 \mathrm{~K} .{ }^{[33]}$ However, the quality leaves much to be desired, as they describe their result as a "quasi-single crystal with a large grain, except for a small area where twinning and cracking are observed". ${ }^{[34]}$ 


\subsection{Containerless metal single-crystal growth via elec- tromagnetic levitation}

To summarize, the goal of this thesis is to develop a novel crystal growth apparatus that employs electromagnetic levitation to grow metal crystals of superior quality and purity. To achieve this, we will first look at the theory of electromagnetic levitation in Chapter 2. We will discuss the mathematical models available in literature, choose the most suitable one, and provide calculations to arrive at the power source requirements. Finally, we discuss several intuitive proportionalities and coil design best practices.

With this knowledge at hand, we design, construct and test an experimental setup for containerless metal single-crystal growth in Chapter 3. We discuss the design requirements and look at coil design, sample temperature control, and potential growth modes. The developed experimental setup is explained in great detail, and we describe some preliminary results.

In Chapter 4, we discuss the importance of three-dimensional (3D) modeling of electromagnetic levitation coils. Currently, coil design is based on two-dimensional (2D) mathematical models combined with empirical data and trial and error. As we will show in this chapter, the 2D modeling of coils for EML is inaccurate, and the predicted performance often deviates substantially from its actual performance. We propose that a truly $3 \mathrm{D}$ model enables a more accurate and rational coil design.

Chapter 5 shows that the same Lorentz forces that make electromagnetic levitation possible, also induce a deformation in the levitation coil itself. We describe a measurement in which the coil bending is apparent and relate this to the levitation height of an aluminum sample. In order to predict the bending of the coil, we develop a model that couples the electromagnetic and solid mechanic calculations to find the steady-state shape of the coil. Lastly, we discuss the influence of self-induced bending of coils on the levitation parameters.

Finally, in Chapter 6, we draw a general conclusion on containerless metal single-crystal growth via electromagnetic levitation and sketch an outlook for future research. 



\section{Theory on electromagnetic levitation}

Electromagnetic levitation (EML) was first proposed by Muck in 1923. ${ }^{[35]}$ It took nearly 30 years before the first experimental work on EML was published by Okress et al., who managed to levitate and melt an aluminum sphere. ${ }^{[27]}$ Figure 2.1 shows an example of EML in action; a copper sample is levitating inside a coil. How does this work? In order to levitate any object, a force is required that counteracts the gravitational force. When both forces are in perfect balance, the net force is zero and the object is held aloft, without mechanical support. Additionally, a smaller stabilizing force is required that pushes the object toward a home position whenever it is a small distance away from that home position.

In the case of EML, these forces are Lorentz forces. A large high-frequency current is passed through a coil such as in Figure 2.1, which generates a large time-varying magnetic field. This alternating field causes an electromotive force (EMF) that leads to eddy currents induced in any conducting sample placed within the coil. These eddy currents are such that the Lorentz force, arising from the currents inside the applied magnetic field, repels the sample away from the coil. Once the sample is repelled, the levitation force diminishes and gravity retakes the upper hand. As soon as the sample falls to its original position, the current polarity is reversed, again causing an EMF, eddy currents, and a repelling Lorentz force. If the current frequency is sufficiently high, this up and down motion is negligible with respect to the inertia of the system, and the sample is at a standstill.

With the repelling Lorentz force gravity is counteracted, but the sample needs to be stabilized as well. Otherwise, although the net force might be zero, any initial velocity would make the sample drift away from the coil until it falls. Stabilization can be achieved by placing a smaller second coil above the other coil, with a reversed current polarity. This coil repels the sample downwards to the larger "lifting" coil. Thus, in between the lifting coil and the "stabilizing" coil, a potential well is created in which the sample is stable. If the sample is disturbed, it might oscillate around its final position, but its motion eventually decreases to zero due to damping effects. As seen in Figure 2.1, a classic levitation coil often combines the lifting and stabilizing coil in a single coil by making a small turn in the middle to change the winding and current direction. 


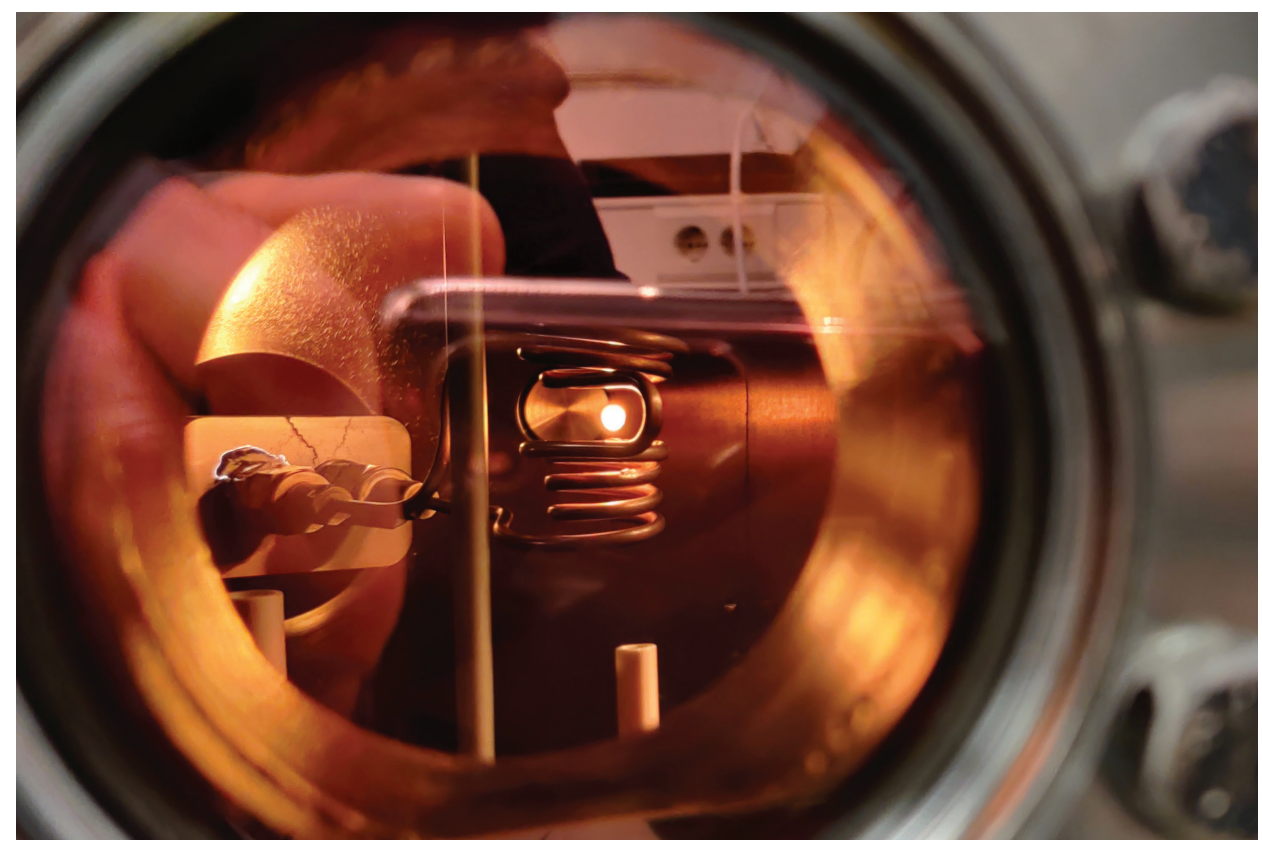

Figure 2.1: A copper sample levitating in an EML coil.

An alternating electric current has the tendency to become distributed within a conductor such that the current density is largest near the surface of the conductor and decreases exponentially with greater depths in the conductor: the skin effect. ${ }^{[36]}$ The current flows mainly at the "skin" of the conductor, between the outer surface and a level called the skin depth. The skin depth decreases with increasing frequency and increasing sample conductivity. The eddy currents in the sample cause the temperature to increase due to Joule heating. At the typical $\mathrm{kHz}$ to $\mathrm{MHz}$ frequencies employed in $\mathrm{EML}$, the current is confined to such a small volume that the effective electrical resistance is sufficiently high to heat most metal samples to their melting point. Both levitation and heating of the sample always occur simultaneously. This offers the advantage that no additional heating source is required to melt the material. However, it means that levitation and heating can be controlled independently only in a very limited range. The solution is found in careful coil design so that a suitable window for temperature control can be found for every metal sample.

The above description is enough to get a qualitative understanding of EML. In order to develop a crystal growth apparatus that employs electromagnetic levitation to grow metal crystals of superior quality and purity, a more quantitative understanding is desired. In other words, we must do some calculations. This chapter will describe and compare the 
mathematical models available in the literature and discuss which one is most suitable for this work. The model is explained and used to perform calculations to make an initial estimate on the required parameters of a power source. Lastly, we describe several intuitive proportionalities and best practices for coil design.

\subsection{Methods}

A good mathematical model should at least be able to predict both the levitation force and the sample temperature. For the (Lorentz) force, we need to find the magnetic flux density inside the sample. For the temperature, we need to find the induced current density within the sample. The magnetic flux density can consequently be found from the induced current density and vice versa. Generally, there are two approaches followed in literature: ${ }^{[37]}$

- The mutual inductance approach uses the concept of mutual inductance to first find the current density

- The magnetic flux density approach solves the partial differential Maxwell's equations to first find the magnetic flux density

A variety of models exist in literature. One of the main differences between the models is which of the two approaches above is followed. Historically, the models contain many simplifying assumptions. With each new model, one of these assumptions is improved or accounted for, or a new method is used to solve the partial differential equations. We will now discuss several examples of models in the literature, starting with the ones employing the mutual inductance approach.

The model used by Okress et al., who first achieved EML experimentally, is a simplified analytical model. ${ }^{[27]}$ It assumes a homogeneous metal sample in a levitation coil consisting of one circular coil loop or two loops with an opposing current in a rotationally symmetric geometry. Thus the three-dimensional (3D) problem is reduced to a two-dimensional (2D) axisymmetrical one. The sample is modeled as a single current loop on the equator of the spherical sample, and the magnetic field is assumed to be uniform within the sample volume. The mutual inductance between the sample current loop and the coil is used to compute the induced current in the sample. The induced current can be used to calculate the Lorentz force and the dissipated power. The temperature is found by equating this power with the radiated power loss. This relatively simple model already provides adequate agreement with experimental results for samples with a diameter smaller than $20 \%$ of the coil loop diameter. 
Fromm and Jehn extended this model by including geometries with multiple coil loops. ${ }^{[36]}$ Figure 2.2 shows an example of such a coil, with multiple lifting and stabilizing coil windings and a spherical sample, which is still modeled as a single loop. Royer et al. realized that the magnetic field is not uniformly distributed across the sample height. To compensate for this for the temperature calculations, they discretize the sample in horizontal slices and modify the absorbed power by taking a volume-weighted average of the original value. ${ }^{[38]}$ Roberts et al. apply the same principle to the force calculations. ${ }^{[39]}$

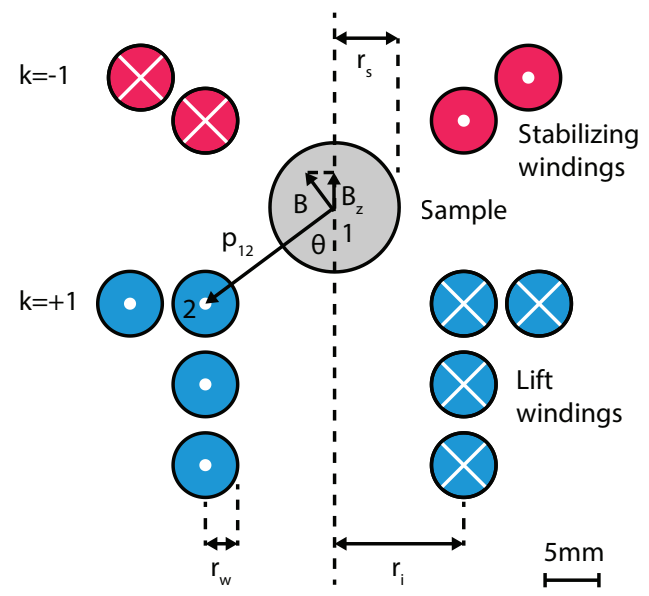

Figure 2.2: Geometric model of an axisymmetric EML system where a metal sample is suspended in a coil with a high-frequency oscillating current. The definitions of the radii, angles, positions, directionality constant, and magnetic field used in this work are indicated.

The beauty of the models above is that they can be solved analytically while still providing reasonably accurate predictions about the force and steady-state sample temperature. This has the advantage that it gives a high degree of intuitive insight into EML when the mathematics is understood. Numerical solutions are required to achieve even more accurate results. Although the results achieved with these numerical solutions might be better, the computational time is significantly higher. Additionally, one must remain careful that the method used to solve the system produces physically correct results.

El-Kaddah and Szekely developed a model using the principle of mutual inductance in finite volume method (FVM) formulations. ${ }^{\left[{ }^{37]}\right.}$ They model the sample as several concentric spherical shells, which are again divided into a number of segments of constant current density. Similarly, Moghimi et al. divide the sample into horizontal disk-shaped slices where each slice consists of several rings. ${ }^{[40]}$ Since the sample is segmented, the assumption of a uniform magnetic field across the sample is unnecessary. This means that the model was in good agreement with experimental results for all sample sizes. 
Let us now take a look at several models using the magnetic flux density approach. Kermanpur et al. developed an electromagnetic-thermal coupled model using the finite elements method (FEM). ${ }^{[41]}$ They assume a sample temperature and run an alternating current harmonic analysis of Maxwell's equations using commercial FEM software to find the magnetic flux density. This is followed by a thermal analysis to find the sample temperature. If the results differ significantly from the assumed temperature, the temperature-dependent material properties are updated to the correct value, and the simulations are repeated until the sample temperature converges.

Feng and Shi developed a FEM model to investigate the effect of eddy currents inside the coil on the sample temperature. ${ }^{[42]}$ They also modeled the internal fluid flow in the spherical sample and found that the temperature is not homogeneous but can vary up to $0.1 \mathrm{~K}$ within the sample. Later, they developed a model using the arbitrary Lagrangian-Eulerian (ALE) finite element technique, which has the main advantage that the computational mesh inside the domains can move arbitrarily to optimize the shapes of elements and follow the contours of moving materials. In other words, the sample can be any shape and size and can even be moving. Thus, they could investigate the influence of coil angle arrangement on the dynamic deformation and stability of molten droplets. ${ }^{[43]}$ Additionally, they describe the influence of the Marangoni effect on the flow and deformation of levitated molten droplets under a static magnetic field. ${ }^{[44]}$ Lastly, they investigate the vibrational frequency shift due to irregular deformation and the positioning force exerted on the molten samples. ${ }^{[45]}$

After the year 2000, with the increasing availability of commercial numerical simulation software, many models were developed that further expand on the magnetic flux density approach in one way or another. The investigations include, among others, flow convection inside the droplet, free surface and droplet oscillations, temperature field simulations, phase transfer calculations in levitating alloys, and the influence of a second static magnetic field. ${ }^{[31]}$ It seems that the sky is the limit with these kinds of simulations, and in this case, the actual limit is the computational time.

To summarize, Table 2.1 shows several characteristics of the existing models as classified by which of the two approaches is taken. Since the mutual inductance approach is primarily analytical, the computation time is relatively short. It is possible to simulate many different coil geometries in a reasonable time span. Thus, it can be used with a gradient-based optimizer scheme to design a coil for the levitation melting of specified sample size and material. ${ }^{[39]}$ Coil design is even possible using machine learning techniques with a genetic-like algorithm. ${ }^{[38]}$ On the other hand, the magnetic flux density approach has longer computation times. Nevertheless, this enables more detailed and 


\begin{tabular}{lcc} 
& Mutual inductance & Magnetic flux density \\
\hline Model type & Analytical solution & Numerical solution \\
Computation time & Short & Long \\
Sample shape & Spherical & Any shape \\
Dynamics & Steady-state & Dynamic \\
Temperature-dependent & No & Yes \\
material properties & &
\end{tabular}

Table 2.1: Comparison of model characteristics between the mutual inductance approach and the magnetic flux density approach.

accurate results. It poses no restrictions on the sample shape, can simulate the frequency response of the moving sample in time, and includes temperature-dependent material properties. Most importantly, it allows the coupled simulation of the sample's levitation, heating, and fluid flow. These kinds of simulations are very insightful to have when investigating the crystal growth in the sample. However, before we can reach that point, we must be able to stably levitate and melt samples of various sizes and materials. To achieve this goal, it is beneficial to try many different coil geometries to find suitable levitation parameters for all these samples. Thus, in this work, the mutual inductance approach is followed in order to design the crystal growth apparatus.

\subsubsection{The mutual inductance approach}

The model used in this work is based mainly on the model by Fromm and Jehn. ${ }^{[36]} \mathrm{A}$ geometric representation of the system is presented in Figure 2.2. The levitation coil consists of $n$ rigid coaxial loops with wire radius $r_{w}$ and winding radius $r_{i}$ at a certain height $z_{i}$. Each winding carries the same high-frequency current $I_{2}$, but the direction can be opposite to other windings. This is described with the directionality constant $k_{i}= \pm 1$. The spherical sample is modeled as one circular current loop along the equator with radius $r_{s}$.

The lifting windings ( $k_{i}=+1$, color-coded blue in Figure 2.2) generate a magnetic field $\vec{B}$ at the sample position. The stabilizing windings $\left(k_{i}=-1\right.$, color-coded red in Figure 2.2) prevent the sample from shooting out of the top of the coil. To simplify, we reduce the system to a 1D problem by only looking at stable positions in the $z$-direction. This is allowed because the sample lies in a potential well in the $r$-plane. ${ }^{[4]}$ Since the current, and thus $B_{z}$, oscillates, an electromotive force is induced in the sample, generating a 
current $I_{1}$. It can be treated as a circular eddy current on account of the skin effect. The sample is levitating when the resulting Lorentz force cancels the gravitational force.

The electromagnetic force of circuit 2 (coil) on circuit 1 (sample) in the $z$ direction is given by: ${ }^{[47]}$

$$
F_{z}(z)=I_{1} I_{2} \frac{\partial \mathcal{L}_{12}}{\partial z}
$$

where $\mathcal{L}_{12}$ is the mutual inductance between the two circuits, defined as the ratio of the flux through circuit 1 due to the current in circuit 2. ${ }^{[48]}$ Assuming that $r_{s}<r_{i}$, so that $B_{z}$ is homogeneous inside the sample, ${ }^{[36]}$ gives:

$$
\mathcal{L}_{12}=\frac{\iint \vec{B} \cdot d \vec{S}_{1}}{I_{2}}=\frac{B_{z} \pi r_{s}^{2}}{I_{2}} \rightarrow \frac{\partial \mathcal{L}_{12}}{\partial z}=\frac{\pi r_{s}^{2}}{I_{2}} \frac{\partial B_{z}}{\partial z}
$$

To calculate $B_{z}(z)$, we start with a Maxwell equation and the definition of the vector potential $\vec{A}:[47]$

$$
\nabla \times \vec{B}=\mu_{0} \vec{J}+\frac{1}{c^{2}} \frac{\partial \vec{E}}{\partial t} \quad \& \quad \nabla \times \vec{A}=\vec{B}
$$

where $\mu_{0}$ is the magnetic permeability of vacuum and $\vec{j}$ is the current density. Substituting the latter equation in the former gives the following relation in the static case:

$$
-\nabla \times(\nabla \times \vec{A})=\nabla^{2} \vec{A}-\nabla(\nabla \cdot \vec{A})=-\mu_{0} \vec{J}
$$

Substituting the Lorenz gauge $(\nabla \cdot \vec{A}=0)$ gives a differential equation with the following solution: ${ }^{[47]}$

$$
\nabla^{2} \vec{A}=-\mu_{0} \vec{J} \rightarrow \vec{A}(1)=\frac{\mu_{0}}{4 \pi} \int \frac{\vec{J}(2)}{p_{12}} d V_{2}
$$

where $p_{12}$ is the distance from the sample to an infinitesimal volume $d V_{2}$ in the coil. Recalling the definition of the vector potential from Equation 2.3 gives the Biot-Savart law:

$$
\vec{B}(1)=\nabla \times \vec{A}(1)=\frac{\mu_{0}}{4 \pi} \int \frac{\vec{\jmath}(2) \times \hat{p}_{12}}{p_{12}^{2}} d V_{2}
$$

Let us first focus on a singular loop and then use the principle of superposition to find the total magnetic field. The cross product drops out since $\vec{\jmath}$ and $\hat{p}_{12}$ are always perpendicular. The current density in the volume is replaced with the current along the loop $I_{2} d \ell$ and directionality constant $k$. Additionally, we substitute $B_{z}=\vec{B} \sin \theta$ so that:

$$
\begin{gathered}
B_{z}=\frac{\mu_{0}}{4 \pi} \int \frac{k I_{2} \sin \theta}{p_{12}^{2}} d \ell=\frac{\mu_{0}}{4 \pi} \frac{k I_{2} \sin \theta 2 \pi r_{i}}{p_{12}^{2}} \\
\sin \theta=\frac{r_{i}}{p_{12}}=\frac{r_{i}}{\left(r_{i}^{2}+z^{2}\right)^{1 / 2}}
\end{gathered}
$$


The final magnetic field and its gradient is given using the superposition of the $n$ loops:

$$
\begin{aligned}
& B_{z}(z)=\frac{1}{2} \mu_{0} I_{2} \sum_{i=1}^{n} \frac{k_{i} r_{i}^{2}}{\left(r_{i}^{2}+\left(z-z_{i}\right)^{2}\right)^{3 / 2}} \\
& \frac{\partial B_{z}}{\partial z}=-\frac{3}{2} \mu_{0} I_{2} \sum_{i=1}^{n} \frac{k_{i} r_{i}^{2}\left(z-z_{i}\right)}{\left(r_{i}^{2}+\left(z-z_{i}\right)^{2}\right)^{5 / 2}}
\end{aligned}
$$

Now that $B_{z}$ and thus $\mathcal{L}_{12}$ are known, the only unknown in Equation 2.1 for the force on the sample is the induced current in the sample $I_{1}$. The magnetic field of a homogeneous sphere due to the eddy currents induced by another homogeneous magnetic field is identical to that of a magnetic dipole. ${ }^{[36]}$ A circular current loop has approximately the same field so that the sample can be replaced with a circular loop along the equator with radius $r_{s}$. Equating the fields of a dipole and a circular loop gives that: ${ }^{\text {[49] }}$

$$
I_{1}=\frac{2 B_{z} D(\delta)}{\mu_{0} r_{S}^{2}}
$$

where $D(\delta)$ is a complex function which attributes for the skin effect, i.e., the fact that the magnetic field has a penetration depth $\delta$ inside the metal sample: ${ }^{[50]}$

$$
\delta=\sqrt{\frac{\gamma}{\pi f \mu_{0}\left(1+\chi_{v}\right)}}
$$

where $\gamma$ is the electrical resistivity of the metal sample, $\chi_{v}$ the volume magnetic susceptibility, and $f$ the frequency of the coil current. $F_{z}$ is alternating in time, as $I_{2}$ and consequently $B_{Z}$ and $I_{1}$ are alternating in time. Integration over one period gives the net force, which can be obtained by taking only the real part of $D(\delta)^{:[27,50]}$

$$
\mathfrak{R}(D(\delta))=-r_{s}^{3} G(x)=-r_{s}^{3}\left(1-\frac{3}{2 x} \frac{\sinh 2 x-\sin 2 x}{\cosh 2 x-\cos 2 x}\right) \quad \text { with } \quad x=\frac{r_{s}}{\delta}
$$

Finally, the total lifting force is given by:

$$
F_{z}(z)=\frac{3}{2} \pi \mu_{0} r_{s}^{3} I_{2}^{2} G(x) \sum_{i=1}^{n} \frac{k_{i} r_{i}^{2}}{\left(r_{i}^{2}+\left(z-z_{i}\right)^{2}\right)^{3 / 2}} \sum_{i=1}^{n} \frac{k_{i} r_{i}^{2}\left(z-z_{i}\right)}{\left(r_{i}^{2}+\left(z-z_{i}\right)^{2}\right)^{5 / 2}}
$$

The only parameters which are not a (material) constant are the current, frequency, coil geometry, and sample radius. The function $G(x)$ approaches 1 if $\delta$ is small, i.e., if the frequency is large or the sample resistivity is small, as seen in Figure 2.3.A. This holds for non-ferrous materials only. $G(x)$ is -2 for ferrous materials, where the minus indicates an attractive force instead of a repelling one. ${ }^{[50]}$ So, stable levitation is not possible with ferromagnetic materials below their Curie point. As seen in Equation 2.14, the force 
(A)

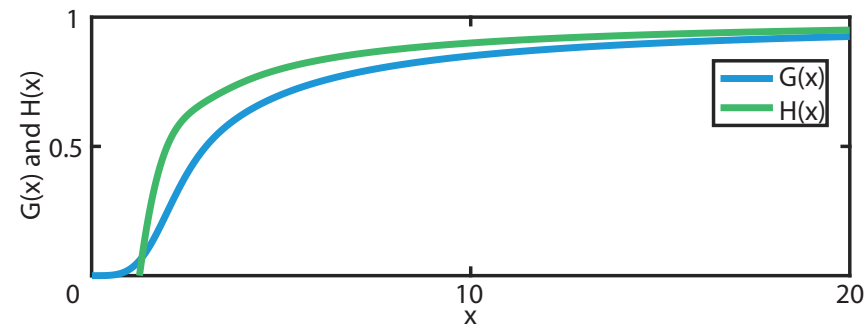

(B)

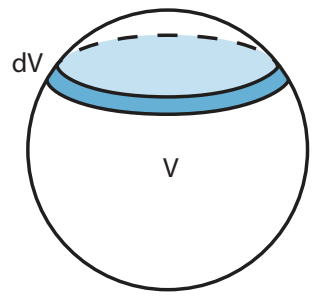

Figure 2.3: (A) The dimensionless functions $G(x)$ and $H(x)$ approach 1 for high frequencies and low sample electrical resistivities. (B) Spherical segment used for numerical integration of the power.

scales with the current squared and the sample radius cubed. The sample levitates when the lifting force cancels the gravitational force, which also scales with the sample radius cubed. Thus, the sample size plays no role in the ability to levitate a sample when $r_{S}>\delta$. Stable levitation requires the spatial derivative of the lifting force to be negative: ${ }^{[48]}$

$$
\left|F_{z}\right|=\left|F_{g}\right|=\frac{4}{3} \pi r_{s}^{3} \rho g \quad \& \quad \frac{\partial F_{z}}{\partial z}<0
$$

where $\rho$ is the mass density and $g$ is the gravitational constant. Solving for $z$ gives the stable levitation position of the sample. Roberts et al. have modified the expression for the force to better account for the spatial distribution of the magnetic field inside the sample volume. ${ }^{[39]}$ The magnetic field is found by summing over a number of spherical segments, as illustrated in Figure 2.3.B. The total magnetic field inside the sample is then calculated by taking a volume-weighted average $\tilde{B}_{z}(z)$ of the original value:

$$
\tilde{B}_{Z}(z)=\frac{1}{V} \int B_{Z}(z) d V
$$

where $V$ is the total volume of the sphere and $d V$ is the volume of the segment.

The temperature of the sample can be calculated by knowing its position in the magnetic field. Heating occurs due to resistive dissipation of the current in the metal. Hence, the power is a function of resistivity and the current density throughout the volume: ${ }^{[49]}$

$$
P_{\text {heat }}=\pi \gamma \int_{0}^{\pi} \int_{0}^{r_{s}} j^{2} r^{2} \sin \theta d r d \theta
$$

For non-ferrous materials, integration yields: ${ }^{[50]}$

$$
P_{\text {heat }}=3 \sqrt{\frac{\pi^{3} f \gamma}{\mu_{0}^{3}}} r_{s}^{2} H(x) B_{z}\left(z_{s}\right)^{2}
$$


where $z_{S}$ is the sample position and $H(x)$ once again a function of the sample size to the penetration depth ratio $x$ :

$$
H(x)=\frac{\sinh 2 x+\sin 2 x}{\cosh 2 x-\cos 2 x}-\frac{1}{x}
$$

Similarly to the volume-weighted average of the force, Royer et al. have modified the heating power expression to better account for the spatial distribution of the sample inside the magnetic field. The total power absorbed is found by summing over the spherical segments as illustrated in Figure 2.3.B, each receiving a weighted amount of heat depending on the segment volume $d V:^{[38]}$

$$
\tilde{P}_{\text {heat }}=\frac{1}{V} \int P_{\text {heat }} d V
$$

To find the steady-state temperature of the sample, we can equate the heating power to the power loss of the sample. The sample can lose heat through radiation, $P_{\text {rad, }}$ and natural convection, $P_{\text {conv }}$ :

$$
\tilde{P}_{\text {heat }}=P_{\text {rad }}+P_{\text {conv }}
$$

Convection plays no role in a vacuum, and we only deal with radiation: ${ }^{[48]}$

$$
P_{\mathrm{rad}}=\epsilon \sigma 4 \pi r_{s}^{2}\left(T^{4}-T_{\infty}^{4}\right)
$$

where $\epsilon$ is the emissivity of the sample, $\sigma$ the Stefan-Boltzmann constant, $T$ the sample temperature, and room temperature $T_{\infty}=298 \mathrm{~K}$. In case levitation occurs in an air or argon atmosphere, natural convection plays a role as well: ${ }^{[51]}$

$$
P_{\text {conv }}=h 4 \pi r_{S}^{2}\left(T-T_{\infty}\right)
$$

where $h$ is the heat-transfer coefficient given by:

$$
h=\frac{k}{2 r_{s}}(2+0.43 \sqrt[4]{G r P r})
$$

where $k$ is the thermal conductivity of the atmosphere, $\operatorname{Pr}$ is the Prandtl number (a dimensionless number approximating the ratio of momentum diffusivity, or kinematic viscosity, to thermal diffusivity) of the atmosphere, and $G r$ is the Grashof number (a dimensionless number approximating the ratio of the buoyancy to viscous forces acting on a fluid) given by:

$$
G r=16 r_{s}^{3} \frac{g}{v^{2}} \frac{T-T_{\infty}}{T+T_{\infty}}
$$

where $g$ is the gravitational constant and $v$ is the kinematic viscosity (ratio of the viscosity to the density) of the atmosphere. 
Finally, solving Equation 2.21 for $T$ gives the sample temperature. We can see that the radiated heat scales with $T^{4}$ while convection scales with $T^{1}$. This means that at high temperatures (roughly above $1000 \mathrm{~K}$ for typical samples), convection will become negligible compared to radiation. We can also note that $P_{\text {heat }}$ scales with $B^{2}$ and $F_{Z}$ scales with $B \nabla B$, which allows for independent control of levitation and the sample temperature.

With the above equations, we have everything available to calculate the stable levitation position and steady-state temperature of a sample. The material properties, sample size, coil geometry, current frequency, and magnitude are taken as input for a custom MATLAB script, which implements the model above. Figure 2.4 shows the user interface (UI) that controls the script. The UI allows the selection of a sample material, after which it loads the relevant material properties from a database. It is easy to make a new coil design by simply clicking in the cross-section view to add a new coil winding. The coordinates of the windings in the cross-section are automatically converted to a fully three-dimensional coil for the model described in Chapter 4. It also generates molds that can be 3D printed to use for coil fabrication, which is described in Chapter 3. For this chapter, the 2D axisymmetrical implementation described above is used. After specifying the sample size, the script calculates the forces, levitation position, and temperature for a specified range of current frequencies and magnitudes and displays the results. Lastly, it has the option to use a gradient-based optimizer native to MATLAB, which varies the coil winding positions, to optimize the coil geometry towards a certain goal, for instance, maximum undercooling of a particular sample.

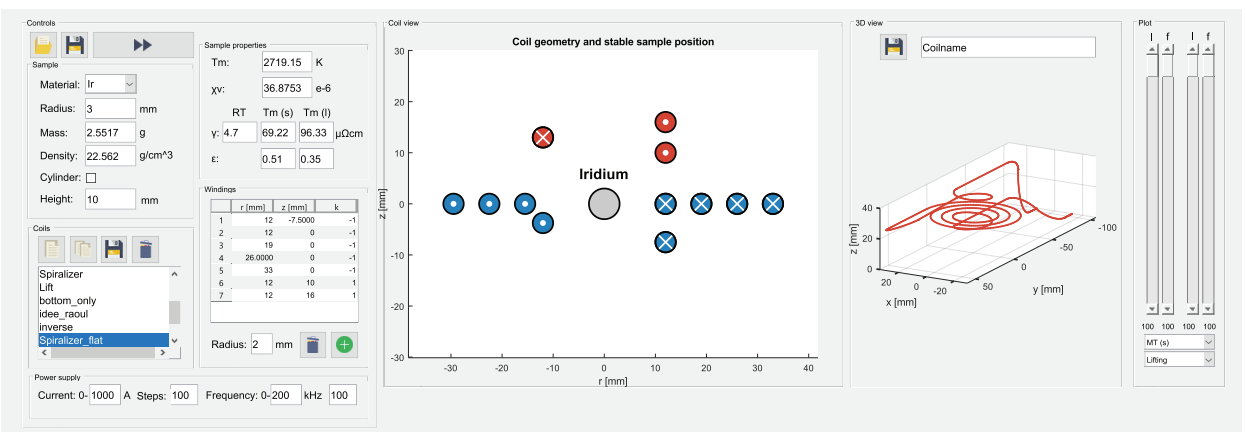

Figure 2.4: Screenshot of the user interface of the custom MATLAB implementation of the levitation model. 


\subsection{Results}

Let us look at some examples of calculations performed using the model implemented in the MATLAB script. Figure 2.5.A shows a spherical copper sample with a diameter of $5 \mathrm{~mm}$. The coil geometry was optimized so that the current required to levitate the sample is minimal, which means that the power used by the power source is minimal. Figure 2.5.B shows the forces acting on the sample versus the sample position. Levitation is possible where the levitation force equals the gravitational force. For stable levitation, the derivative of the levitation force should be negative.

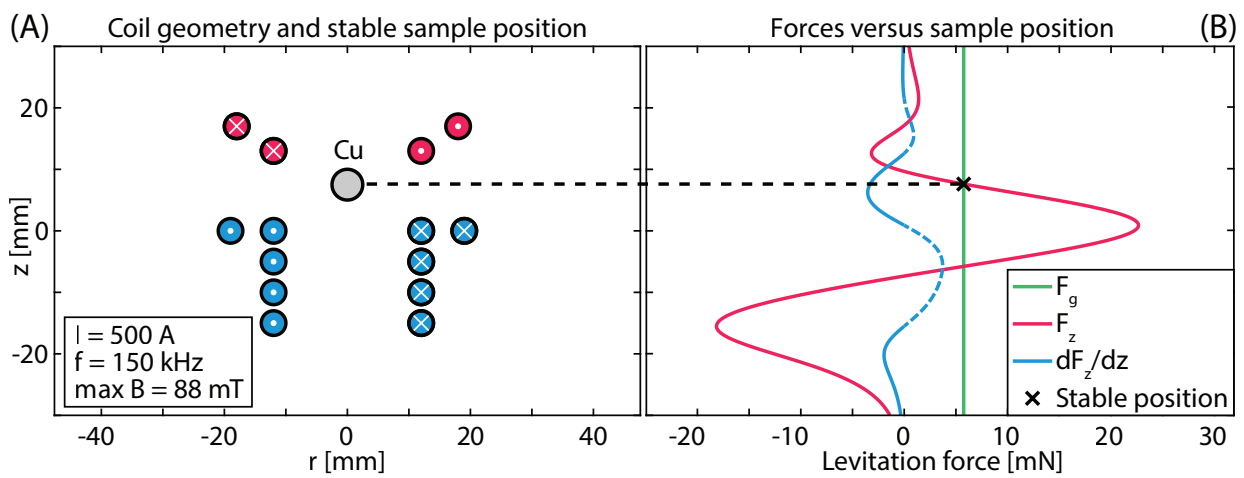

Figure 2.5: (A) Coil geometry optimized for minimal power use when levitating a copper sample.

(B) Gravitational force, levitation force and its derivative versus the sample position. The stable levitation position is found where both forces are equal and the derivative is negative.

The plot is calculated for a current of $500 \mathrm{~A}$ at a frequency of $150 \mathrm{kHz}$, using the material properties of copper at room temperature (RT). We can also calculate the stable sample position using the material properties at the melting temperature (MT), both for the solid and liquid state. These sample positions are plotted versus the coil current in Figure 2.6. The levitation height increases with increasing current. A minimum current is required for levitation, below which the levitation force is smaller than the gravitational force. A liquid sample levitates lower than a solid sample at the melting point, which in turn levitates lower than a solid sample at room temperature. This is explained by the increasing resistivity of copper for increasing temperature, which lowers the levitation force. 


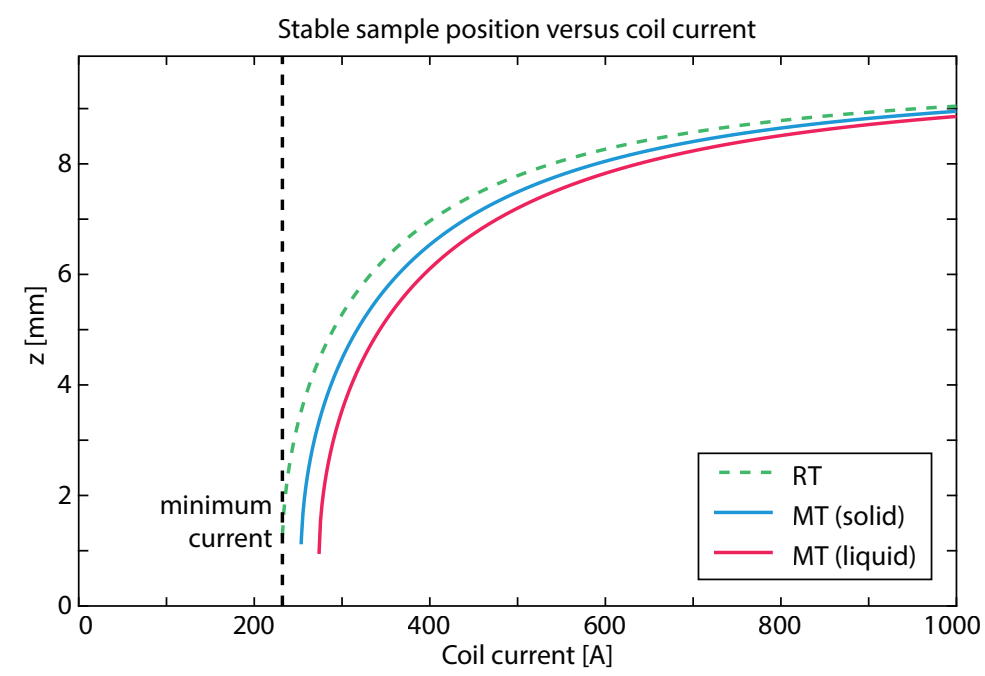

Figure 2.6: Stable sample position of a copper sample versus the coil current at room temperature and at the melting temperature, both for the solid and liquid state. A minimum current is required for stable levitation.

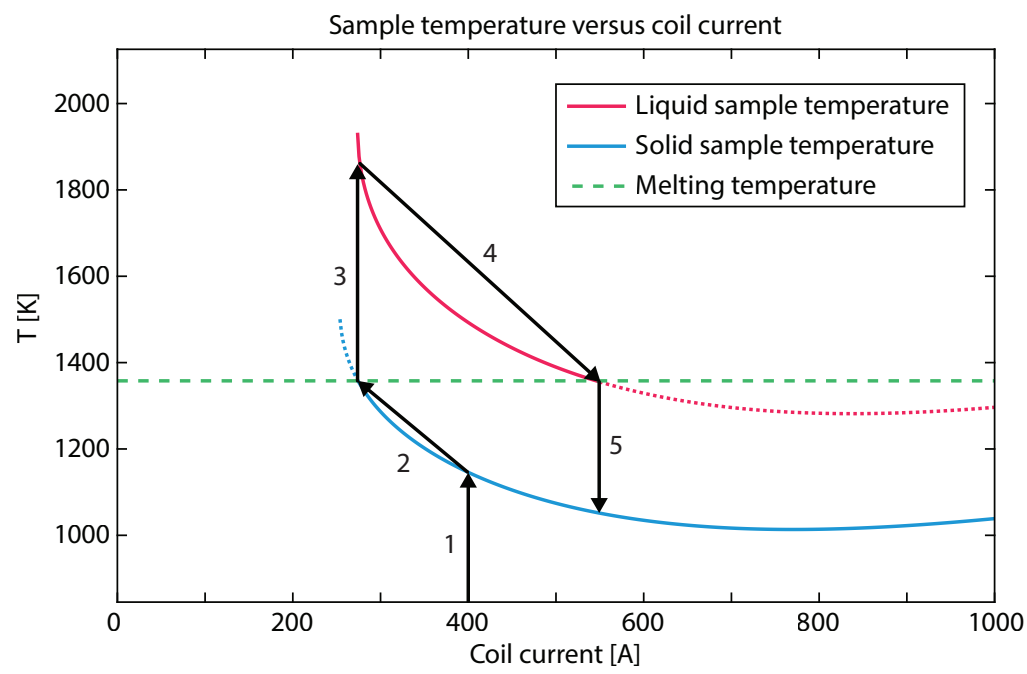

Figure 2.7: Temperature of a copper sample at the melting point in solid and liquid state versus the coil current. By controlling the current following the 5 step procedure the sample is levitated, molten, and solidified. 
The sample temperature versus current graph is visible in Figure 2.7. Once again, it is calculated using the material constants of copper at the melting point in both the solid and liquid states. The liquid (red) line is only valid above the melting temperature, the solid (blue) line below. We can see some surprising behavior as the sample temperature decreases with increasing current/power. Although counterintuitive at first, this is easily explained by looking back at Figure 2.6. At low currents, the sample position increases substantially with only a small current increase. The heating power is maximum where $|B|$ is maximum, which is in the center of the bottom coil. This implies that the sample is effectively moved away from the center of the bottom coil, the hottest point, with increasing current. And thus, the temperature decreases. However, this effect is limited. The position changes are less significant for higher currents due to the stabilizing coil pushing back on the sample. Additionally, the stabilizing coil also has a center with a high magnetic field magnitude. Thus, when the sample is "trapped" between the two coils at high currents, the temperature does increase with current, as is expected from Equation 2.17. This is also visible above $800 \mathrm{~A}$ in Figure 2.7.

Figure 2.7 also shows a theoretical melting and solidifying procedure. First, a sample is levitated at $400 \mathrm{~A}$ so that the temperature reaches roughly $1100 \mathrm{~K}$ (1). By slowly lowering the current to $275 \mathrm{~A}$, the sample heats to its melting point (2). Three things happen as soon as the sample starts to melt. First of all, the liquid part of the sample wants to levitate at a lower position, as seen in Figure 2.6. This means that it levitates closer towards the bottom coil, so it receives even more heating power, increasing the temperature. Secondly, the resistivity of liquid copper is higher than that of solid copper. Thus the temperature increases due to increased Joule heating. Thirdly, the emissivity of liquid copper is less than that of solid copper. This means that the sample cannot lose as much power through radiation, also increasing the temperature. As such, we see the temperature in Figure 2.7 increase by almost $500 \mathrm{~K}$ if the current is not changed (3).

The current is increased to cool the sample down (4). Ideally, this is done at the first sign of melting so that the sample remains close to its melting point when it is fully molten. When the sample is cooled below the melting point, the opposite reaction of the three effects described above causes the sample to cool down rapidly. As we will discuss in Chapter 3 , such a melting and solidifying procedure is roughly the procedure followed to grow a single crystal.

Ultimately, the goal is to develop a crystal growth apparatus that can handle all metals, not just copper. To get a feeling for the required current and frequency output of a power source that can handle multiple materials, we can calculate the minimum values required to levitate 15 different metals. These values are shown in Figure 2.8.A. In each 
(A)
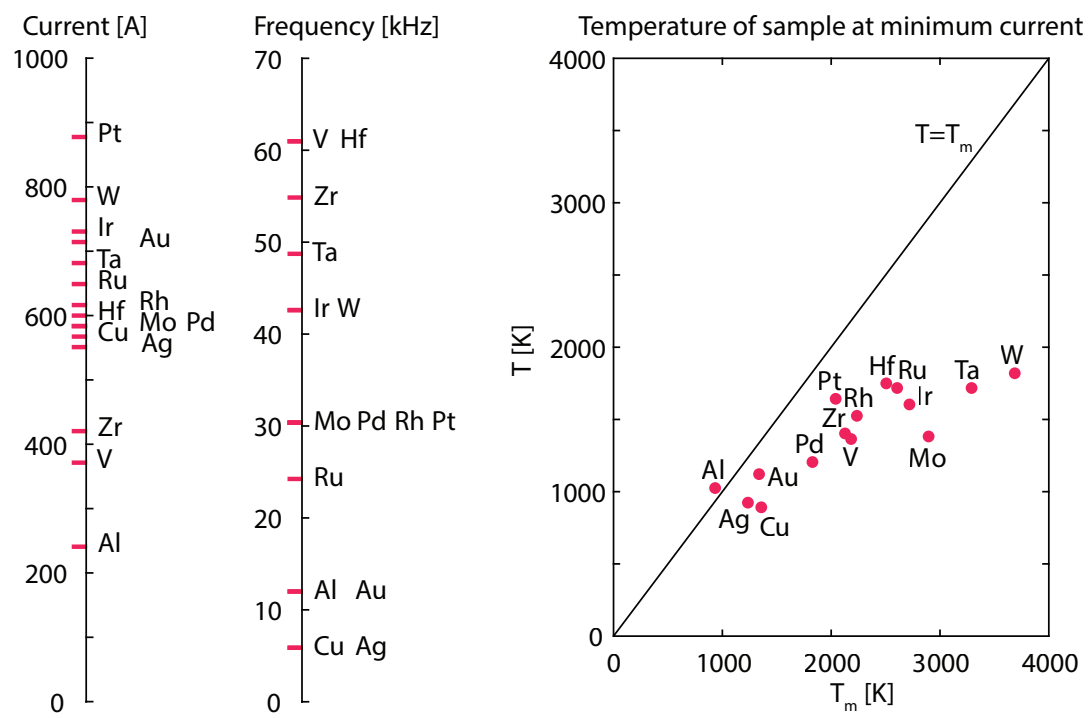

(B)

Figure 2.8: (A) Minimum current and frequency required to stably levitate a sample of the corresponding material. (B) The temperature of these samples at these minimum current and frequency values, compared to its respective melting point.

case, the sample radius is $6 \mathrm{~mm}$, the coil geometry is that of Figure 2.2, and convection is not taken into account (i.e., levitation in vacuum). The values should be taken as an order of magnitude estimate, as the coil geometry is not optimized towards each specific material. However, we can conclude that the power source should be able to deliver at least $880 \mathrm{~A}$ at $61 \mathrm{kHz}$.

The sample temperature at these minimum current values is calculated and plotted against their respective melting point in Figure 2.8.B. We can see that an aluminum sample will melt, so additional cooling (through convection) is required to grow aluminum crystals in this coil. For the other metals, we see that the relative temperature difference to the melting point becomes larger for higher melting points. Thus, additional heating is necessary, especially for the more extreme cases of tantalum and tungsten. Still, we must remember that this coil is not optimized for these metals and is only used to estimate the required power source parameters. The first step would be to design a coil with a higher magnetic field magnitude, thus increasing the temperature as follows from Equation 2.18. If this is not sufficient, a secondary high-frequency heating coil could provide more heating, as well as a better decoupling between heating and levitation. ${ }^{\text {[29] }}$ 


\subsubsection{Coil design}

It should be clear by now that coil design plays a vital role in achieving successful EML crystal growth. Therefore, it is helpful to list several proportionalities between levitation parameters, as this will give intuitive insight into how a coil geometry might influence the achieved results. Furthermore, Moghimi et al. performed an excellent study on coil design and came up with several rules of thumb and coil design best practices. ${ }^{[40]}$ Both the proportionalities, which can be derived from the equations above, and the conclusions by Moghimi et al. are listed here:

- If a sample is big enough (the diameter is larger than ten times the skin depth), the levitation force is not dependent on the sample size. This poses no theoretical limit on the maximum sample size, only a practical one (the, to our knowledge, largest sample levitated is a $500 \mathrm{~g}$ aluminum sample ${ }^{[52]}$ ).

- The temperature is related to the sample size. As a larger sample "catches" a larger magnetic flux, it has higher eddy currents, more Joule heating, and thus a higher temperature.

- If a sample is big enough, the heating power scales with $\sqrt{f}$.

- The sample height increases with current, up to the point where it is pushed back by the stabilizer coil, and the height reaches its asymptote.

- Up to this height asymptote, the temperature decreases with increasing current.

- Flat coils provide more lift and lower sample temperatures, whereas conical coils provide less lift and higher sample temperatures.

- A larger distance between the bottom lifting coil and upper stabilizer coil results in a less stable sample, as the sample has more space to move and the magnetic field gradient is less strong, so the potential well is less steep.

- A larger distance between the bottom and upper coil results in a lower temperature, as the sample can levitate further away from the bottom coil.

- A larger distance between the bottom and upper coil results in a lower minimum current at which levitation is possible, as the upper coil cancels some of the lifting power of the bottom coil.

- More windings in the bottom coil increase the magnetic field strength and hence the lifting power. 
- More windings in the upper coil increase stability at the expense of lifting power. Too many turns in the upper coil "pins" the sample down hard, resulting in a high temperature with limited freedom in temperature control.

- A smaller tube diameter allows for a higher turn density and thus a stronger and more concentrated magnetic field. This increases both the lift and the temperature.

\subsection{Conclusion}

A quantitative understanding of EML is desired in order to develop a crystal growth apparatus that employs electromagnetic levitation to grow metal crystals of high quality and purity. For this, a suitable mathematical model should be able to accurately predict the levitation forces, stable levitation position, and the sample temperature for a given coil geometry, sample size, material, and power source settings. We compared models with two different approaches. The magnetic flux density approach is able to predict all of the above, plus many more physical effects important to crystal growth, such as internal fluid flows inside the sample. However, the complexity of a simulation and the long computational time make this approach unsuitable to quickly design tailored coils for many different materials and sample sizes.

The mutual inductance approach is mostly limited to the levitation and steady-state sample temperature, but it is far easier to implement, and computation times are significantly shorter. This makes it possible to quickly optimize coil designs to find a melting and solidifying procedure for many different metals. Thus, for the design of the EML crystal growth apparatus, we have decided to use the mutual inductance approach. In future studies, when the focus shifts on the growth of even better crystals, we recommend focusing on a singular material and optimizing the coil design using the magnetic flux density approach.

A model following the mutual inductance approach was presented and implemented in a MATLAB script. It was used to find a coil design that requires the minimum possible current to levitate a copper sample. In this coil geometry, it is possible to levitate samples of 15 different materials if the power source is able to deliver at least $880 \mathrm{~A}$ at $61 \mathrm{kHz}$. Lastly, we used the model and the calculations to arrive at several intuitive proportionalities between the levitation parameters, and we discussed several coil design considerations. 
2 
- $19 x$

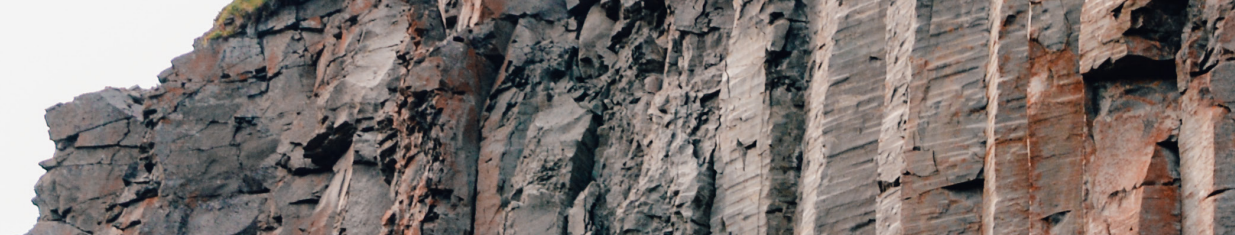

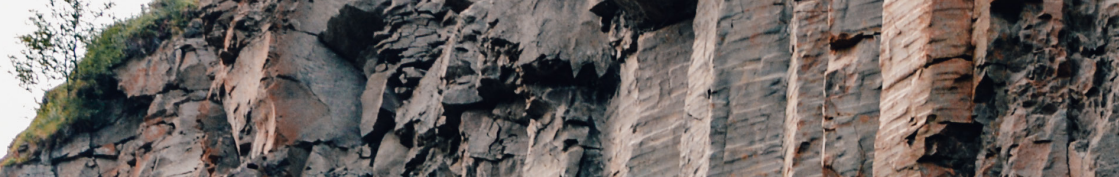
2.5nom? 5 Int

(2.

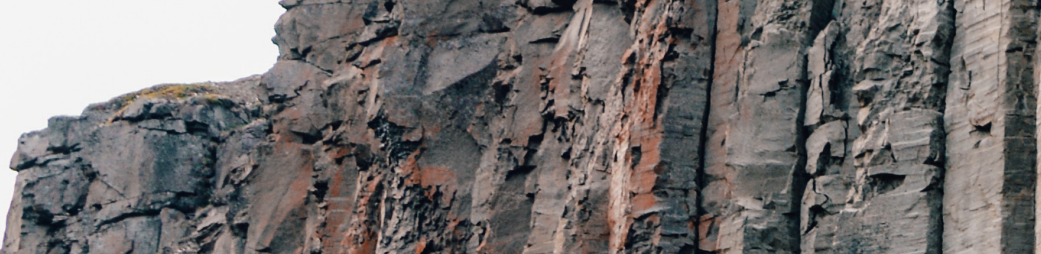
Mrit th

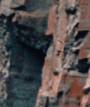
C $-\cos ^{2}+\mathrm{x}^{4}$

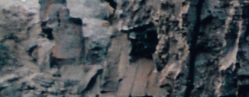

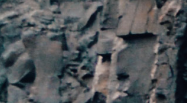

te

at

(2)

.

(2)

a. 5

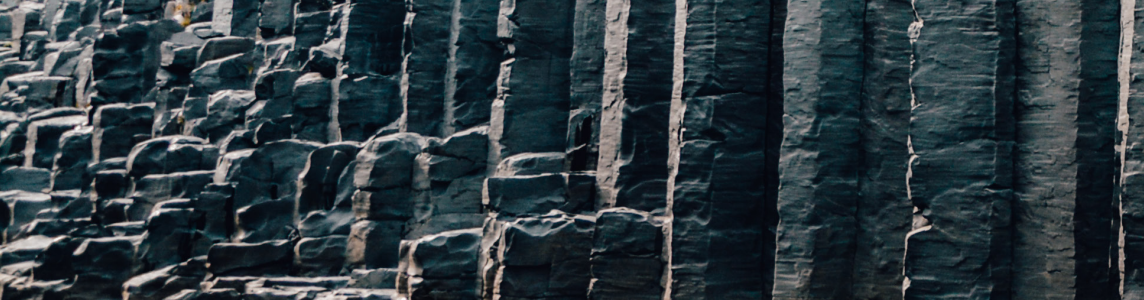

25 $[x]-1]$

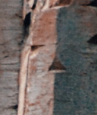




\section{Experimental setup for}

\section{containerless metal single crystal growth}

Traditionally, the growth of elemental metal single-crystals is achieved through classic growth techniques, such as the Czochralski, Bridgman, or floating zone methods. Using these techniques, decent-quality crystal rods can be fabricated with relative ease for most metals. The rods, typically $10 \mathrm{~mm}$ in diameter and lengths up to $100 \mathrm{~mm}$, can be shaped using electrostatic discharge machining and subsequently polished to the desired crystal orientation. For decades, the crystals grown with these methods have been used in a myriad of scientific experiments. As the characterization techniques, such as $\mathrm{X}$-ray standing waves (XSWs), that are used at synchrotron facilities, become more and more accurate, the demand for high-quality crystals exceeds the current state-of-the-art quality and purity of metal crystals.

The traditional arsenal of growth methods suffers from a number of drawbacks that hinder the fabrication of perfect single-crystals. First of all, the molten ultra-pure source material is in contact with a crucible, typically made of graphite or an oxide material. It is not surprising that this leads to contamination of the metal with impurities coming from the crucible. ${ }^{[7-9]}$ Therefore, extensive research into the crucible material is needed before relatively clean conditions are met. ${ }^{[10]}$

Second, the crucible creates a thermal gradient within the system, which, in turn, gives rise to crystal defects. ${ }^{[11-13]}$ Although the floating zone method does not directly use a crucible (the rod used as a starting material is, however, usually still shaped in a crucible), this does not mean the material is free from thermal stress. Actually, all growth methods, in one way or another, mechanically suspend the crystalline rod that is in contact with the melt, again leading to thermal stress-induced crystal defects. ${ }^{[3,16]}$

To overcome these hurdles, it would be useful to grow crystals in a containerless environment. The absence of a crucible solves both the contamination problem and the thermal stress-induced crystal defect problem. This has already been done for very small samples with the use of a drop tube ${ }^{[20]}$ or for larger samples in the micro-gravity environment of space. ${ }^{[18,19]}$ The drop tube samples are too small for common research applications, and 
the growth is difficult to control. The crystals grown in space are too expensive from a commercial point of view. The goal is then to be able to grow decent-sized crystals in a containerless environment on the Earth.

In this chapter, we discuss the development of a novel crystal growth apparatus that employs electromagnetic levitation (EML) in a vacuum to grow elemental metal singlecrystals of superior quality and purity. ${ }^{[53]}$ EML relies on the Lorentz force induced by the levitation coil and exerted on the metal sample. ${ }^{[27]}$ A large high-frequency current is passed through a coil, which generates a large time-varying magnetic field. This alternating field causes an electromotive force (EMF) that leads to eddy currents induced in any conducting sample placed within the coil. These eddy currents are such that the Lorentz force, arising from the currents inside the applied magnetic field, repels the sample away from the coil. During levitation, the gravitational force is balanced by the Lorentz force. In addition to generating a Lorentz force, the eddy currents cause Joule heating of the sample. Through careful coil design, the coupling between levitation and sample temperature can be controlled in order to create a comfortable temperature window suitable for crystal growth. ${ }^{[54]}$

A few examples exist in the literature based on another form of EML. The levitationassisted self-seeding crystal growth method makes use of a conventional crucible and an induction heating coil setup, but part of the melt is lifted by the electromagnetic forces to form a seed for the melt still at the bottom of the crucible. ${ }^{[55]}$ Another example is that of a Hukin-type crucible design, where the melt levitates in the crucible, and a single-crystal is grown using the Czochralski technique. ${ }^{[3,56]}$ Still, in both examples, the material is at some point in contact with the crucible, so contamination cannot be completely avoided. Furthermore, the complexity of Hukin crucibles makes it difficult to tailor to multiple masses and materials. In our design, the complete cycle of melting and solidifying the material as a single-crystal is performed while levitating in a truly containerless environment. The classic EML coils that are used are easy to tailor to a wide

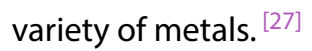

It is notoriously difficult to grow defect-free large-sized single-crystals from the platinum group metals, such as iridium, ruthenium, and rhodium. At least equally difficult are the refractory group metals, such as tantalum and tungsten, or, in the broader definition of refractory, chromium. Most of these metals share a high melting point well above $2000 \mathrm{~K}$ or even above $3000 \mathrm{~K}$ in some extreme cases. Metals having such a high melting point are normally very difficult to melt contamination-free, as (water-cooled) crucible material choice becomes even more critical at such high temperatures. The large thermal gradients also make these metals challenging to grow grain-, dislocation- and defect-free. 
Although the aim is to keep the apparatus as generic as possible - a slight improvement might also be expected in the crystal growth of lower melting point materials, such as copper - the primary focus lies on the aforementioned metals.

In the following section, we first define the design requirements of a fully containerless crystal growth apparatus. Then, we describe the experimental setup in terms of coil design, sample insertion and collection, seed insertion, sample position and temperature tracking, and more generally in terms of vacuum considerations, power supply specifications, and required water cooling.

\subsection{Methods}

In order to grow perfect metal crystals, the system should allow the following:

1. The insertion and levitation of a wide variety of metals.

2. Precise control of the sample temperature in both liquid and solid state.

3. The growth of a single-crystal with a well-defined nucleus.

4. The reduction in contamination from parts in contact with the sample as well as from the air.

5. The reduction in thermal gradients in the sample (and seed crystal, if used).

6. Collection of the sample after levitation without inducing crystal defects due to kinetic shocks (i.e., dropping on a solid surface).

\subsubsection{Coil design and sample temperature control}

A classic levitation coil consists of two parts: a bottom coil provides the lift and a smaller upper coil with reversed current polarity stabilizes the sample. Figure 3.1 shows an example of such a coil. Temperature control is possible since the force, $F$, is proportional to the magnetic field as $B \nabla B$, whereas the dissipated power, $P$, in the sample is proportional to $|B|^{2} \cdot{ }^{[27]}$ The temperature follows from the balance of this dissipated power and the radiated power. It is clear that the sample temperature is highest where the magnitude of $B$ reaches its maximum, which is in the middle of the bottom coil. Another "hot zone" is present in the middle of the top coil. 


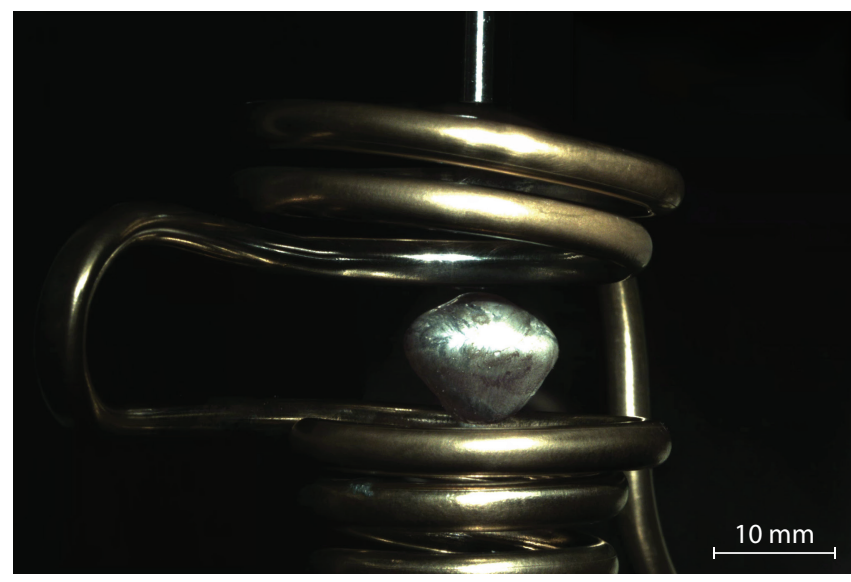

Figure 3.1: An aluminum sample levitating in a levitation coil. The bottom coil provides lift, and the top coil stabilizes the sample. A crystal seed is visible above the coil.

A sample requires a minimum amount of current to levitate, depending on its conductivity. With increasing current, the sample levitates higher in the coil, with asymptotic behavior toward a maximum height between the two coils. The sample temperature approaches the maximum value at the minimum current needed for levitation; since then, the sample is closest to the middle of the bottom coil. It is, however, difficult to achieve stable levitation with this minimum current setting. Upon heating or even melting, the sample conductivity decreases, and a rapid adjustment of the current is required in order to avoid dropping the sample. At high currents, the sample moves toward the second hot zone, where stability is not an issue. Here, the maximum temperature is capped by the maximum current that the power supply can deliver. From a crystal growth point of view, the material properties and coil design determine if it is preferential to melt the sample in the lower or the upper zone. Since the material properties are fixed, careful coil design is of utmost importance, before attempting to grow crystals of a specific metal. The sample temperature for a given current can be calculated using a simple model, ${ }^{[54]}$ which is based on one of the first analytical descriptions of EML by Fromm and Jehn. ${ }^{[36]}$ This particular model improves upon the model by Fromm and Jehn by modeling the coil as a truly 3D path instead of concentric rings, and modeling the sample as multiple rings stacked in a spherical geometry instead of a single ring. Where most studies using EML are only interested in measuring certain thermophysical properties, ${ }^{[31]}$ we also want to precisely control the temperature when cooling down in order to crystallize the sample. When a metal sample melts, generally, both the conductivity and the emissivity decrease. ${ }^{[57,58]}$ This causes the temperature of the liquid to increase sharply, due to increased Joule heating and decreased thermal radiation. Thus, after melting, nature is 
not in our favor for subsequent cooling and solidification. Less power input in EML does not necessarily mean a lower temperature due to the sample levitating closer toward the hot zone of the lower coil. Again, the solution is found in careful coil design such that a temperature vs current path exists that enables crossing the melting point in both directions.

Finally, the temperature is proportional to the alternating current frequency as $\sqrt{f}$, [36] which, together with the current magnitude and coil design, makes the frequency the third parameter to vary in finding optimal growth conditions.

Using the model, ${ }^{[54]}$ described in more detail in Chapter 4, we can calculate the temperature of a given sample for a given coil and frequency vs the current. The design of the coil is changed manually until a viable solid-liquid-solid cycle is found for a particular material. Parameters to consider are the coil tubing diameter, the distance between the lower and upper coils, the number of windings, and the angle and positions of the windings. ${ }^{[40]}$ For our requirements, described at the beginning of Section 3.1, for a generic system with a focus on platinum group and refractory group metals, we manually designed several levitation coils with a $4 \mathrm{~mm}$ outer tubing diameter that could levitate, melt, and solidify spherical samples up to $12 \mathrm{~mm}$ in diameter for 15 different metals. According to our calculations, this requires frequencies in the order of $100 \mathrm{kHz}$ and currents up to $1000 \mathrm{~A}$. The power source and cooling capabilities of the experimental setup were chosen accordingly.

In trial experiments we found that a difference of just $1 \mathrm{~mm}$ in the distance between the upper and lower coil can be the difference between stable and unstable levitation. Moreover, we can see temperature differences of up to a few $100 \mathrm{~K}$ when comparing a new coil with an older, slightly bent coil. Thus, it is absolutely essential that coils are fabricated as accurately as possible to ensure consistent results. For this purpose, we make use of 3D-printed molds to fabricate the coils. The MATLAB software can automatically generate the 3D models for the coil and the molds, see Figure 3.2.A. To bend a coil in shape, copper tubing ( $4 \mathrm{~mm}$ outer- and $3 \mathrm{~mm}$ inner diameter) is annealed in an open flame. The soft copper can now be bent until it is rigid. It takes multiple cycles of annealing and bending before the tube is fully wrapped around the molds. The molds are tapered so that they can be screwed out of the coil along the thread. The right coil in Figure 3.2.A requires an additional manufacturing step. After the molds are taken out, the coil is compressed like a spring folding in on itself. The correct dimensions can be ensured by placing the coil as an overlay on a template 2D drawing, which is to scale. Finally, the mounting connections are soldered on. An example of a finished coil and its molds is pictured in Figure 3.2.B. 
(A)
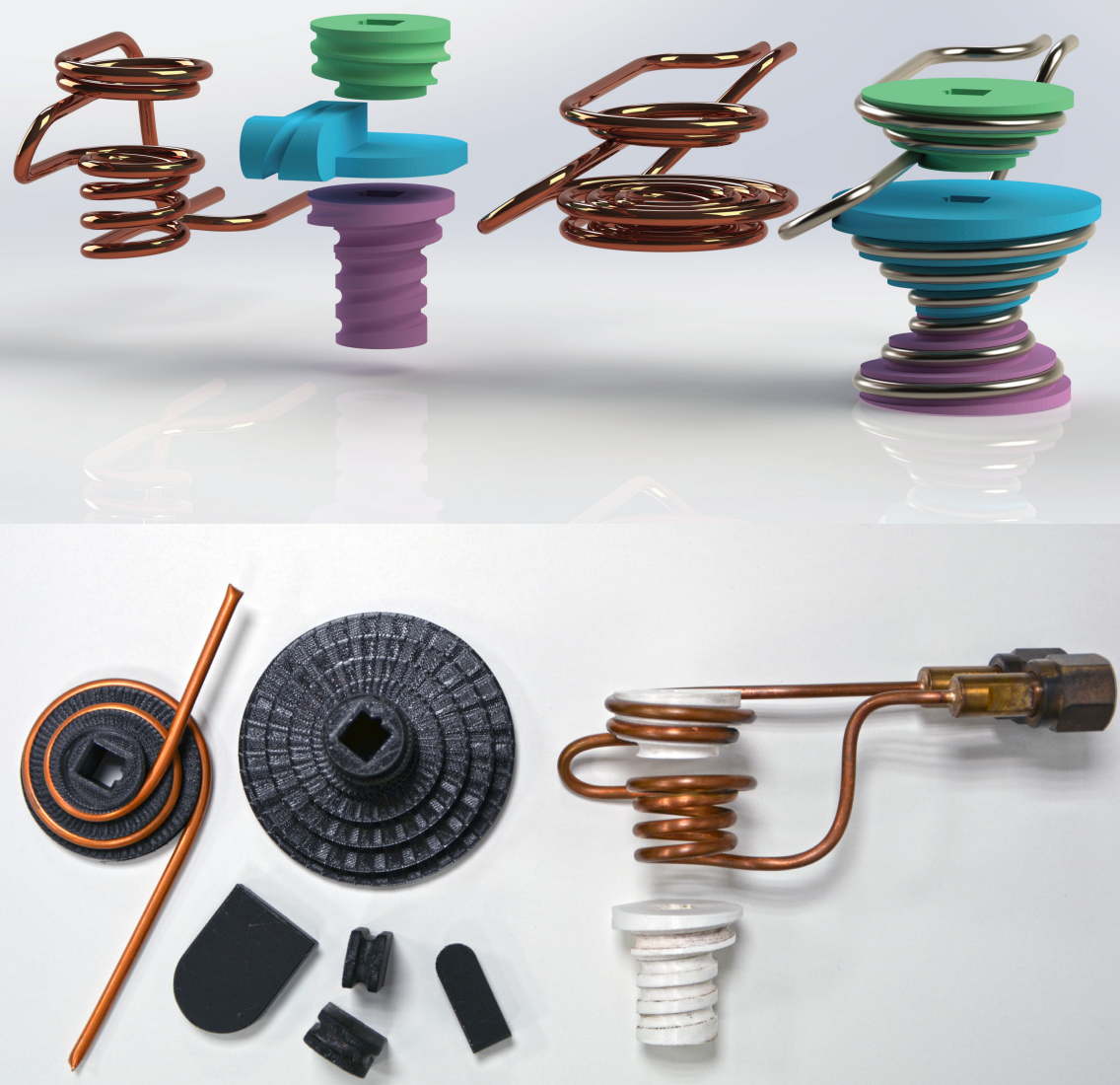

(B)

Figure 3.2: (A) Examples of computer generated coils and mold designs for a simple (left) and more complex (right) coil. (B) A levitation coil and several 3D-printed molds used to fabricate the coils.

\subsubsection{Growth modes}

We envision two potential crystal growth modes: containerless undercooled crystallization and levitation-based Czochralski growth.

In the first mode, the sample is levitated and heated until it is completely molten. Then, the current is adjusted such that the liquid cools down to below the melting point. Samples levitated by EML are very stable, and therefore, the formation of a critical nucleus 
far below the melting temperature might be an issue. A solution is to externally induce the crystallization process using a very thin and sharp needle with a nanoseed at its apex. The temperature should be closely monitored using a pyrometer, such that the crystal growth velocity can be controlled, as the quality of the end result greatly depends on this velocity. ${ }^{[17]}$

In the second mode, the sample is molten, but then kept slightly above the melting point. Growth then proceeds as usual with the Czochralski technique, with the difference that the levitation coil, in essence, replaces the crucible. In this case, special attention must be devoted to the design of the top coil, as the magnetic field induced there will also heat the seed crystal. The advantage is that there is less thermal stress between the liquid and the seed. The disadvantage is that the seed might melt if the current becomes too high.

\subsubsection{Experimental setup}

A setup that fulfills the criteria described at the beginning of Section 3.1 has been designed and constructed. The schematic in Figure 3.3 shows a cross-section of this experimental setup, a 3D render is shown in Figure 3.4, and a photograph is shown in Figure 3.5. At the heart of the setup is the sample (1), levitated by the water-cooled coil (4). The entire system resides inside a high vacuum chamber (15) to prevent contamination from airborne particles and to prevent oxidation at high temperatures. At the start of an experiment, the sample is held in position in one of the alumina cups of the sample carousel (5). When the current is turned on, the sample starts to levitate. The sample carousel can then be retracted downward using the Z-manipulator (20) and subsequently rotated away from the coil using a rotary feedthrough (23). Note that the manipulator axis (19) is off-center from the middle of the coil/chamber. During levitation, the sample position is tracked with a camera (17). The sample temperature is monitored using a pyrometer (2) so that optimal growth conditions can be obtained by controlling the coil current.

To introduce the seed crystal (3), the seed carousel (6) can be rotated in a position above the coil with the rotary feedthrough (22), which rotates independently from the sample carousel. Since it is possible that the sample might not levitate precisely in the middle of the coil, it is possible to adjust the seed position with the XY-manipulator (21) before lowering the seed to make contact with the molten sample. To avoid large thermal gradients in the hot seed crystal, it is suspended by a tungsten wire (8), which in turn is connected to a cold alumina rod (7). The alumina rods of both carousels are in place to electrically decouple all objects in the vicinity of the coil from the chamber, as metallic 
parts are susceptible to induction heating and could even short circuit the entire system when touching the coil.

After growth, the seed has fused with the crystal so that the crystal can be easily collected through the quick access door (18). If the thin seed crystal cannot support the weight of the sample crystal, the sample will fall when the levitation current is turned off. In this case, the sample falls down on a soft bed of annealed carbon felt (14), after which the surface of the sample can be cleaned and used as usual.

The power source is an Ambrell EKOHEAT system with an output power of $40 \mathrm{~kW}$, capable of delivering a current with a frequency of 50 to $150 \mathrm{kHz}$, depending on the capacitor bank (13) configuration. With a typical coil, the maximum current output is in the order of $1500 \mathrm{~A}$.

The camera (17) captures images with 60 frames per second and has a resolution of 3072 by 2048 pixels. In practice, this translates to a resolution where one pixel corresponds to $25 \times 25 \mu^{2}{ }^{2}$, enabling sample tracking with very high accuracy. Figure 3.1 shows a snapshot of an aluminum sample levitating in a coil. A tracking system relying on in-house developed software tracks the sample position in real-time using either Hough circle detection or blob detection for samples of an irregular shape. We have already discussed the dependence of the sample temperature on its height in the coil. Thus, in addition to the pyrometer data, live tracking of the sample position gives valuable information about the temperature, which can be directly applied to optimize the crystal growth.

The above description is, in essence, the heart of the experimental setup. We will now discuss several other characteristics. First of all, the current-carrying rods between the coil and the capacitor bank are subjected to large Lorentz forces due to the opposite current directions and thus tend to separate from each other. Without clamping the rods in place with several polyether ether ketone (PEEK) spacers (9), the maximum deflection at the coil end is in the order of a centimeter. This can potentially put so much force on the electrical feedthrough (10) that it starts leaking or, worse, the ceramic of the feedthrough can break. Even more importantly, without the spacers, the coil itself is greatly deformed since the rods push both endpoints of the coil apart. With these deformations, careful coil design would not be very useful, as the geometry used in calculations would not match the experimental one. The choice is made for PEEK spacers since a ceramic such as alumina is not able to withstand the forces without fracturing. 


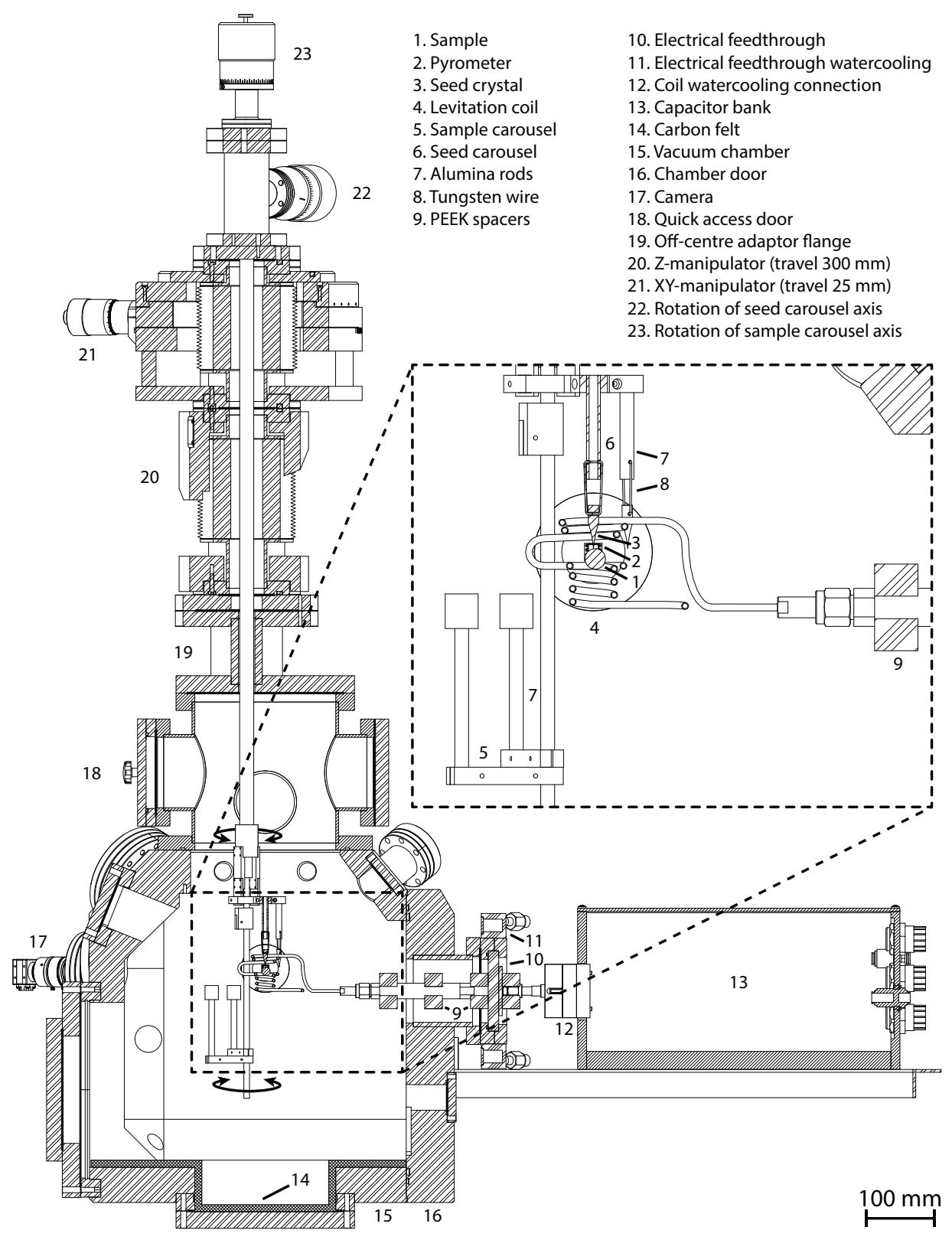

Figure 3.3: Schematic cross-section of the experimental setup (drawn to scale). 


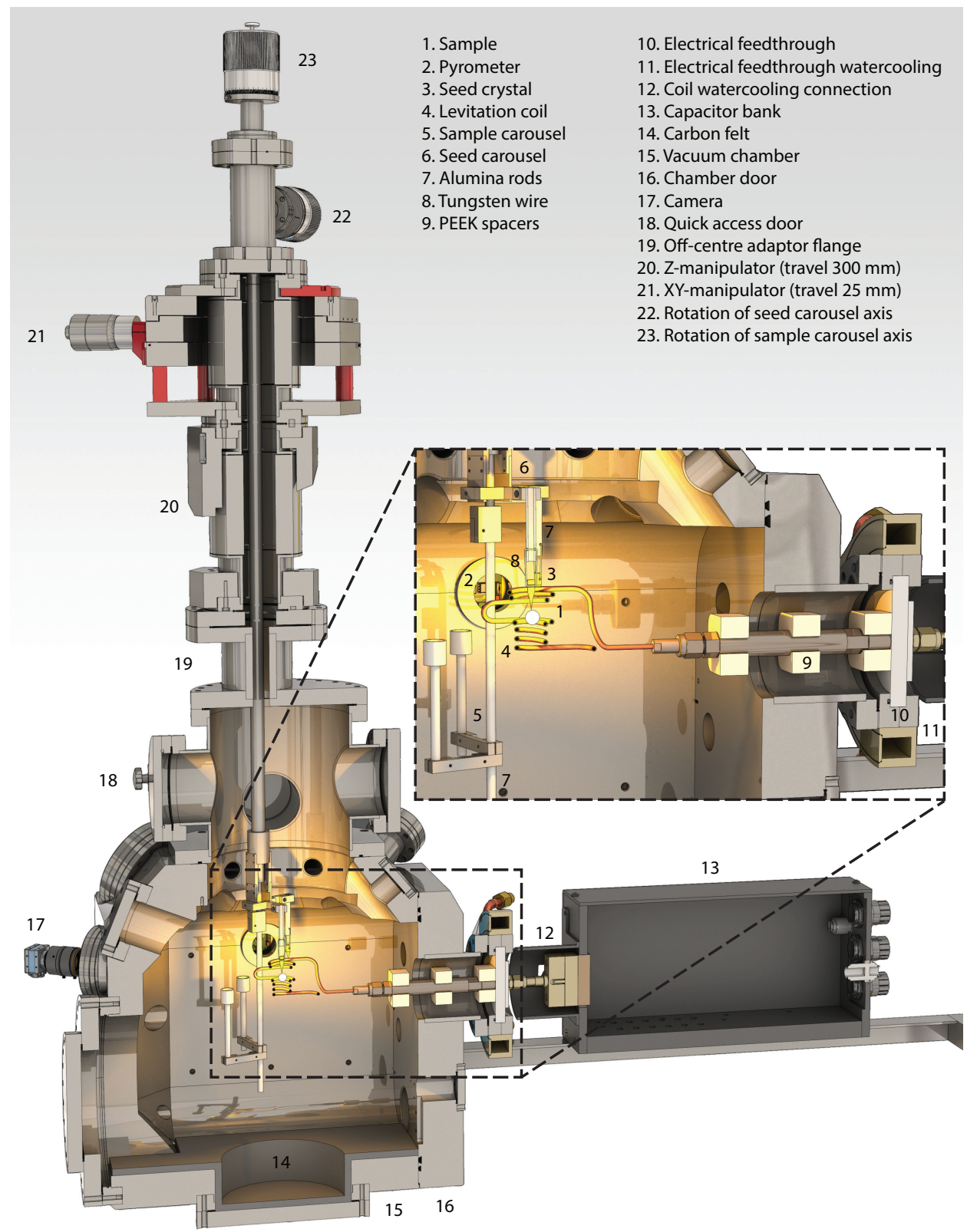

Figure 3.4: 3D rendered cross-section of the experimental setup. 


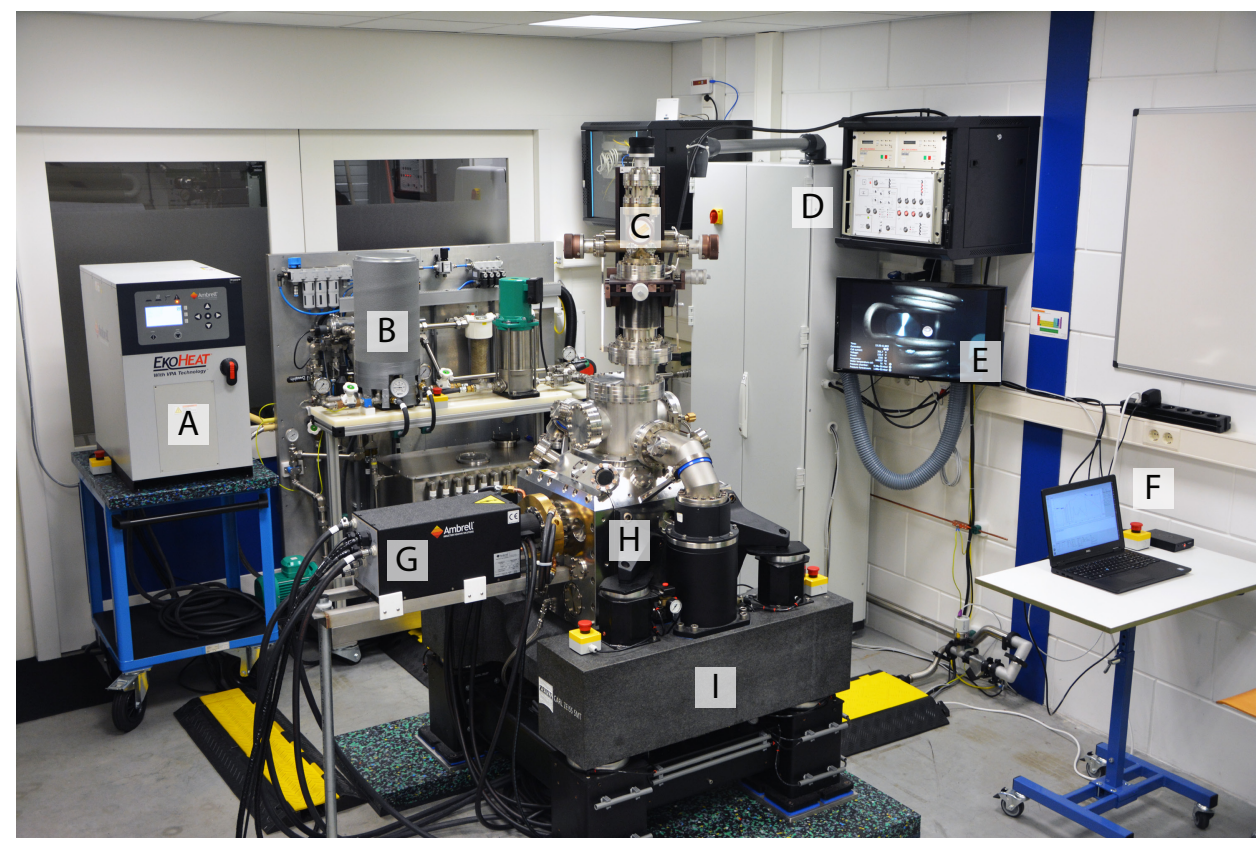

Figure 3.5: Photograph of the experimental setup. (A) Power source. (B) Watercooling tank and pump circuit. (C) Vacuum manipulator. (D) Pump and safety control cabinet. (E) Monitor with live camera feed of the coil. (F) Operator workstation. (G) Capacitor bank and electrical feedthrough. (H) Vacuum chamber. (I) Self-leveling table.

Second, the same magnetic fields that levitate and heat the sample also heat the vacuum chamber. Although the coil itself is sufficiently far away from the chamber walls, the electrical feedthrough is heated substantially by the current-carrying rods and thus requires active water cooling (11). In addition, the coil itself needs to be cooled (12). With an inner coil diameter of $3 \mathrm{~mm}, 20$ bar of water pressure is required to reach a flow of $8 \mathrm{l} / \mathrm{min}$ necessary to transport a theoretical maximum power of $40 \mathrm{~kW}$. The coil is attached to a sliding door (16), making it easy to service and replace.

The pyrometer (2) is custom-made and based on the OPT101 photodiode chip. Figure 3.6 shows a picture of the pyrometer. A 3D-printed housing containing the circuit board attaches to the vacuum chamber, so that the photodiode is centered behind a viewport with a direct line of sight to the levitating sample. The circuit gives an output voltage between $0-10 \mathrm{~V}$ proportional to the radiant power illuminating the sensor. The photodiode has a surface area of $5.2 \mathrm{~mm}^{2}$, is placed $24 \mathrm{~cm}$ away from the sample, and is most sensitive for light with a wavelength of $840 \mathrm{~nm}$. The circuit allows for four different sensitivity settings by toggling a switch. The highest sensitivity setting gives a measurable voltage output for a radiant power on the sensor of $1 \mathrm{nW}$ to $4 \mu \mathrm{W}$, the lowest 
setting for $0.1 \mu \mathrm{W}$ to $400 \mu \mathrm{W}$. As an example to get a feeling for these numbers, a $10 \mathrm{~mm}$ solid spherical sample of aluminum, copper, and iridium at their melting point give a radiant power at the sensor of $5.8 \mathrm{nW}, 104 \mu \mathrm{W}$, and $3.6 \mathrm{~mW}$, respectively. Thus, the low melting point metal aluminum falls just in the detectable window at the most sensitive setting. Copper is nicely detectable in the lowest sensitivity setting. For iridium and other metals with a melting point above $2000 \mathrm{~K}$, an additional filter is required between the sample and the pyrometer to reduce the intensity of the incoming light. Although a custom-made solution like this pyrometer is cheap, it does mean no calibration curve is available for a quantitative measurement of the sample temperature. Still, the qualitative data provides plenty of information to make decisions on the power input with respect to crystal growth experiments. If necessary, the quantitative temperature can be obtained by using the phase transition of the metal from solid to liquid as a calibration point. ${ }^{[59]}$

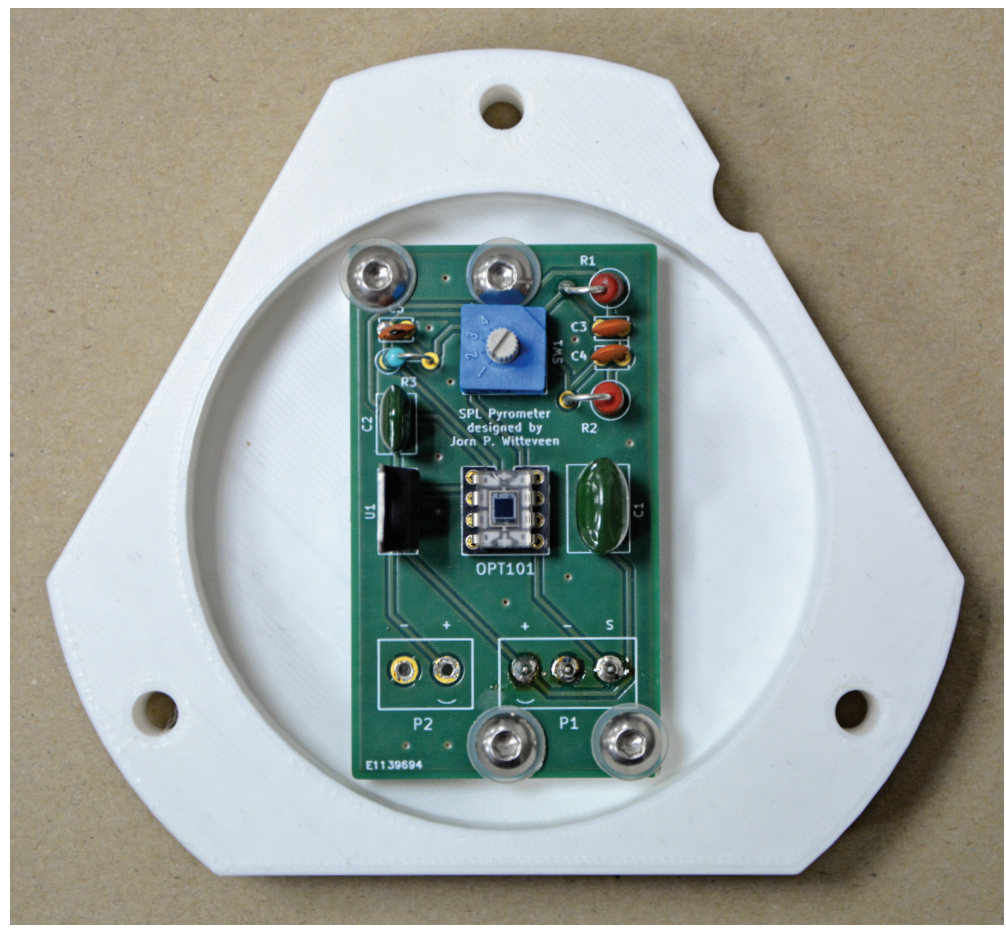

Figure 3.6: Photograph of the custom-made pyrometer.

The vacuum chamber can be filled with argon gas to prevent vapor deposition of the hot source material on the viewports. This also provides an additional method for temperature control, as the sample can lose energy by convection in addition to radiation. However, this is of limited use for high melting point metals, as radiation quickly takes the upper hand (scaling with $T^{4}$ ) over convection (scaling with $T$ ). Finally, the entire chamber 
is placed on a self-leveling granite table to reduce vibrations as much as possible. More pictures and details on the hardware of the setup can be found in Appendix A.

Lastly, we give a short description of the software we developed for the setup. The control cabinet seen in Figure 3.5.D houses four micro-controllers. They monitor and control the vacuum and cooling water circuits. A schematic of both circuits is given in Appendix A. To summarize, the micro-controllers have autonomous control over the detection of faults (overheating, power loss, flow irregularities, short circuits, pressure loss, etc.) and act accordingly, either by warning the operator or safely shutting down (parts of) the system. Since the system is fully automatic, the operator has to pay little attention to the vacuum and water-cooling system, and is free to worry about the, difficult enough, levitation parameters. The micro-controllers, as well as the power source, connect to the laptop on the operator workstation. As such, the power source can be controlled from the laptop with custom software written in the Qt framework. Moreover, the software has the ability to log, display and save all controlled and measured parameters that are of relevance to the experiments. Several screenshots of the software are shown in Appendix A. The main overview window features the graphs of the logged parameters, as well as several quick-access controls of the most used power source, sensor and camera parameters. The camera window gives extensive control over the camera, as well as sample position detection options. Additionally, it is possible to perform image analysis and several other post-processing steps on recorded videos of previous experiments. Another window is dedicated entirely to all power source controls, options and readouts. The control window provides options for quick set-points, automatic ramps, and PID controlled power or voltage regulation. Another window gives an easy to glance overview of the status of all micro-controllers and their most important sensor and variable states. Lastly, the checklist window provides several checklists which can be used to safely start, pause, or stop all individual parts of the setup. 


\subsection{Results and discussion}

As a proof of concept, we have grown copper single-crystals in the levitation setup. The experiment was performed by suspending a solid copper rod (diameter of $12.7 \mathrm{~mm}$, 99.99+\% purity, Advent R.M.) in a coil. The chamber is pumped down to $5 \cdot 10^{-6}$ mbars, at which point it is filled with 1 bar of argon (99.999\% purity, Westfalen). The current in the coil is varied from 175 to $350 \mathrm{~A}$ at $93 \mathrm{kHz}$, which increases the temperature in the rod until the bottom of the rod starts to melt. A liquid droplet is formed, which is levitated in contact with the solid rod. A crystal is subsequently grown by cooling down the sample. The crystal is cooled down by decreasing the current with $4.5 \mathrm{~A} / \mathrm{min}$ to $70 \mathrm{~A}$, at which point the power is switched off and the crystal is left to cool to room temperature by convection. The experiment was repeated to ensure that the results are reproducible.

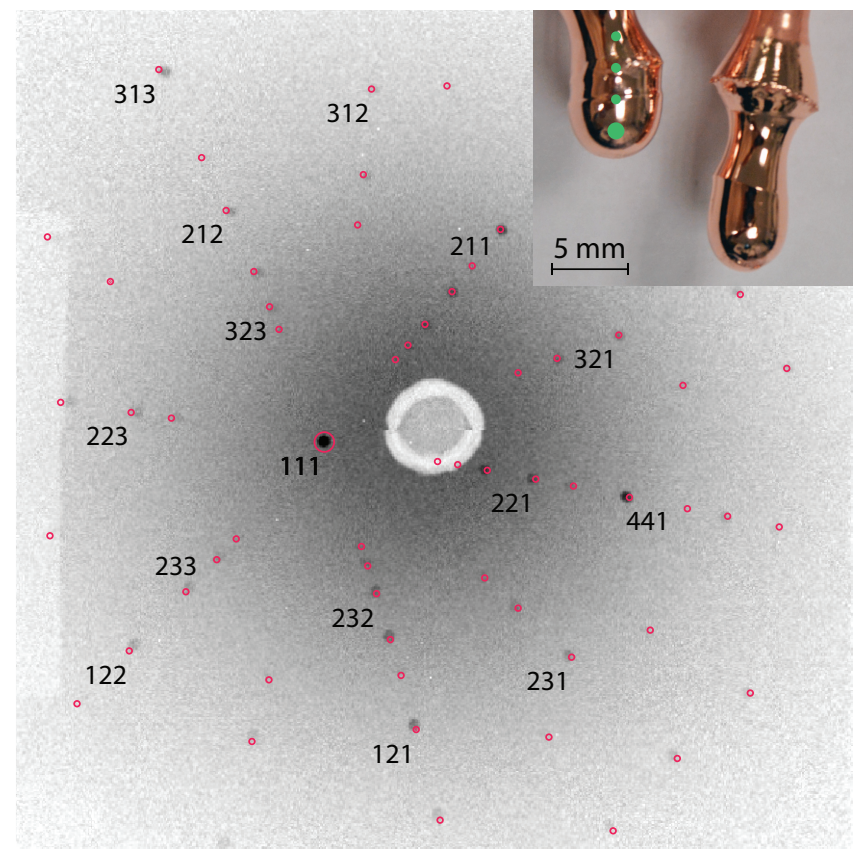

Figure 3.7: Laue x-ray diffraction image of a copper crystal grown in the levitation setup. The theoretical spot positions are indicated in red, together with their corresponding Miller indices. Two unpolished crystals are shown in the inset. The diffraction image is taken at the position of the large green dot visible in the inset.

Two resulting unpolished copper samples are shown in the inset of Figure 3.7. At the position of the large green dot, a Laue x-ray diffraction pattern is recorded, which is also shown in Figure 3.7. We can see a clear $\mathrm{Cu}(111)$ pattern with no apparent spot smearing or 
spot splitting, indicating a low defect density. To ensure the monocrystallinity throughout the sample, a series of images has been taken on four locations along the crystal. The locations are spaced $2 \mathrm{~mm}$ apart and are indicated by the green dots in Figure 3.7. At every position, the Laue diffraction image had a single-crystal appearance as in Figure 3.7. A fifth image recorded another $2 \mathrm{~mm}$ further showed two distinct diffraction patterns, indicating a grain boundary. This shows that it is possible to grow levitation-based single-crystals.

To compare the quality of the levitated crystal with a commercially available crystal grown using the traditional Czochralski technique, we aligned and polished both crystals following an identical preparation procedure. The raw diffraction measurements of the crystals are shown in Figure 3.8. To the eye, we see no significant differences between the two measurements, indicating that the levitation-based crystal is at least equal in quality to commercially available single-crystals. A more thorough investigation on the quality of the crystal would warrant higher resolution diffraction measurements, to make a quantitative comparison of, for instance, the spot width. In future research, we will also perform contamination measurements to compare our samples with those grown using traditional techniques, where the material is in contact with a crucible, and explore the parameters required for controlled growth of materials with a higher melting point.

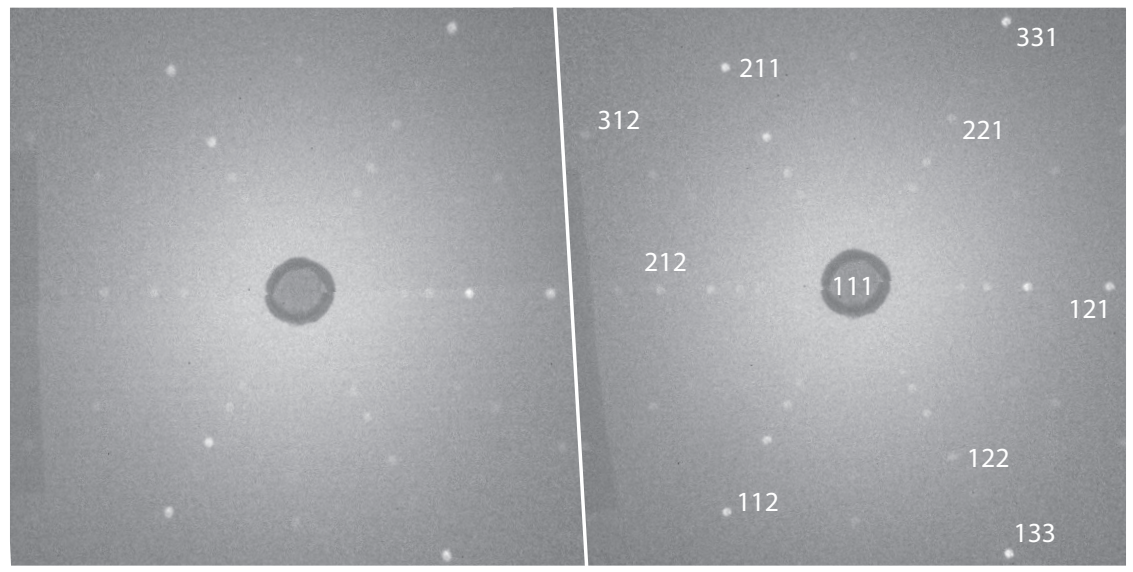

Figure 3.8: Raw data of Laue x-ray diffraction image of a copper crystal grown in the levitation setup, aligned and polished (left) compared to a commercially available crystal prepared identically (right). Several spots are labeled with their respective Miller index. 


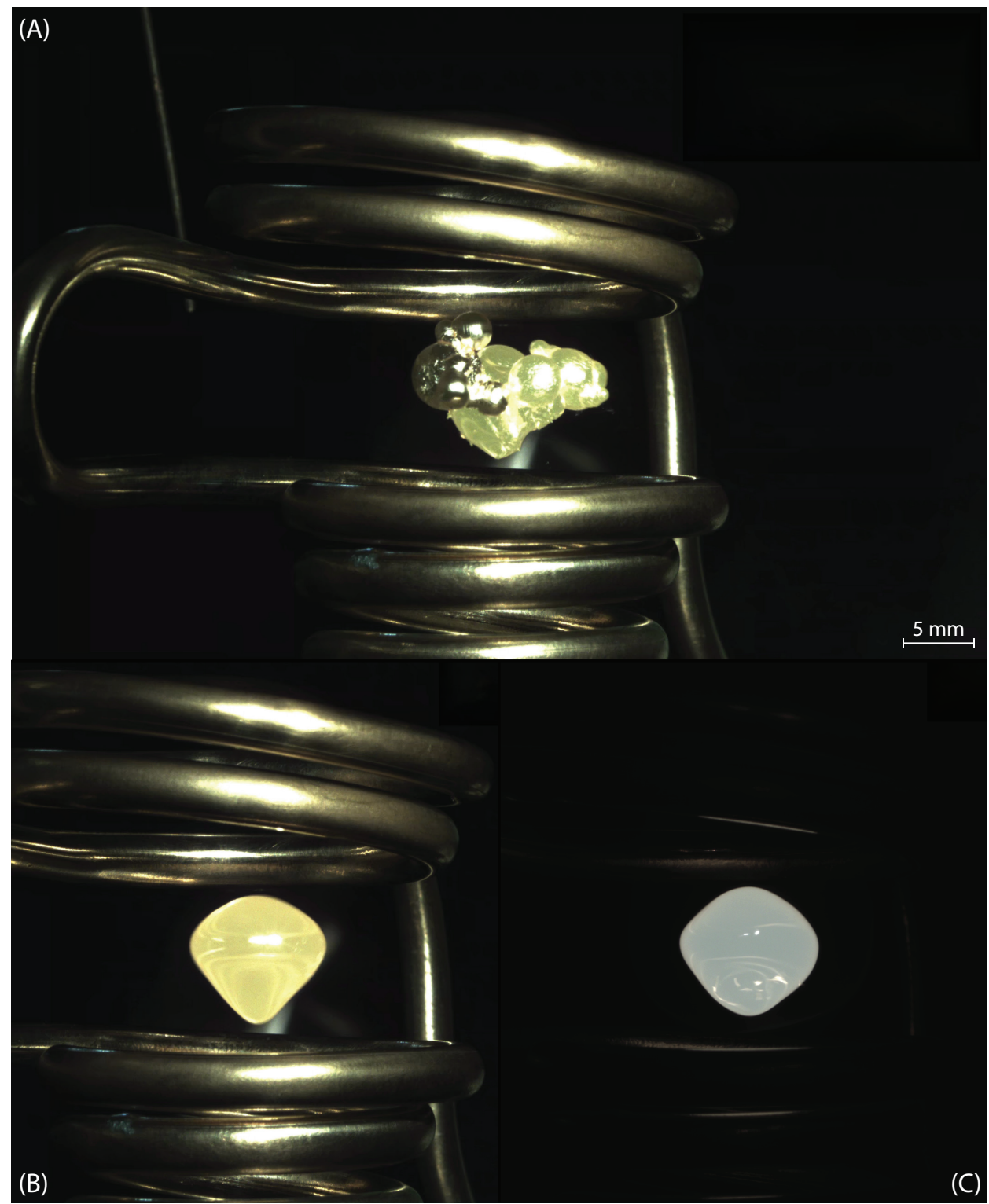

Figure 3.9: (A) Multiple copper shots levitating while clumped together. (B) All the copper is molten, the shape of the liquid droplet is now determined by the surface tension and the magnetic pressure. (C) Low exposure photo of the liquid droplet. The bright white spots are (oxide) contamination that is stirred toward the surface. The reflection of the bottom coil is visible in the droplet as well. 
Finally, it is important to mention the shape of the samples inserted in the coil. Although spherical samples are easy to model, ${ }^{[27]}$ they can be difficult to acquire commercially for various high purity metals. Moreover, spherical samples have an inherent rotational instability, ${ }^{[60]}$ potentially causing the sample to spin at such high speeds that it fractures. Thus, in practice, it is beneficial to start with an asymmetric sample shape. Very pure metals are often commercially available as shots. In our setup it is possible to levitate multiple copper shots (99.9999\% purity, Goodfellow); see Figure 3.9. The magnetic force clumps the individual shots together, while friction prevents the shots from spinning individually. Upon melting, they fuse together to form a single droplet, after which the shape is determined by the interplay of surface tension and magnetic pressure. ${ }^{[61]}$ Thus, it is possible to insert any desired mass of material into the coil while preventing highspeed rotations of the solid object(s). The rotational instability poses less of a problem in the liquid form. On the contrary, the resulting excessive stirring can even be beneficial to purify the sample as (oxide) contamination is separated; ${ }^{[62]}$ see also Figure 3.9.C.

\subsection{Conclusion}

We presented a novel crystal growth apparatus that employs EML in a vacuum to grow metal single-crystals of superior quality and purity. The system is capable of levitating a wide variety of metals while having precise control over the sample temperature in both the liquid and solid states within $1 \mathrm{~K}$. Crystal growth is possible with either containerless undercooled crystallization or levitation-based Czochralski growth. As a proof of concept, we have shown the growth of copper single-crystals. The crystals grown in the EML setup are at least equal in quality to commercially available single-crystals grown using the traditional Czochralski technique. In future research, we will more accurately determine the crystal quality and compare the purity of crystals grown in our containerless setup with crystals grown in a crucible. 


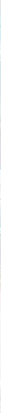
- $1 \times-12 \times$

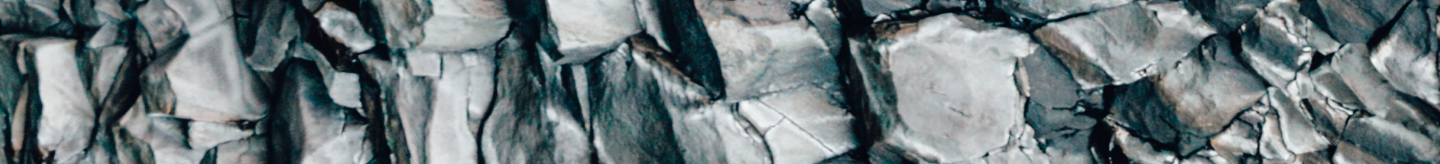

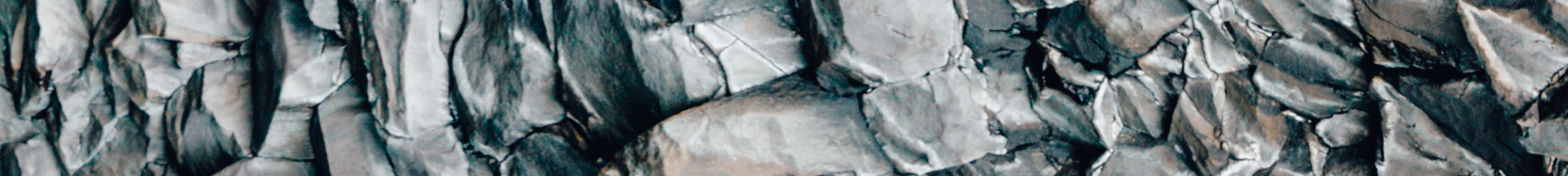

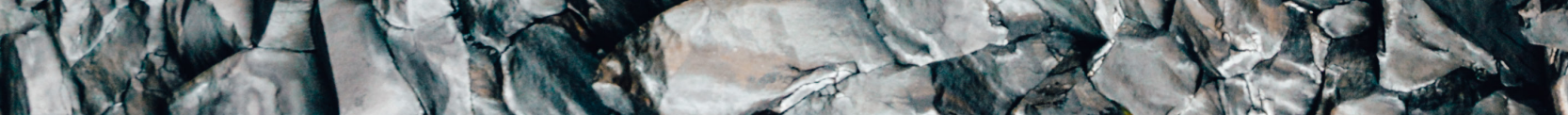

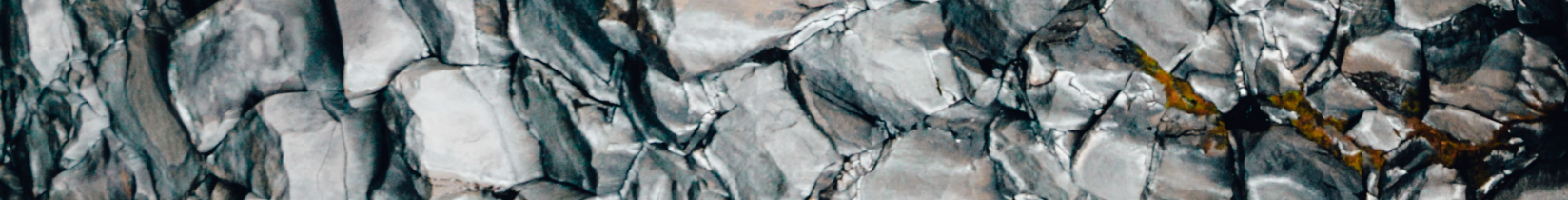
14) $\left(x x^{2}\right)$ (1) v l in है -12 15,252 's 212 a b as 5

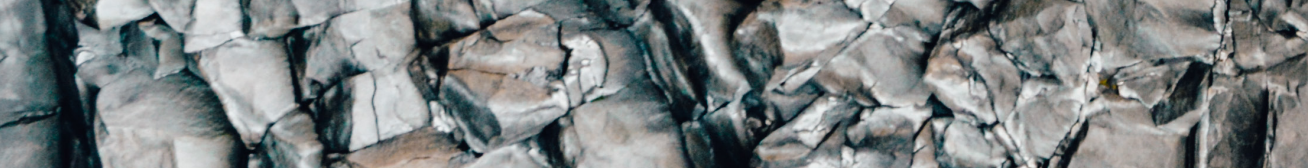
(a) 15025 (1) b. (1) b. I. $=1215$ to

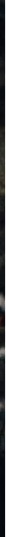




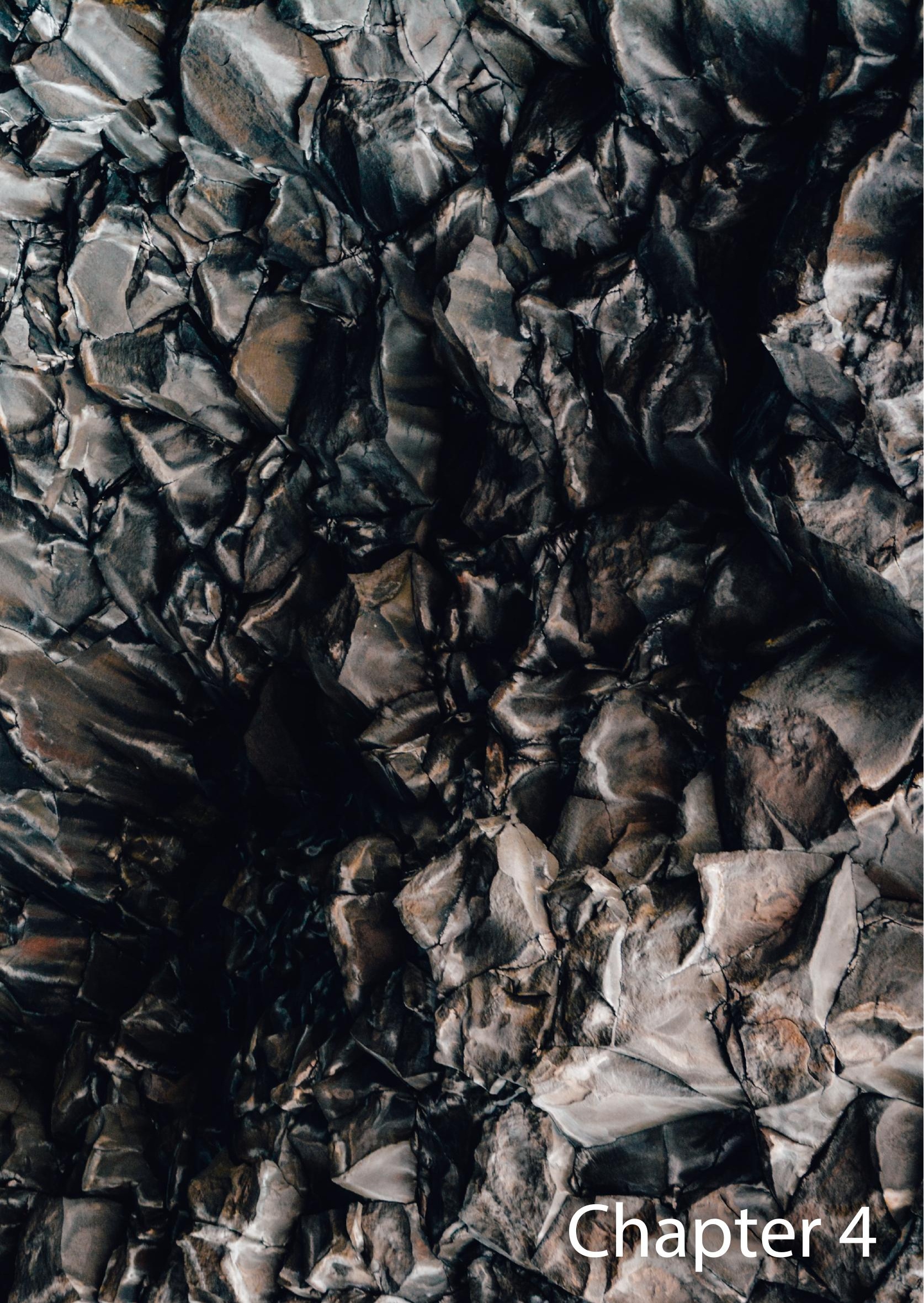




\section{D modeling of electromagnetic levitation coils}

Electromagnetic levitation (EML) enables the handling of electrically conductive samples in a containerless manner. The lack of for instance thermal gradients, nucleation or impurities due to contact with a container leads to more precise measurements or manipulation of materials. As such, it has been used in solidification studies, thermophysical property measurements and nanoparticle production. ${ }^{[31]}$ An EML coil induces eddy currents in the sample, which simultaneously lift and heat the sample. Control is possible by balancing the lift (Lorentz force) and heat (Joule heating) through careful coil design. ${ }^{[27]}$

Designing coils is a delicate process, as the smallest perturbation can have a large influence on sample stability and temperature. ${ }^{[43]}$ To date, coil design is based on empirical data and experience: trial and error. ${ }^{[41]}$ A reliable mathematical model would enable a more rational coil design.

In the 1950s, the first mathematical models for an EML system used a simplified axisymmetric system where the coil and sample are replaced by concentric rings, see Figure 4.1.1. In these models, the magnetic field is calculated analytically using the Biot-Savart law. The lift force, calculated using the principle of mutual inductance between the rings and the sample, the stable levitation position and the sample temperature are derived from the magnetic field. ${ }^{[27,36]}$

Over the years, improvements of these models appeared, such as the determination of the exact solution of the total force acting on a spherical sample as a series of Bessel functions. ${ }^{[63]}$ These improvements and additions to the models gained momentum around the year 2000 with the arrival of more computational power and commercial physical modeling software, with an emphasis on numerical techniques such as the finite element method (FEM). ${ }^{[31]}$ Examples include electromagnetic-thermal coupled simulations ${ }^{[41]}$ or calculating the dynamic shape of a sample in its liquid state, ${ }^{[64]}$ while considering sample oscillations ${ }^{[65]}$ or the influence of the Marangoni effect. ${ }^{[44]}$

However, most of these improvements have been made on the sample-side of mathematical modeling, whereas the coil-side has essentially remained unchanged. A notable exception to this is the work by Feng et al. These authors investigated the effect of 
the eddy current distribution inside the coil. ${ }^{[42]}$ Still, the coil is modeled as a set of concentric rings. In reality the coil is, of course, often helical in shape and has intricate three-dimensional (3D) details such as a small loop to reverse the current polarity between the bottom and upper half. Figure 4.1.2 \& Figure 4.1.3 show examples of such coils. Recently, Yan et al. modeled a 3D coil. ${ }^{[66]}$ However, their model still shows considerable deviations from their real levitation coil and they did not show the differences with the classic 2D coils.

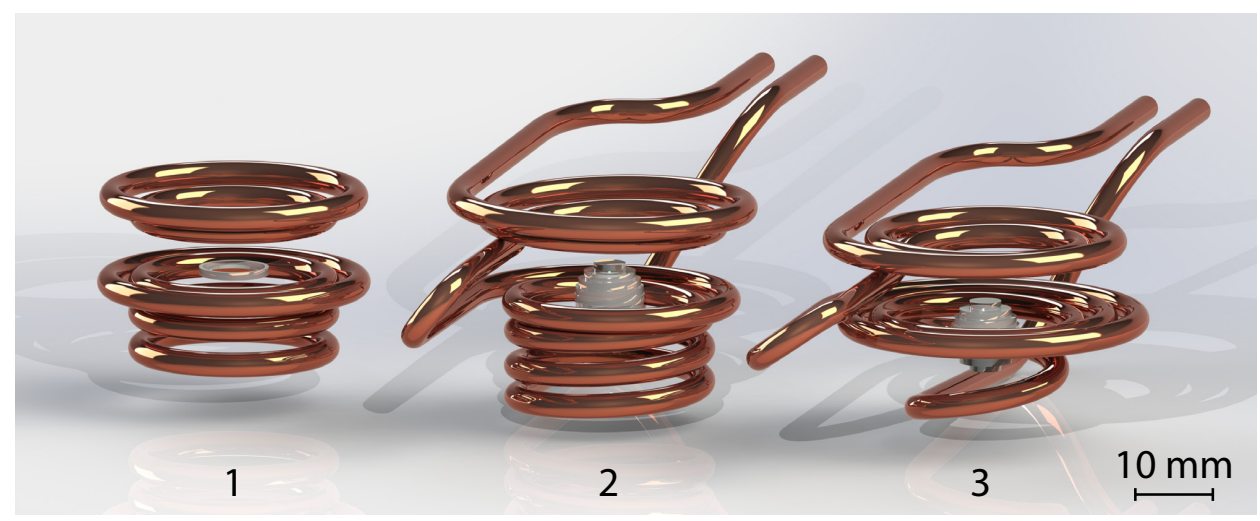

Figure 4.1: Three electromagnetic levitation coils, according to the classic 2D- (1) and our proposed (2 \& 3) 3D mathematical model. 1) A coil from Royer et al. optimized for aluminum levitation ${ }^{[38]}$ and a single circular ring as levitation sample. 2) A 3D interpretation of coil 1. 3) A coil designed using a gradient based optimizer with the goal to produce the same magnetic field as coil 1. The (discretized) horizontal slices of the sample are illustrated by the ring and the stacked disks.

In this chapter we use the simplicity of the classic mathematical model, combined with an adjustment, to model the effects of a truly 3D coil on the magnetic field used for sample lifting in the central axis of the coil. ${ }^{[54]}$ We discuss the consequences and importance of this change for the classic and contemporary models alike. In addition, we investigate the validity of an often made assumption that the axial magnetic field is homogeneous within the sample volume. Finally, we show that it is possible to levitate and melt pure iridium in a coil designed using a 3D model. 


\subsection{Methods}

For the classic 2D calculations, we follow the model by Fromm and Jehn. ${ }^{[36]}$ As said before, both the coil and sample are modeled as concentric rings with zero diameter, see Figure 4.1.1. The Biot-Savart law is used to calculate the magnetic field $B_{z}$ along the cylindrical axis of a single circular current loop:

$$
B_{z}(z)=\frac{\mu I}{2 \pi\left(z^{2}+r_{\text {loop }}^{2}\right)^{3 / 2}}
$$

with $\mu$ the permeability, $I$ the current through the loop, $z$ the height and $r$ the radius. The magnetic field of all individual loops is summed to find the total $B_{z}$ at $(0,0, z)$. The assumption that the axial magnetic field is homogeneous within the sample volume readily provides the magnetic flux through the sample, by multiplying the sample ring area by $B_{z}$. The lift force acting on the sample is calculated using the gradient of the magnetic flux and the principle of mutual inductance between the rings and the sample: ${ }^{[36]}$

$$
F=\frac{-2 \pi}{\mu} r_{\text {sample }}^{3} B \frac{d B}{d z} G(x)
$$

where $G(x)$ is a dimensionless function of $x=r_{\text {sample }} / \delta, \delta$ being the skin depth. $G(x)$ is zero in a static field and approaches unity for high frequencies or low electrical resistivity of the sample. ${ }^{[36]}$

Due to the non-uniform distribution of $B_{z}$ over the height of the sample, Royer et al. discretized the sample in horizontal slices, ${ }^{[38]}$ as illustrated in Figure 4.1.2 \& Figure 4.1.3. This allows them to modify the absorbed power by taking a volume weighted average of the original value. We apply the same principle to the force. Finally, stable levitation positions are found by equating the lift force with the gravitational force.

The temperature of the sample, in vacuum conditions, can be calculated by equating the absorbed power due to Joule heating ${ }^{[36]}$ with the power loss due to gray body radiation. ${ }^{[17]}$ In the scope of this work, it is sufficient to realize that the absorbed power scales with $|B|^{2}$, and consequently that the sample temperature increases with increasing magnetic field magnitude. ${ }^{[17]}$

In our proposed 3D model, the coil is not modeled as a set of rings, but as a continuous tube composed of line segment, see Figure 4.1.2 \& Figure 4.1.3. This tube spans the entirety of the coil, i.e. both helical coil segments, the small loop to change the current polarity and the connections towards the power source. Since the scope of this article is to show the differences between 2D and 3D modeling, we keep the model simple and do not consider the skin effect or mutual inductance between individual windings for the coil. ${ }^{[42]}$ 
The magnetic field at $(x, y, z)$ is calculated numerically using the Biot-Savart law by summing over $n$ discrete line segments that make up the coil. The calculations are performed using a custom written code in MATLAB. The number of line segments $n$ was increased until the relative change in the magnetic field per added segment was below $0.1 \%$. As this method also provides the magnetic field in the $x$ and $y$ direction, one can optionally calculate $F_{x}$ and $F_{y}$ to find the stable levitation points in the $x y$-plane before proceeding with further calculations.

Without the assumption of axial homogeneity of the magnetic field within the sample volume, the magnetic flux is calculated by integrating $B_{z}$ over the area of the (circular) sample. Finally, $F_{z}$ and the stable levitation positions are calculated in the same manner as in the $2 \mathrm{D}$ case.

\subsection{Results and discussion}

\subsubsection{Comparison of 2D models with 3D coils}

Royer et al. optimized a coil for the levitation of aluminum using the classic 2D model, ${ }^{[38]}$ see coil 1 in Figure 4.1. Trying to approach the dimensions and amount of windings as closely as possible, coil 2 is our 3D interpretation of coil 1. For all coils, we define $z=0$ at the top winding of the bottom part of the coil. Using our proposed 3D model, the magnetic field $B_{z}$ is calculated in a point grid of 500 by 500 by 500 using $n=2875$ line segments for coil 2. The magnitude of $B_{z}$, normalized to the current, is shown in Figure 4.2 for two slices of the grid. Taking only the vertical center line $(0,0, z)$ of Figure $4.2, B_{z}$ is plotted versus $z$ in Figure 4.3. We can compare that with the magnetic field of 2D coil 1 at $(0,0, z)$, calculated using the classic model. Although the trend is similar, the values differ, especially in the lower regions of the coil.

To illustrate the importance of these differences, Figure 4.3 also shows the gradient $d B_{z} / d z$. This provides information on the magnetic force according to Equation Equation 4.2. Not surprisingly, the gradient also shows differences between coil 1 and coil 2. The absolute value of the gradient for coil 2 is, for $z$ values between 2.5 and $7.5 \mathrm{~mm}$, actually smaller than for coil 1. Since also the normalized field strength for coil 2 is lower in this regime, the lift force will be lower for coil 2. As an example we consider the stable levitation positions for an aluminum sample with a diameter of $10 \mathrm{~mm}$. Figure 4.4 shows the current required (with a frequency of $180 \mathrm{kHz}$ ) to achieve these positions for both coils. It can be seen that the $3 \mathrm{D}$ coil 2 requires significantly more current to reach the same position as with the 2D coil 1. Intuitively, it makes sense that the $3 \mathrm{D}$ coil 2 needs a higher current, since some of the magnetic energy is lost in the $x$ and $y$ direction. 
$3 \mathrm{D}$ magnetic field $\mathrm{B}_{\mathrm{z}}$

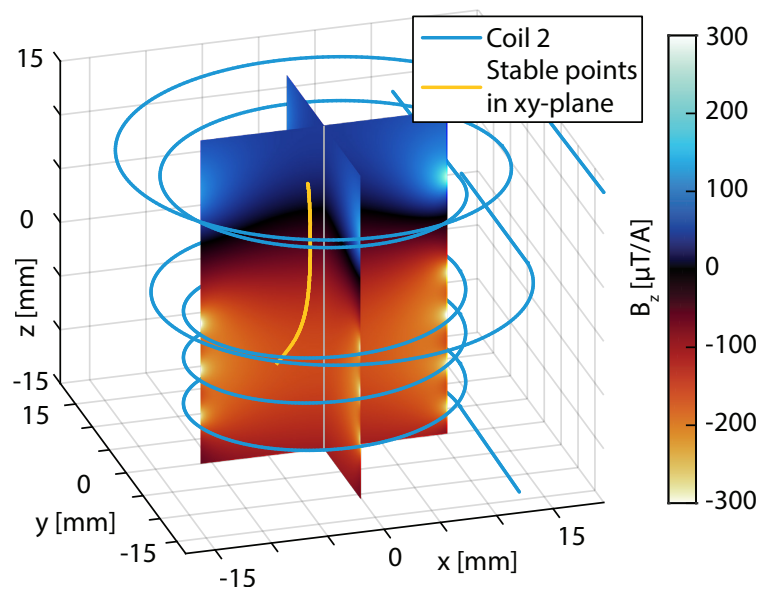

Figure 4.2: $B_{z}$-field magnitude of coil 2 in 3D and the stable levitation points in the $x y$-plane.

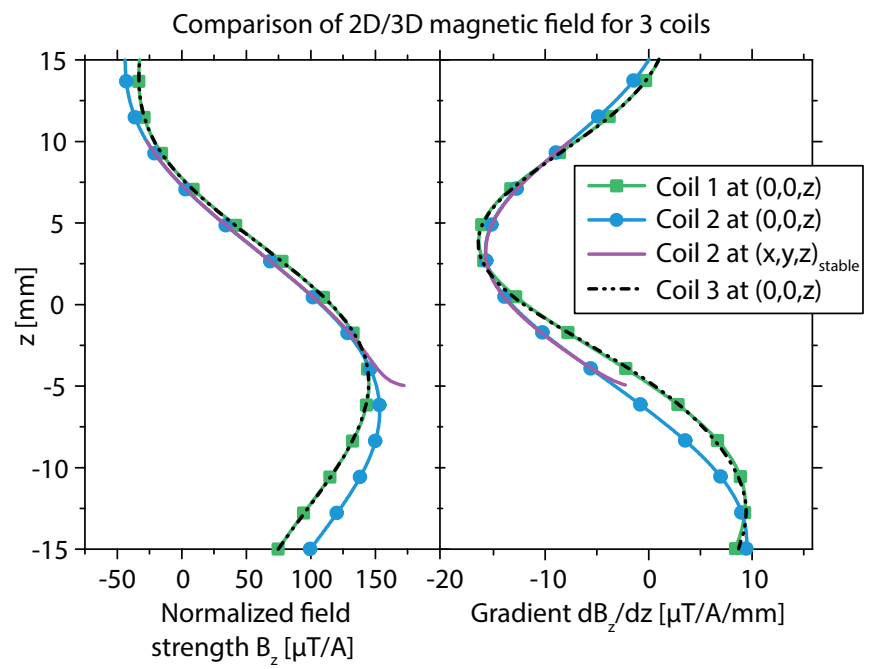

Figure 4.3: Comparison of $B_{z}$ (left) and its gradient (right) of the three coils at $x=y=0$ and at the stable points for coil 2. Coil 1 is calculated using the classic 2D model, coil $2 \& 3$ using the 3D model. 


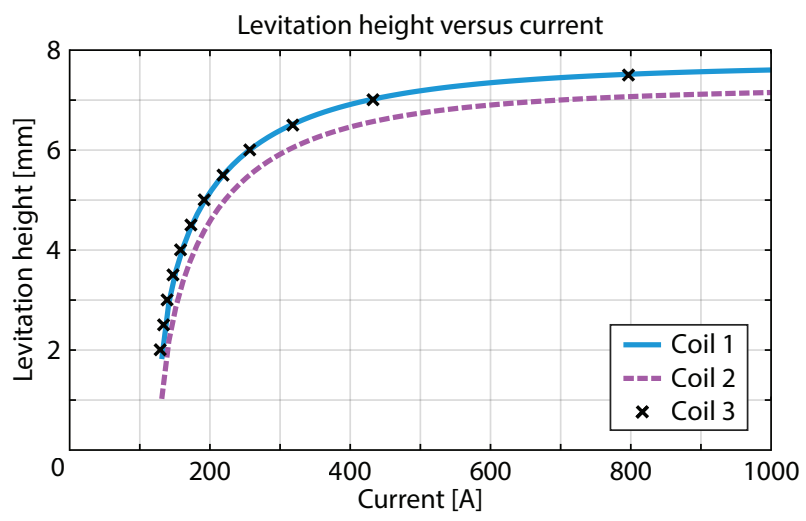

Figure 4.4: Current required to reach a stable levitation height for a spherical aluminum sample for coil 1, 2 and 3. The sample has a diameter of $10 \mathrm{~mm}$, the current has a frequency of $180 \mathrm{kHz}$. Coil 1 is calculated using the classic 2D model, coil $2 \& 3$ using the 3D model.

To further substantiate the point that 3D modeling is important, we now reverse the situation. Given 2D coil 1 and its magnetic field, what 3D coil would produce precisely the same magnetic field? Using a gradient based optimizer native to MATLAB, which is set to vary the position of the coil windings, the $B_{z}$ differences at $x=y=0$ are minimized. The result is coil 3 as shown in Figure 4.1. Figure 4.3 shows that coil 1 and 3 give the exact same magnetic field and gradient at $x=y=0$. Figure 4.4 shows that this 3D coil 3 behaves precisely as $2 \mathrm{D}$ coil 1 for the example with an aluminum sample. Still, Figure 4.1 shows that the coils do not look alike at all. The bottom windings of coil 1 are mostly stacked vertically, while those of coil 3 are mostly spiraling horizontally. This evidences that to get predictable results, 3D modeling is of the utmost importance.

In contrast to the classic model, $B_{x}$ and $B_{y}$ are not cylindrically symmetric in the 3D case. These field asymmetries are especially generated in the part of the coil where the current polarity changes, and they influence the lateral stability and sample symmetry. ${ }^{[66]}$ It is possible to find the stable levitation positions in the $x y$-plane using the 3D model by equating $F_{x y}$ in Equation Equation 4.2 to zero. These stable positions are shown in Figure 4.2 and are independent of sample size. ${ }^{[36]}$ Figure 4.3 also shows $B_{z}$ of coil 2 at these positions. The magnetic fields at $(0,0, z)$ and at $(x, y, z)$ stable deviate significantly around $z=-5 \mathrm{~mm}$. It is near this position that the sample is heated to the maximum temperature, since $|B|^{2}$ is maximum. ${ }^{[17,36]}$ Therefore, if the focus is on heating, one should take the $x y$-position into account. 


\subsubsection{Inhomogeneous magnetic field within the sample volume}

An often made assumption in the classic model is that the magnetic field is homogeneous in the $x y$-plane within the sample volume, ${ }^{[27]}$ when the radius of the sample is smaller than half the radius of the coil. ${ }^{[36]}$ This assumption can be tested using our 3D model.

Using the same approach as before to calculate the magnetic field in a grid, Figure 4.5 once again shows the magnitude of $B_{z}$ normalized to current, but this time for two slices in the $x y$-plane. Indeed, the magnetic field seems to be homogeneous for small radii, but has more significant deviations towards the edges.

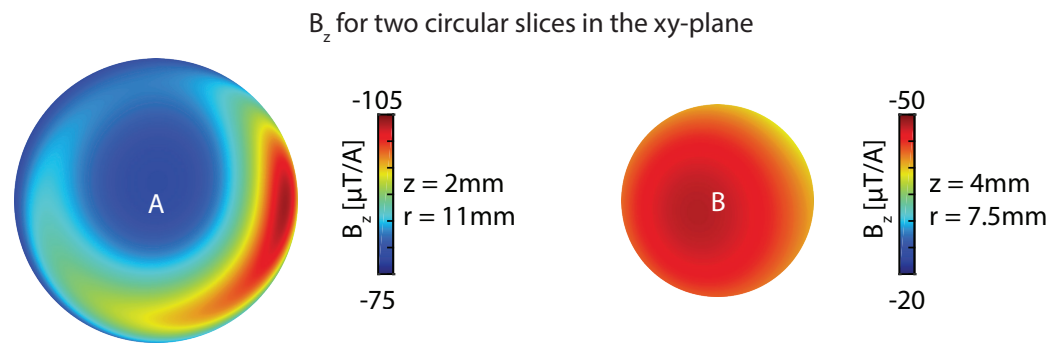

Figure 4.5: $B_{z}$-field magnitude of coil 2 for two slices in the $x y$-plane.

For EML purposes, the important property is the (variation of) the magnetic flux through the sample, since this relates to the levitation force and sample heating. The magnetic flux through slice A in Figure 4.5 is calculated and normalized to the area, i.e. the mean $B_{Z}$ is calculated. The average value of $B_{z}$ is color coded in Figure 4.6 for the corresponding sample height and radius at the point labeled $A$. The same is done for slice $B$, and all other possible sample heights and radii. In the classic model, the average value of $B_{Z}$ is independent of the sample radius for every sample height, while in the 3D model the average value of $B_{z}$ varies with increasing $r$, especially for high and low sample positions. Both models only give the same results regardless of sample size when $z$ is around $2.5 \mathrm{~mm}$.

Interestingly, the absolute value of the magnetic flux increases with increasing sample radius. This means that the classic model gives an underestimation of the total magnetic flux through a realistic sample. Consequently, as the absorbed power in the sample scales with the magnetic flux squared, ${ }^{[17,36]}$ the classic model gives an underestimation of the sample temperature.

We now return to the validity of the assumption that the magnetic field is homogeneous when $r_{\text {sample }}<0.5 r_{\text {coil }}$. For coil 2 , the radius of the innermost winding $r_{\text {coil }}=12 \mathrm{~mm}$, so at $r_{\text {sample }}=6 \mathrm{~mm}$ the deviation should be negligible. This is clearly not the case in the 
lower and upper regions of the coil. At the lower region of the coil the generated heat is maximal. Therefore, if the focus is on heating, one should consider the underestimation of the temperature in the classic model, even for small samples.

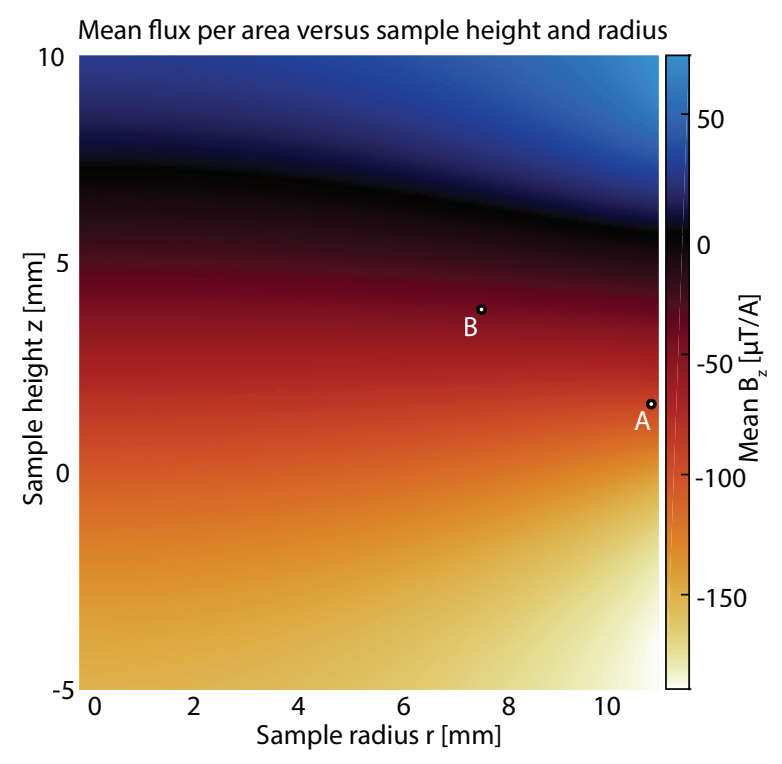

Figure 4.6: Normalized mean magnetic flux through a sample versus the sample height and radius. The values of slices A \& B in Figure 4.5 are indicated by the labels.

\subsubsection{Experimental coil design}

Using the improved 3D model, which takes into account both a truly 3D coil and an inhomogeneous axial magnetic field within the sample volume, it is possible to design a new coil capable of levitating and melting a $6 \mathrm{~mm}$ in diameter spherical sample of iridium for the first time. Iridium is difficult to levitate, due to its high density of $22.6 \mathrm{~g} / \mathrm{cm}^{3}$. It is also difficult to melt, due to its relatively high melting temperature of $2719 \mathrm{~K}{ }^{[67]}$ To melt a sample, the current is decreased, so that the sample levitates in a lower region of the coil with a larger field strength, thus increasing temperature. ${ }^{[17]}$

Figure 4.7 shows a levitating iridium sample in its solid state with a coil current of $1055 \mathrm{~A}$ at $112 \mathrm{kHz}$. Stable levitation was achieved for a total of 10 minutes, at which point the current was slowly decreased. At 929 A, the sample levitated at a height of $1.9 \mathrm{~mm}$ and melted. This is evidenced by the solidified puddle of iridium after dropping the sample, see the inset of Figure 4.7. Our model shows that for a similar 2D coil, levitation is not even possible at this height. In general, we did not manage to find a coil design capable of melting iridium using the classic 2D model. 


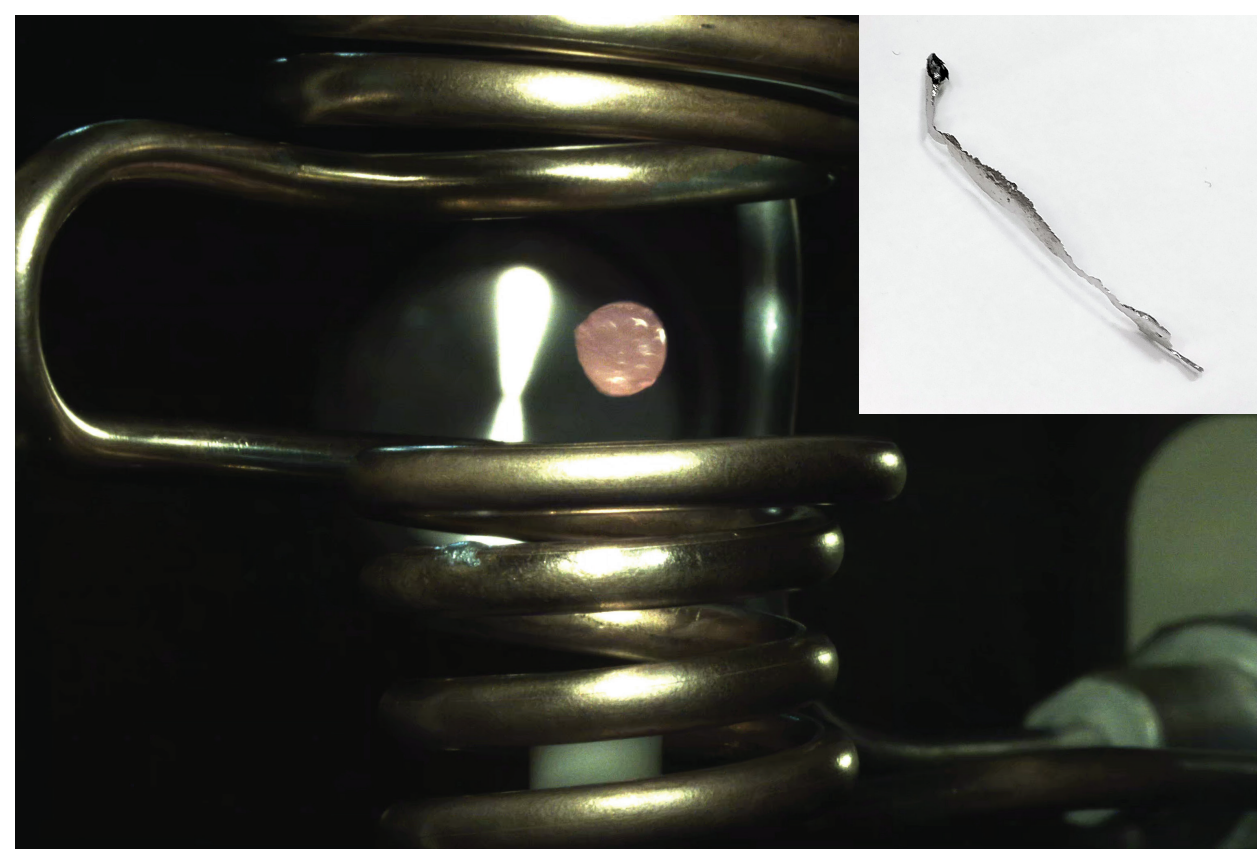

Figure 4.7: A $6 \mathrm{~mm}$ in diameter spherical sample of iridium levitating in a coil designed using the proposed 3D model. Inset: Solidified iridium after dropping the liquid sample.

\subsection{Conclusion}

Using the simplicity of the classic 2D model, with a minor adjustment to the way the magnetic field is calculated using the Biot-Savart law, we showed significant differences in the resulting lift and heating properties between a set of concentric circles and a realistic 3D coil. When designing coils using a 2D model, more current will be required during actual experiments than expected. Also, the stable sample position in the $x y$ plane should be taken into account when levitation is desired in the lower regions of a coil. Lastly, to get the same magnetic field in a 3D coil as in a 2D coil, a vastly different design is required.

The assumption that the magnetic field is homogeneous in the $x$ and $y$ direction within the sample volume is invalid in the upper and lower regions of the coil. This leads to an underestimation of the magnetic flux and sample temperature in the classic model. 
In summary, we presented a mathematical model for truly 3D electromagnetic levitation coils and showed significant quantitative differences between 2D and 3D coils. The importance of 3D modeling is experimentally validated by the levitation and melting of iridium. Although coil design and optimization has received attention in literature, ${ }^{[38,39]}$ a substantial step forward is made by combining coil optimization with the evaluation of a truly 3D coil. 
$62 x$

$$
121+2
$$

a) $-42+3$

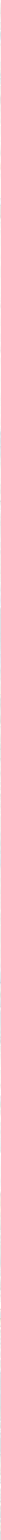

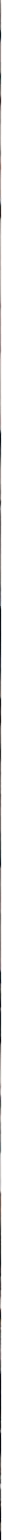

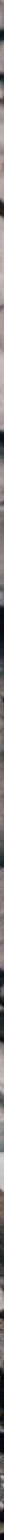

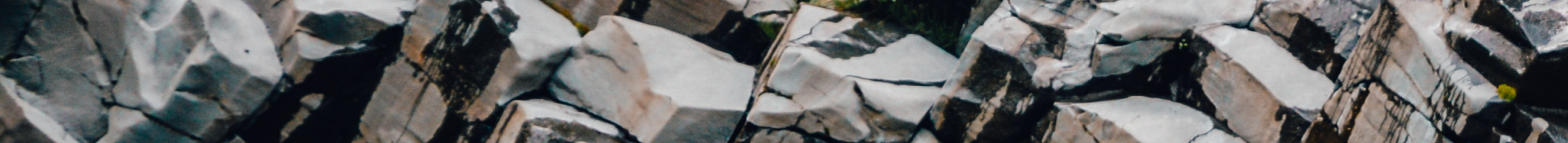

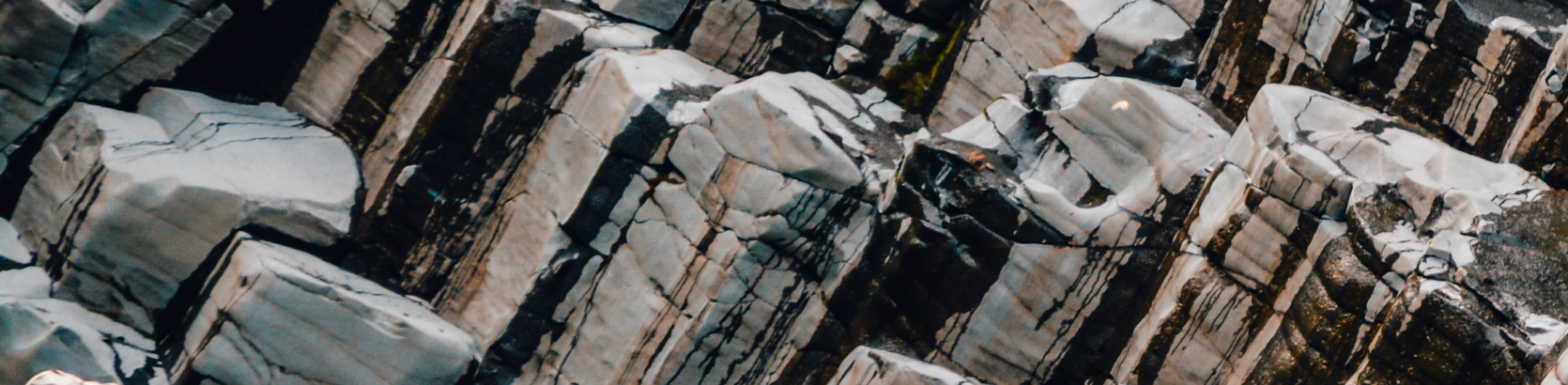


$2-201$ ato $\Rightarrow$

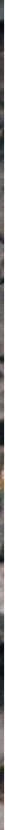

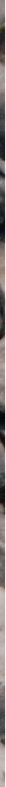

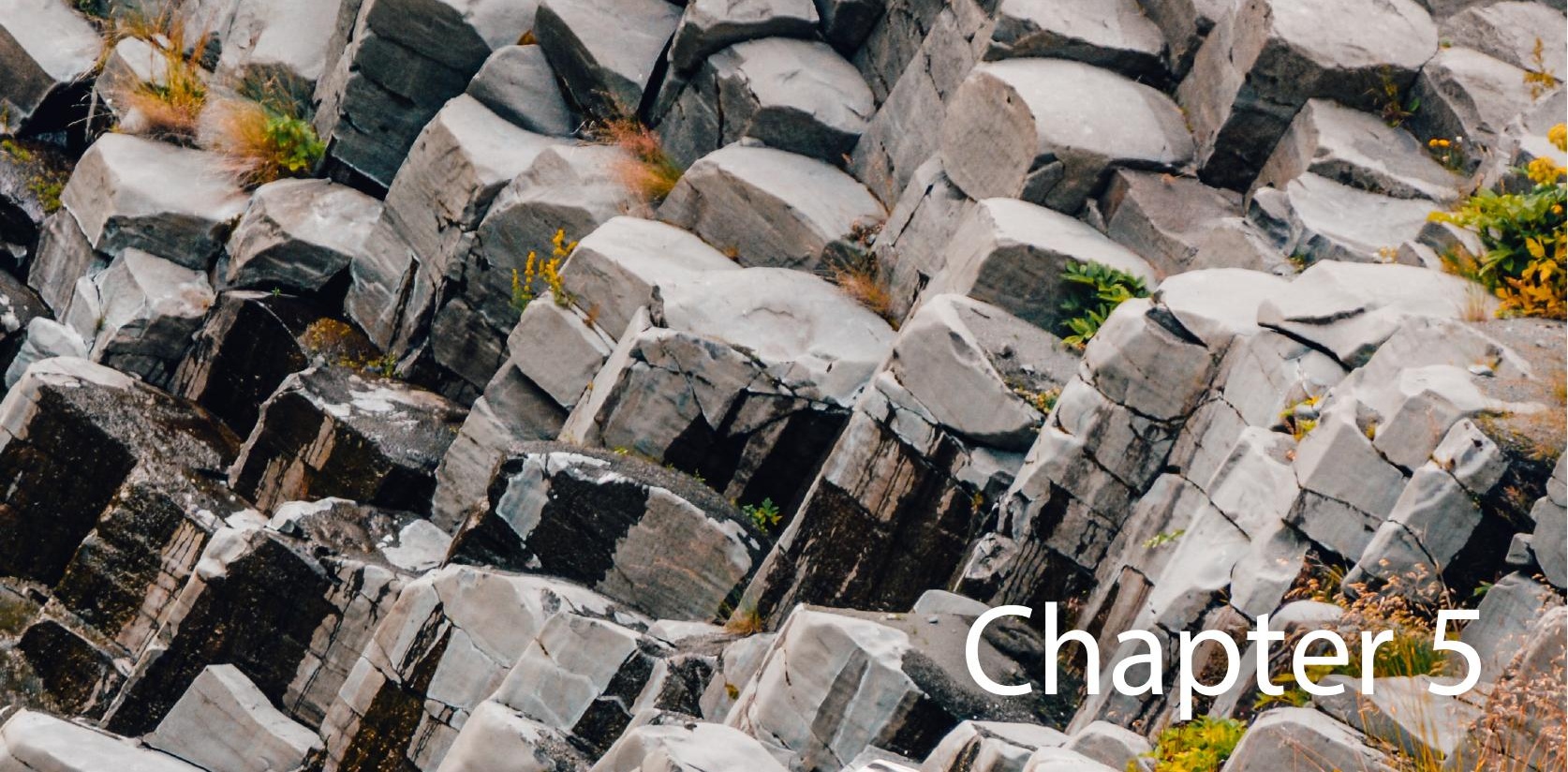




\section{Self-induced bending of electromagnetic levitation coils}

Electrically conductive samples can be handled in a containerless manner via electromagnetic levitation (EML). ${ }^{[27]}$ The absence of thermal gradients, nucleation, or impurities due to contact with a container leads to more precise manipulation or measurements of materials. EML has been used in solidification studies, thermophysical property measurements, nanoparticle production, ${ }^{[31]}$ and to grow pristine single-crystal materials, as described in Chapter 3. EML relies on the Lorentz force that acts between a levitation coil and the metal sample. Eddy currents are induced in the sample as a high-frequency alternating current passes through the coil, generating a magnetic field. The Lorentz force arises from these currents in the magnetic field. The same current in the sample that provides the lift also causes the sample temperature to increase due to Joule heating. However, the magnetic field is not limited to the position of the sample but extends well beyond the geometry of the coil. This means that any conducting material in the vicinity of the current-carrying coil will be affected by the force and the heating. Interestingly, this includes the coil itself.

Figure 5.1 shows an electromagnetic levitation setup. The coil is connected to the end of two thick current-carrying rods. The hollow rods are made of phosphor bronze, with an outer diameter of $22 \mathrm{~mm}$ and an inner diameter of $6 \mathrm{~mm}$. They are $206 \mathrm{~mm}$ long, and their centers are $25.4 \mathrm{~mm}$ apart. When a high-frequency current is passed through the rods, the resulting Lorentz forces push the two rods apart. At $1000 \mathrm{~A}$ and $112 \mathrm{kHz}$, the maximum observed deflection at the end of the rods is in the order of $1 \mathrm{~cm}$. To prevent this, an aluminum oxide spacer was used to clamp the rods together. However, at $1100 \mathrm{~A}$, this spacer was not able to withstand the forces and fractured. Three stronger PEEK spacers were used in the final design of our levitation setup described in Chapter 3.

This example illustrates one of the engineering challenges that follow from the forces generated by EML coils. As we will see in this chapter, these forces also cause the levitation coil itself to bend under the influence of its own magnetic field. Traditionally, induction heating coils are fixated with nylon bolts, Teflon tape, or even cast in concrete. ${ }^{[68]}$ However, doing so with EML coils would block a significant portion of the view of the sample inside the coil. This prevents us from using optical non-contact characterization techniques, defeating the purpose and advantages of utilizing EML. 


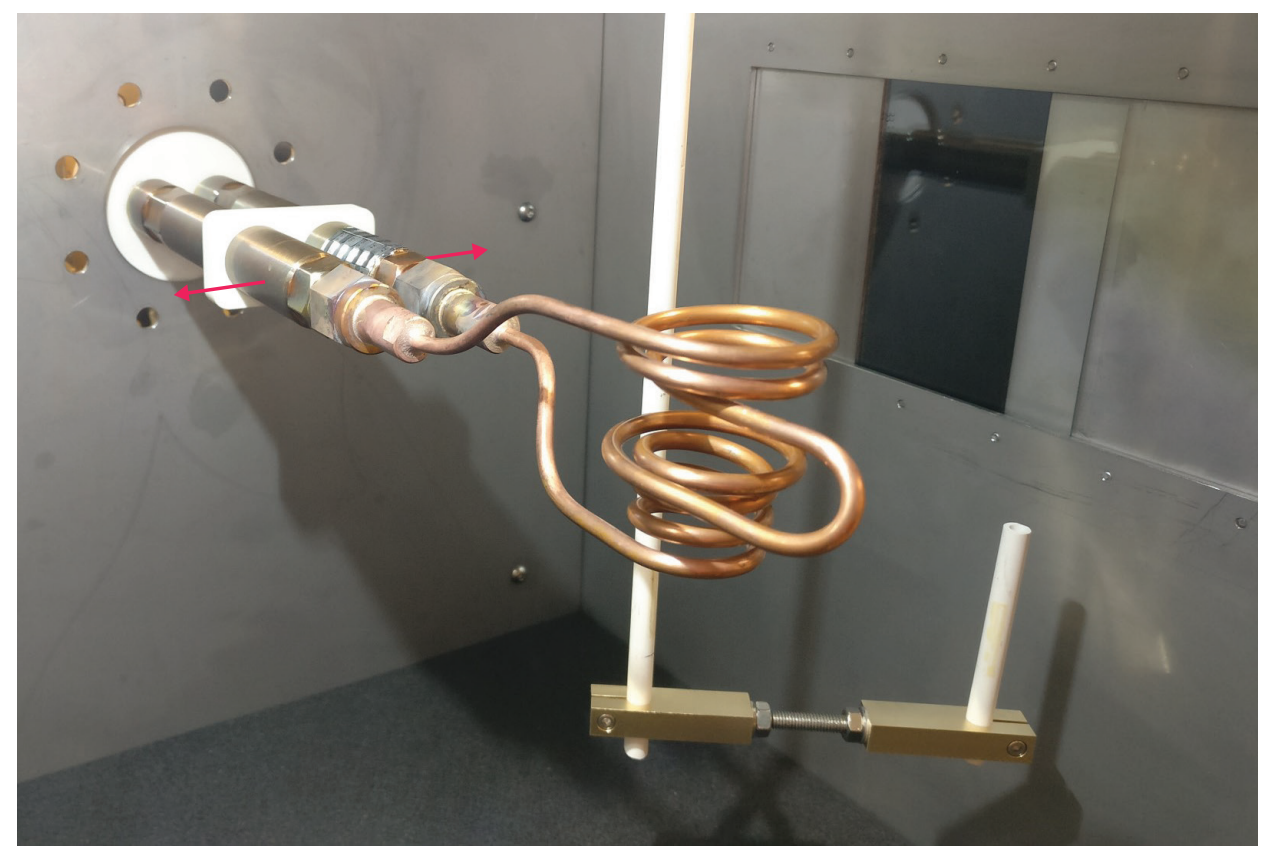

Figure 5.1: The current-carrying rods leading to the EML coil are subject to repulsive Lorentz forces, pushing the two rods apart as indicated by the arrows.

Designing levitation coils is an intricate process, as even a tiny change in coil geometry can significantly influence sample stability and temperature. Thus, we expect that the bending of the coil will influence the levitation dynamics. To this day, coil design is mainly based on empirical data and experience: trial and error. A reliable mathematical model predicting the geometry of the coil when it is bent would enable a more rational coil design.

Takaghi et al. investigated the bending of superconducting helical coils wrapped around a torus for use in a fusion reactor to find the mechanical constraints for the structural design. ${ }^{[69]}$ Liu et al. developed a model to predict the bending of thin, flexible spiraling coils used for transcranial magnetic stimulation, a painless and non-invasive method for treating brain disorders. ${ }^{[70]}$ To the best of our knowledge, no research has been performed on self-induced coil bending in relation to electromagnetic levitation.

In this chapter, we describe a measurement in which the coil bending is apparent and relate this to the levitation height of an aluminum sample. In order to predict the bending of the coil, we develop a model that couples the electromagnetic and solid mechanic calculations to find the steady-state shape of the coil. Lastly, we discuss the influence of self-induced bending of coils on the levitation parameters. 


\subsection{Experiments}

Figure 5.2 shows four screenshots of a movie taken during a levitation experiment with an aluminum sample (sphere with diameter $6 \mathrm{~mm}, 99.0 \%$ pure, Goodfellow) in the setup described in Chapter 3. Figure 5.2.A shows the start of the experiment; the sample is resting on top of an aluminum oxide rod. The power is switched on, and the sample is levitated at 297 A until its initial vibrational motion is reduced and steady-state conditions are reached, as seen in Figure 5.2.B. At this point, the current is increased with steps of roughly $50 \mathrm{~A}$ up to $1079 \mathrm{~A}$, see Figure 5.2.D. As expected, the sample height increases with increasing current. However, we can also see the deformation of the levitation coil. This is most evident by looking at several locations taken on a central axis of the coil indicated by the dotted red line. With no current, in Figure 5.2.A, we mark four locations: the top of the top coil, the bottom of the top coil, the top of the bottom coil, and the bottom of the bottom coil. If we extend lines from these locations to Figure 5.2.D, where the current is maximum, we see that these locations have shifted as the coil deforms. For good measure, the same lines are drawn at identical positions in Figure 5.2.B and Figure 5.2.C.

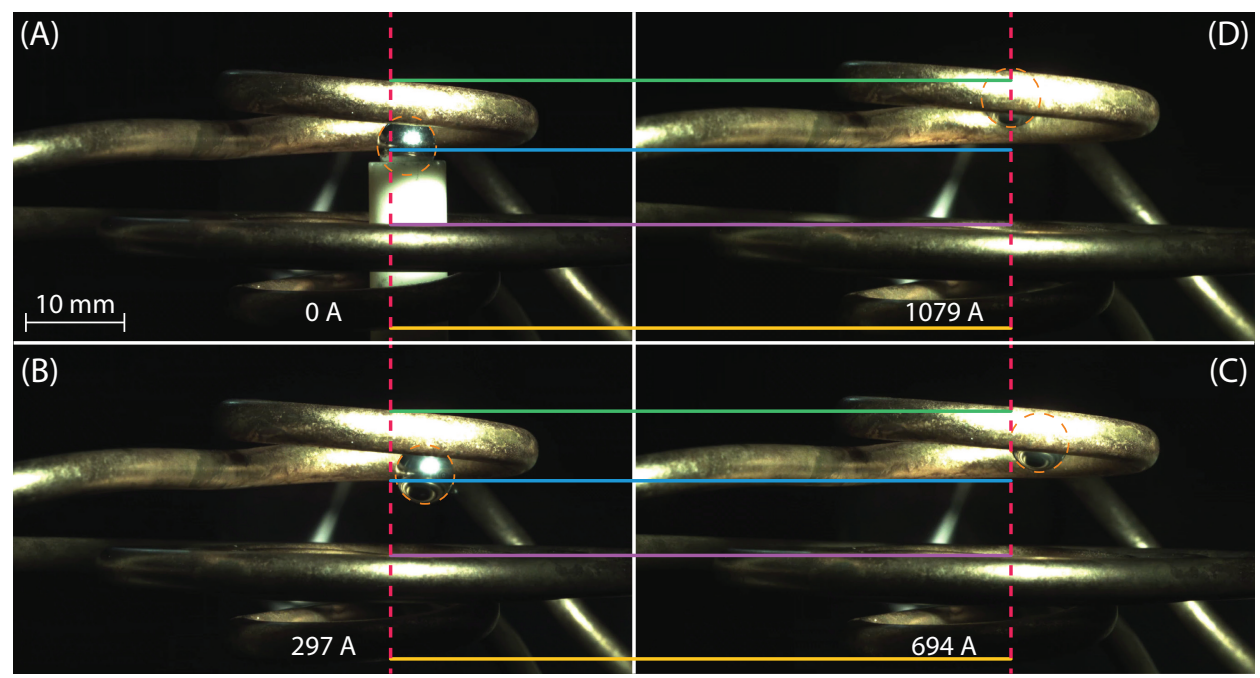

Figure 5.2: Four screenshots of a movie taken during the levitation experiment with a spherical aluminum sample. The coil deforms with increasing current, as can be seen by comparing the four locations on the coil indicated by the colored lines. 
As seen in Figure 5.2, we can track the sample position by applying a Hough circle transform to each movie frame. The camera is leveled and calibrated using a ruler placed inside the coil. In this case, we have a resolution of 44.13 pixels $/ \mathrm{mm}$, and the center of the top winding of the bottom coil at the start of the experiment is defined as the origin. In-house developed software analyzes the sample position for all frames of the movie. To verify the results, we check for every frame that the detected circle indeed has a diameter of $6 \pm 0.1 \mathrm{~mm}$. If not, the corresponding data point for the sample position is omitted. The levitation height of the sample and the coil current are plotted versus time in Figure 5.3. As we can see, the sample height increases with increasing current. The sample is oscillating about its stable position, which explains the oscillations visible in the levitation height.

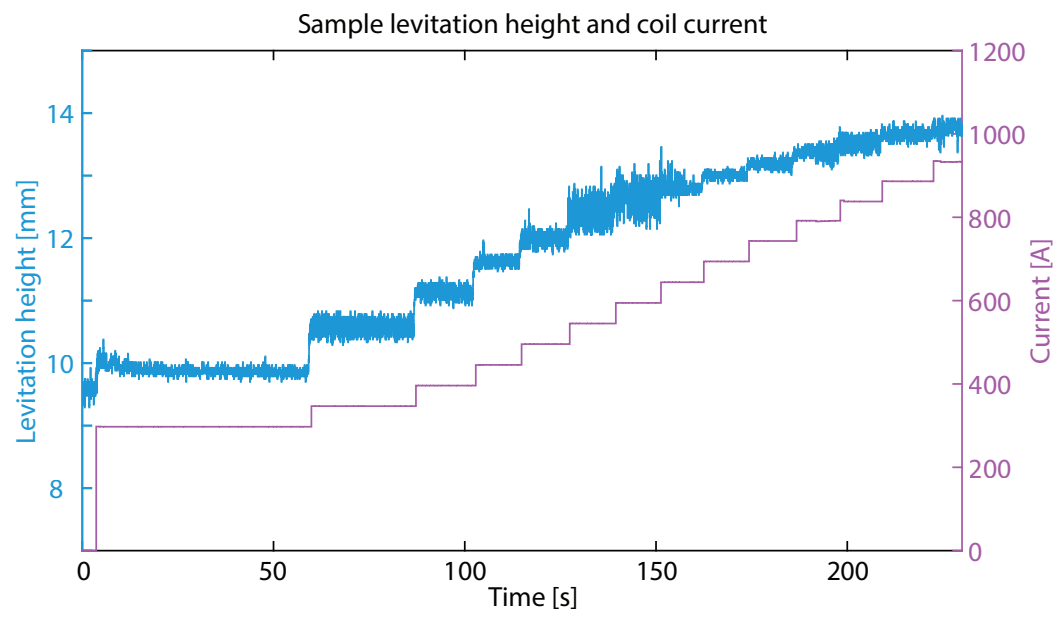

Figure 5.3: The sample levitation height resulting from the Hough circle transform tracking software versus the time (left axis) and the applied coil current versus time (right axis).

For each coil current, we take the average value and calculate the standard deviation. These values are shown in Figure 5.4. The theoretical values as calculated using the model described in Chapter 4 are also included in the plot. Although the measurements correspond with the theory at low currents, the sample levitates lower than predicted at high currents. It is also at high currents that we expect the largest self-induced deformation of the coil, so it is helpful to quantify the observed coil bending.

For each of the four coil locations described before, we manually measure the position in the movie for each current value. We normalize these positions to each respective starting position at zero current, so that we can compare the relative deformation of each location. This is shown in Figure 5.5. The top coil has a positive displacement, and the bottom coil has a negative displacement. Generally, a larger distance between the top and bottom coil results in a less stable sample, more lift, and a lower temperature. ${ }^{[40]}$ 


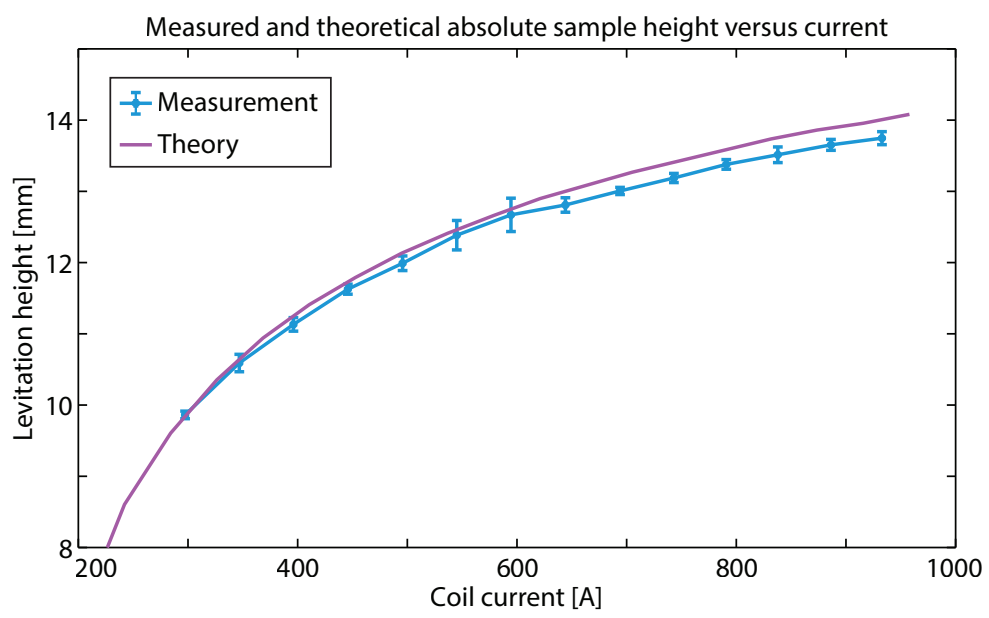

Figure 5.4: Comparison of measured and theoretical sample levitation height versus current.

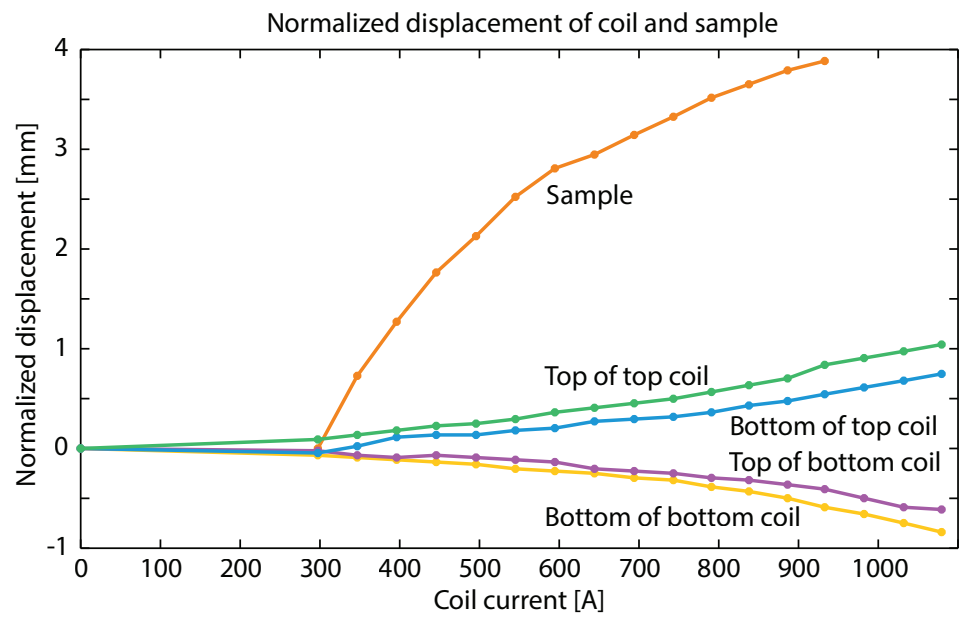

Figure 5.5: Displacement of the sample and the four locations on the coil as indicated in Figure 5.2 versus current. The displacement is normalized to each respective starting position at zero current.

Furthermore, we see that the top of the top coil displaces more than the bottom of the top coil: the coil elongates. We see the same for the bottom coil. This results in a lower turn density and thus a weaker and less concentrated magnetic field. This decreases both the lift and the temperature. ${ }^{[40]}$ 
Lastly, the sample position changes roughly $4 \mathrm{~mm}$ over the complete current range, where the distance from the top of the coil to the bottom increases by almost $2 \mathrm{~mm}$. Since both displacements have the same order of magnitude, it might be possible that the bending of the coil will have a significant influence on the levitation parameters. In order to obtain a qualitative and quantitative understanding of the coil bending, we will now investigate the self-induced coil bending through the use of finite elements method (FEM) calculations. The coil geometry employed in this study is slightly different from the coil shown in Figure 5.2, but it also shows significant bending under the influence of its own magnetic field. This coil is pictured in Figure 5.6. We see a qualitative displacement similar to the previous coil: the top and bottom coil are repelled.

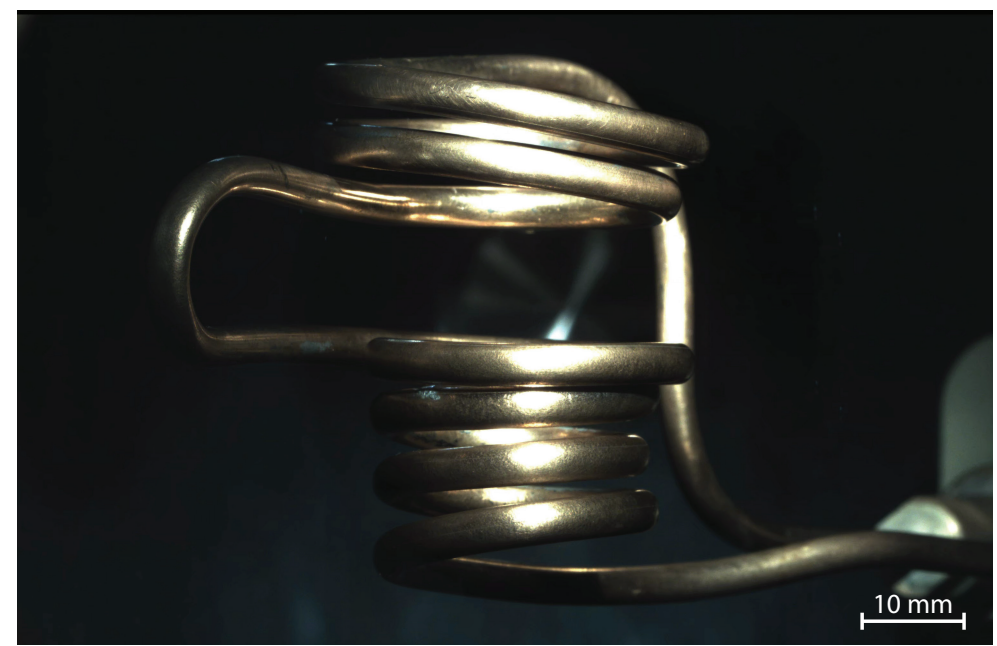

Figure 5.6: The levitation coil geometry used in the self-induced coil bending FEM calculations.

\subsection{Methods}

To model coil bending under the influence of its own magnetic field, we use COMSOL, a commercial finite element analysis, solver, and multiphysics simulation software. The geometry of the model is shown in Figure 5.7. The current-carrying rods have the exact dimensions as in Figure 5.1 and their position is fixed, as if it were clamped in the PEEK spacers described in Chapter 3. The coil is made of copper, has an outer diameter of $4 \mathrm{~mm}$ and an inner diameter of $3 \mathrm{~mm}$. It is surrounded by a cylindrical vacuum domain, which is in turn surrounded by an infinite element domain. Infinite elements represent a region stretched along specific coordinate axes to approximate an infinitely large domain and are used internally by COMSOL to ensure correct boundary conditions when solving the differential equations. 


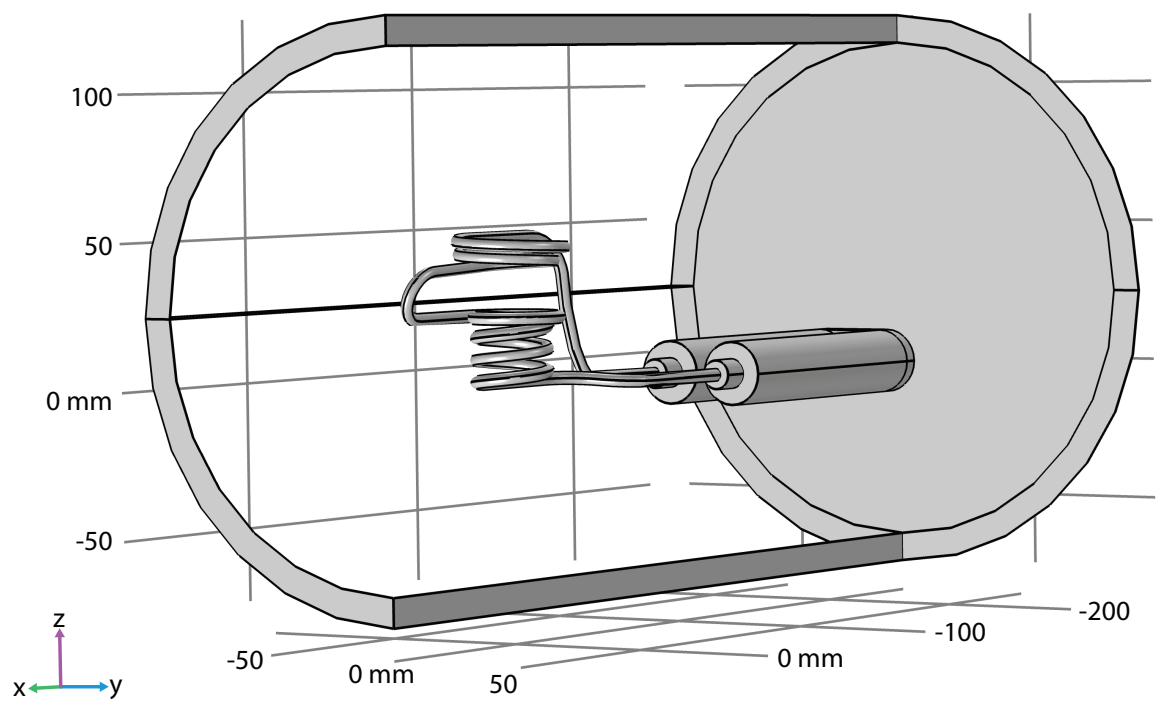

Figure 5.7: Geometry of the COMSOL model. A copper coil is surrounded by a cylindrical vacuum domain, which is in turn surrounded by an infinite element domain.

We use the magnetic fields interface in combination with the solid mechanics interface. The magnetic fields interface solves Maxwell's equations for all elements in the mesh, and the solid mechanics interface solves for the forces, motion, and stress. The multiphysics interface couples all interfaces, so that the Lorentz force resulting from the magnetic fields interface is used as an input for the solid mechanics interface. In turn, the moving mesh and deformed geometry interfaces couple the resulting deformed coil geometry from the solid mechanics interface back to the magnetic fields interface. This back and forth coupling is repeated until the solution converges.

We use the default COMSOL free tetrahedral mesh, with the element size set to "Finer". Even smaller elements did not yield significantly better results but did increase computation time from hours to days. The first study step involves a coil geometry analysis, which computes the physical current flow through our complex 3D coil, instead of following the direction of a wire. This is followed by a stationary solver that terminates when a relative tolerance of 0.001 is reached. 


\subsection{Results and discussion}

To ensure the numerical model produces correct results, we plot the magnitude of the magnetic field in the $z$-direction in Figure 5.8 for a coil current of $1000 \mathrm{~A}$. As expected, the magnetic fields in the top and bottom coil are opposite in direction, with a region of zero magnetic field magnitude in the middle. To validate this result, we have compared this to the $B_{z}$ values generated by the analytical model described in Chapter 4 (not shown). The maximum error over all values on the grid is $2 \%$, confirming that the numerical magnetic fields interface in the COMSOL model produces correct results.

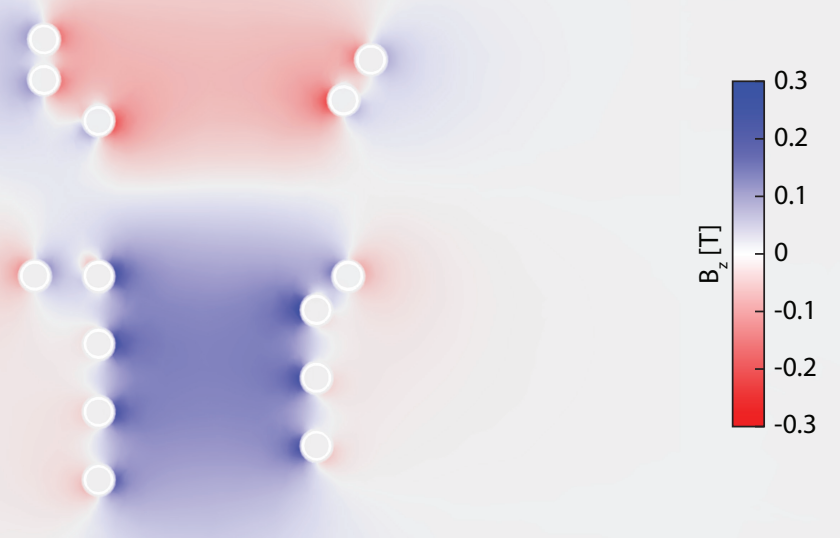

Figure 5.8: Magnitude of the magnetic field in the $z$-direction for a cross-section at the center of the coil.

Figure 5.9 shows the displacement of the coil under the influence of its own magnetic field. The arrows indicate the direction of displacement. The bottom and top coil repel each other, and they are separated by a maximum of a few micrometers. Although this qualitatively corresponds with the experiments, the quantitative displacement is one or two orders of magnitude too small compared to the observed displacement. Thus, in the model, the Lorentz forces are not large enough. Since the current is a constant input parameter, this means that the magnetic field magnitude at the position of the coil must not be large enough.

In conventional EML models, the skin effect is considered in the metal samples but is usually ignored in coils. Feng and Shi pose that, since the distance between the coil windings is several millimeters in general, the non-uniform distribution of current density in the coil influences the magnetic field calculations. ${ }^{[42]}$ They show that the inclusion 

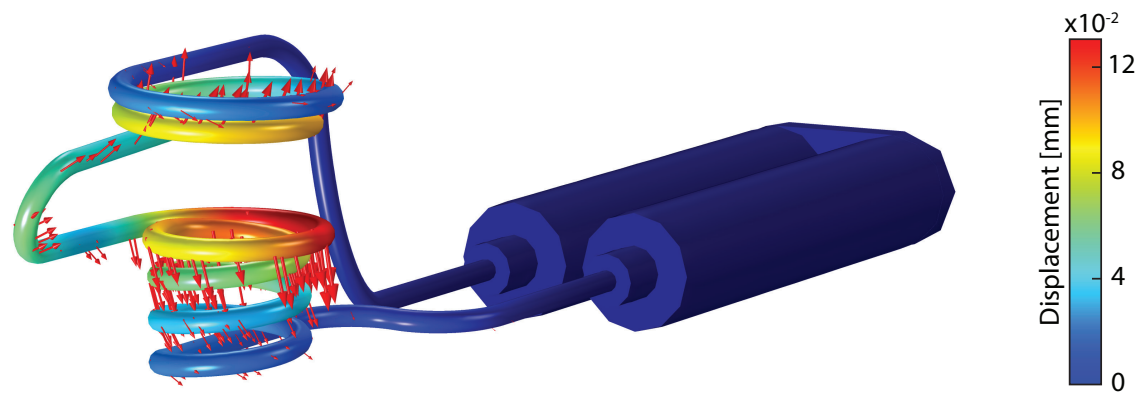

Figure 5.9: The self-induced coil bending for a constant current of $1000 \mathrm{~A}$ : the arrows show the direction of the displacement, and the arrow size and the color map show the magnitude.

of the skin effect in their model leads to a higher magnetic force. As such, we change our COMSOL model to use a solver in the frequency domain instead of the stationary solver. Figure 5.10 shows the resulting current density distribution in a cross-section of the coil for a current of $1000 \mathrm{~A}$ at a frequency of $100 \mathrm{kHz}$. The skin effect causes the current to flow primarily at the surface of the conductors. The alternating magnetic field of individual windings also induces eddy currents in the adjacent conductors: the proximity effect. This results in a redistribution of current such that it is concentrated in the areas of the conductor farthest away from nearby conductors carrying current in the same direction.

Figure 5.10: The current density distribution in the coil for a current of $1000 \mathrm{~A}$ at a frequency of $100 \mathrm{kHz}$. 
The COMSOL multiphysics interface is not capable of coupling the magnetic fields, solid mechanics, moving mesh, and deformed geometry interfaces in a time-dependent study, as the time scale involved in the calculation of the high-frequency currents differs too much from the time scale involved in the solid mechanics calculations. Therefore, after performing the frequency domain analysis, we once again use a stationary solver with the solution from the frequency domain as the input. The resulting coil deformation is shown in Figure 5.11.
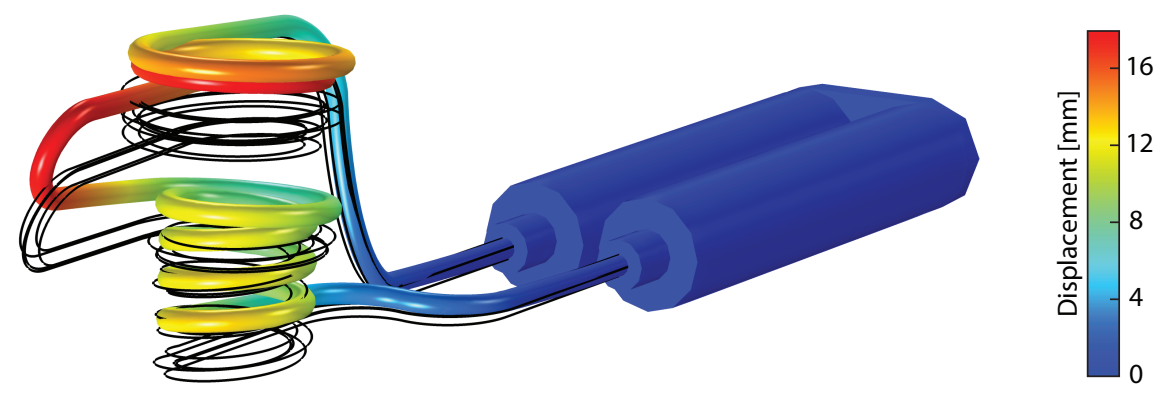

Figure 5.11: The self-induced coil bending for a current of $1000 \mathrm{~A}$ at a frequency of $100 \mathrm{kHz}$ : the color map shows the magnitude of the displacement. The black wireframe indicates the original coil geometry.

Now, the deformation is in the same order of magnitude as observed experimentally. In that sense, the inclusion of the skin effect has improved our results. On the other hand, we are now faced with several qualitative inaccuracies. First of all, the coil windings intersect themselves, which is most visible in the top coil. This is physically impossible. Secondly, the entire coil seems to bend upwards, which is not observed experimentally. If we take a look at the internal stress in the coil in Figure 5.12, we see that its magnitude is large at the connections to the fixed rods. Apparently, the forces here are such that the copper tube bends the coil upwards. Another position with high stress is in the bend between the top and bottom coil. This is expected, since the two coils repel each other, and this bend acts as a spring keeping them together.

To summarize, the model without the skin effect gives correct qualitative and incorrect quantitative results. The model that includes the skin effect gives better quantitative results but incorrect qualitative results. The experimentally observed coil bending lies somewhere in the middle of the behavior covered by these two models. Further research is needed to improve the model, and several considerations might influence the results. 

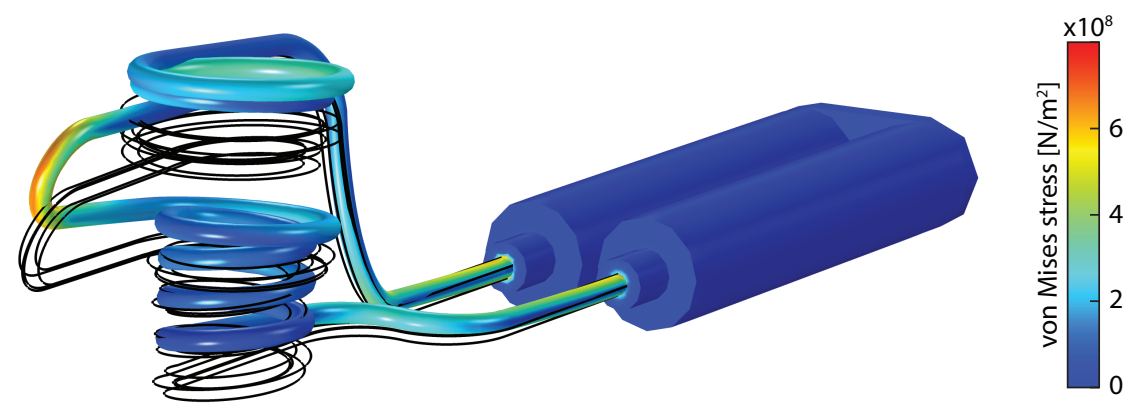

Figure 5.12: The magnitude of the internal stress in the coil, which is most prominent at the bend between the lower and upper coil, and at the two connections to the fixed rods.

First, since the multiphysics interface cannot couple all physics interfaces in time-dependent studies, it can be beneficial to run several simulations consecutively, each time manually importing the deformed coil geometry as the starting geometry for the next iteration. However, this will drastically increase the computation (and manual labor) time of the model. Second, the physical coil is, in fact, a spring. Actually, we introduce some tension while connecting the coil to the fixed rods in the experimental setup. Moreover, the repeated heating, quenching, and bending of the coil during the fabrication process introduce internal stresses and local variations of the material properties, such as the Young's modulus. All these forces and stress are not considered in the model, and might improve the qualitative results if implemented. Lastly, the model should prevent the self-intersection of the mesh.

Thus, the presented model is not yet fully suitable to investigate the influence of the selfinduced bending of EML coils on the levitation dynamics. But, back to the experiments in Section 5.1. How far are we actually off from the theoretically predicted levitation height? Figure 5.4 compared the theoretical and experimental sample height versus the coil current. Although we cannot change the theoretical model to accurately include the coil deformation, we can correct the measurement for the deformation. The theoretical height is calculated with respect to a fixed origin, defined at the center of the top winding of the bottom coil. In the measurement, this origin moves down with increasing current, as seen in Figure 5.5. Thus, we can measure the sample height relative to the moving origin in the movie, which is shown in Figure 5.13. As we can see, this already gives a much better correspondence with the theoretical model, which does not yet include any coil deformation. 


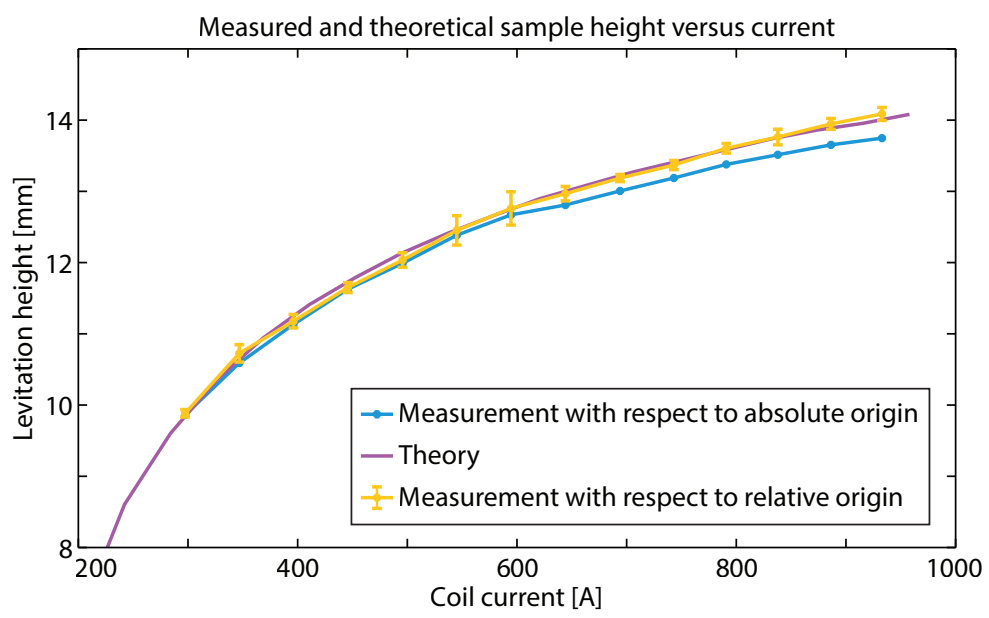

Figure 5.13: Sample levitation height versus current for theoretical values, measured values, and measured values relative to the middle of the top of the bottom coil.

Then, has the self-induced bending of levitation coils no influence on the levitation parameters? Not necessarily. Figure 5.5 shows a separation and elongation of the upper and lower coil. The separation results in a less stable sample, more lift, and a lower temperature. ${ }^{[40]}$ The elongation results in less lift and a lower temperature. ${ }^{[40]}$ In a way, the effect of separation and elongation on the lift is canceled. Thus, the sample position is not a suitable variable for measuring the effect of coil bending on levitation. However, we expect the bending of the coil to decrease the sample stability and temperature. Indeed, at currents above $1080 \mathrm{~A}$, the sample in our experiments became unstable and started oscillating vigorously. Reducing the current below $1080 \mathrm{~A}$ stabilized the sample again. This behavior cannot be explained without the influence of coil bending, as a higher current typically results in more stability as the sample is "pinned" in the large gradient of the magnetic field between the two coils. In order to find a suitable parameter to investigate the effect of self-induced coil deformation, future experiments could focus on the temperature behavior of samples in a range of coils with different amounts of bending. 


\subsection{Conclusion}

Our experiments show that the same Lorentz forces that make electromagnetic levitation possible, also induce a deformation in the levitation coil itself. Where the levitated sample displaces by $4 \mathrm{~mm}$ when the current varies from 0 to $1000 \mathrm{~A}$, the top and bottom part of the levitation coil separate by almost $2 \mathrm{~mm}$. We presented a FEM model in COMSOL that qualitatively predicts the coil deformation for direct current, but with an amplitude which is too small by two orders of magnitude. For a high-frequency current, resulting in an inhomogeneous eddy current distribution within the coil, we find an amplitude that is in better agreement with experiments, but with incorrect qualitative bending behavior. The coil bending seems to have little effect on the levitation height in our experiments, but it does cause stability problems at high currents. Additional research is required to make a definitive conclusion on the influence of self-induced bending of EML coils on the levitation parameters such as sample temperature. 


\section{Conclusion \& outlook}

In this thesis, we report, to the best of our knowledge, for the first time on the advantages and challenges of using electromagnetic levitation (EML) to grow metal crystals of superior quality and purity. As such, we made an essential contribution towards improving the currently available state-of-the-art crystals, which are relevant in many different scientific fields. In this general discussion, we elaborate on the focus point of this thesis, to develop an apparatus that grows high-quality crystals of multiple metals. We summarize the previous chapters' results and draw a general conclusion on containerless metal single crystal growth via electromagnetic levitation. Finally, we discuss the remaining challenges and sketch an outlook in what way the setup might be improved.

\subsection{Conclusion}

In Chapter 1 we described several traditional crystal growth techniques. The techniques have two major drawbacks that hinder the growth of high-quality ultra-pure crystals: contamination from the crucible and thermal-stress-induced defects. We hypothesized that growing crystals in a containerless environment could mitigate these drawbacks. After discussing the available levitation techniques, we concluded that EML is most suitable for our purpose.

A quantitative understanding of EML is desired in order to develop a crystal growth apparatus that employs electromagnetic levitation to grow metal crystals of high quality and purity. As such, we compared mathematical models with two different approaches in Chapter 2: The magnetic flux density approach and the mutual inductance approach. We concluded that the mutual inductance approach is most suitable for the development of the setup, because it is able to accurately predict the levitation forces, stable levitation position, and the sample temperature for a given coil geometry, sample size, material, and power source settings. Most importantly, the fast computation times make it possible to quickly optimize coil designs to find a melting and solidifying procedure for many different metals. A model following the mutual inductance approach was presented and implemented in a MATLAB script. It was used to find a coil design that requires the minimum possible current to levitate a copper sample. In this coil geometry, it is possible to levitate samples of 15 different materials if the power source is able to deliver at least $880 \mathrm{~A}$ at $61 \mathrm{kHz}$. 
In Chapter 3, we presented a novel crystal growth apparatus that employs EML in a vacuum to grow metal single-crystals of superior quality and purity. The system is capable of levitating a wide variety of metals, whilst having precise control over the sample temperature in both the liquid and solid state within $1 \mathrm{~K}$. Crystal growth is possible with either containerless undercooled crystallization or levitation-based Czochralski growth. As a proof of concept, we have shown the growth of copper single-crystals. The crystals grown in the EML setup are at least equal in quality to commercially available single-crystals grown using the traditional Czochralski technique.

We presented a mathematical model for truly 3D electromagnetic levitation coils in Chapter 4. Using the simplicity of the classic 2D model from Chapter 2, with a minor adjustment to the way the magnetic field is calculated using the Biot-Savart law, we showed significant differences in the resulting lift and heating properties between a set of concentric circles and a realistic 3D coil. When designing coils using a 2D model, more current will be required during actual experiments than expected. Also, the stable sample position in the $x y$-plane should be considered when levitation is desired in the lower regions of a coil. A vastly different design is required to get the same magnetic field in a $3 \mathrm{D}$ coil as in a 2D coil. Lastly, the assumption that the magnetic field is homogeneous in the $x$ and $y$ direction within the sample volume is invalid in the upper and lower regions of the coil. This leads to an underestimation of the magnetic flux and sample temperature in the classic model.

Our experiments in Chapter 5 show that the same Lorentz forces that make electromagnetic levitation possible, also induce a deformation in the levitation coil itself. Where the levitated sample displaces by $4 \mathrm{~mm}$ when the current varies from 0 to $1000 \mathrm{~A}$, the top and bottom part of the levitation coil separate by almost $2 \mathrm{~mm}$. We presented a FEM model in COMSOL that qualitatively predicts the coil deformation for direct current, but with an amplitude that is too small by two orders of magnitude. For a high-frequency current, resulting in an inhomogeneous eddy current distribution within the coil, we find an amplitude that is in better agreement with experiments, but with incorrect qualitative bending behavior. The coil bending seems to have little effect on the levitation height in our experiments, but it does cause stability problems at high currents. Additional research is required to make a definitive conclusion on the influence of self-induced bending of EML coils on the levitation parameters such as sample temperature.

In general, we have achieved the containerless single-crystal growth via electromagnetic levitation of metal samples using the theory, models, and setup described in this thesis. 


\subsection{Outlook}

As shown in Chapter 3, the experimental setup we designed and constructed can grow crystals in two distinct modes: containerless undercooled crystallization and levitationbased Czochralski growth. This resulted in the growth of copper crystals that are at least equal in quality to the commercially available crystals. However, the goal was to develop an apparatus that could grow crystals of many different kinds of metal. As such, we have already shown that we can levitate and melt aluminum in Chapter 3 and iridium in Chapter 4. In Appendix B, we show several figures that summarize the results of trial experiments with other metals such as gold, vanadium, and tungsten. A handful of challenges remain concerning the containerless undercooled crystallization of especially the high melting point (above $1500 \mathrm{~K}$ ) metals.

In Chapter 1, we hypothesized that containerless growth could reduce contamination from the crucible and that it could reduce thermal-stress-induced crystal defects. Contamination from the crucible speaks for itself; there is none, since there is no crucible. Indeed, we discussed that large temperature gradients cause stress in the material leading to crystal defects. ${ }^{[11-13]}$ However, from a crystal growth point of view, thermal gradients might actually be necessary.

Suppose we have a $100 \%$ pure containerless liquid metal with a perfectly homogeneous temperature distribution and no internal fluid flows. Homogeneous nucleation would only occur at significant amounts of undercooling. Since we have no temperature gradients (and if we do not consider latent heat), the entire droplet would solidify extremely quickly. For crystal growth, low and controlled growth speeds are required so that each atom will have the time to find its place in the lattice.

We see this effect in our experiments with gold levitation in air. In Chapter 2 we showed that the sample temperature rises quickly upon melting, since for most metals the resistivity increases and the emissivity decreases. In our experiments, this was especially problematic for metals with a high minimum levitation current, such as gold and iridium. The samples typically reach their melting point within 30 seconds of levitation. They start to melt, and the molten part of the sample heats so violently that the resistivity increases even further until the current is not enough to support the liquid part of the sample. As such, a jet of small liquid droplets is ejected from the bottom of the coil.

These droplets cool rapidly during their fall. This technique is used to study the undercooled solidification of containerless metals in drop tubes. ${ }^{[17]}$ In an 8.5-meter high drop tube, germanium high-undercooling-induced single crystals were found for some droplets less than $200 \mu \mathrm{m}$ in diameter. ${ }^{\left[{ }^{20]}\right.}$ In our experiments, with a drop of $30 \mathrm{~cm}$, we 
found gold single-crystals in droplets up to $3 \mathrm{~mm}$ in diameter. Larger droplets were polycrystalline. Ejected droplets of palladium and iridium, which show similar levitation behavior, did not solidify before reaching the chamber floor.

So, spontaneous homogeneous nucleation is not the way to grow larger single-crystals. That is why we proposed to introduce a seed crystal to induce heterogeneous nucleation. Still, we can repeat our thought experiment with a $100 \%$ pure containerless liquid metal and a perfectly homogeneous temperature distribution. If the sample is above the melting point, we will melt the seed. If the sample is below the melting point, it will solidify. However, if we have no temperature gradient, although desirable from a defect point of view, we also have no way of controlling the crystal growth speed. In fact, we might have no growth at all in a perfect equilibrium. This is a more fundamental challenge that we realized during all our experiments. A large seed with a high thermal gradient, and enough heat capacity, gives more freedom in temperature control and thus crystal growth than a small seed with a low thermal gradient used just to initialize the growth.

This is the reason why we used $20 \mathrm{~cm}$ long solid rods of copper as a seed in our experiments in Chapter 3. A large copper droplet levitating in a vacuum would heat well beyond its melting point, making solidification impossible. The introduction of the large rod provided enough cooling to have precise (within $0.1 \mathrm{~K}$ ) temperature control around the melting point. Another method for temperature control is convection. Although our setup can operate in an argon environment between zero and one bar, this only provides cooling through natural convection. Forced convection or high-pressure argon environments can be used to achieve a higher amount of cooling with more control. ${ }^{[71]}$ Additionally, a background gas helps with the inherent spin instability present for highly symmetrical samples, which potentially causes the sample to spin at such high speeds that it fractures. ${ }^{[60]}$ The gas causes drag, which reduces the rotational velocity. Lastly, a background gas is absolutely required for metals with a low vapor pressure. This became painfully clear in our experiment with a chromium sample. While the solid sample was levitating, the sublimation of chromium vapor increased the pressure in the chamber from $8 \cdot 10^{-6} \mathrm{mbar}$ to $6 \cdot 10^{-3} \mathrm{mbar}$, at which point a plasma ignited. The scope of this thesis does not extend to crystal growth from the plasma phase.

We have grown aluminum crystals in both the containerless undercooled crystallization and levitation-based Czochralski growth modes. However, in both cases, oxygen contamination caused many crystal defects and in the worst-case multiple grains. The samples were placed in the vacuum chamber immediately after etching. Still, an oxide layer cannot be prevented. The seed crystal cannot penetrate this oxide layer unless the 


\section{Chapter 6 Conclusion \& outlook}

temperature is increased. The oxide layer hinders the growth of perfect single-crystals, as it provides ample nucleation points for grains to start growing.

We managed to levitate ruthenium and vanadium samples smaller than $3 \mathrm{~mm}$ in size. However, they reached the melting point within seconds, which caused such a violent instability that molten material was sprayed from the sample in all directions. These conditions are far from ideal for controlled crystal growth. Samples that were $5 \mathrm{~mm}$ in size were stable for 30 seconds, before ultimately they also started to spin and oscillate. So it seems that larger samples are more stable during the phase transition. On the other hand, we achieved very stable levitation of a tungsten sample with negligible sample oscillation, but were unable to melt it. This would require an additional heating source, such as a secondary high-frequency induction coil or laser heating.

All in all, each metal has its own behavior, peculiarities, advantages, and challenges. Perhaps we must conclude that it is not feasible to make a single machine that can produce crystals of such a wide variety of materials. If one were to try anyway, the route of levitation-based Czochralski growth is probably more fruitful than truly containerless undercooled crystallization. In the future development of the setup, we recommend focusing on a single metal or a group of similar metals, and adapt the mathematical model to optimize for this focus metal.

The model first introduced in Chapter 2 and improved in the other chapters is very suitable for predicting the steady-state levitation parameters for all coil geometries, sample materials, and sizes. We showed the importance of 3D modeling of levitation coils and discussed the effect of self-induced coil bending. In literature, we have seen the effect of the eddy current distribution in levitation coils. ${ }^{[42]}$ A perfect model would combine all these considerations. In Chapter 2 we also discussed the differences between the models in literature following the mutual inductance approach and the models following the magnetic flux density approach. Our goal was to levitate and melt samples of various sizes and materials stably. To achieve this goal, it is beneficial to try many different coil geometries to find suitable levitation parameters for all these samples. A model which followed the mutual inductance approach allowed us to reach this goal.

We recommend adopting a model following the magnetic flux density approach when future research focuses on a single metal instead of a broad range. This approach poses no restrictions to the sample shape, can simulate the frequency response of a moving sample in time, and includes temperature-dependent material properties. Most importantly, it allows the coupled simulation of levitation, heating, and fluid flow. This will give a better understanding of the crystal growth dynamics inside the sample. We recommend that a new model, following the magnetic flux density approach, includes 3D modeling of coils 
as described in Chapter 4 and self-induced coil bending as described in Chapter 5. Ideally, the new model would then use a stable coil geometry provided by the model presented in this work as a starting point for further optimizations, manually or algorithmic, of the coil design with regards to all crystal growth aspects, such as internal fluid flows, temperature fields and the dynamic behavior on contact with the seed.

Lastly, we propose to further investigate the purity and quality of the crystals grown in the setup with additional characterization techniques. We already compared the quality of our copper crystals with commercially available crystals by comparing the Laue diffraction images in Chapter 3. However, the resolution of the Laue diffraction setup is not enough to accurately measure, for instance, the spot width and consecutively determine the defect density. We recommend a more thorough investigation on a higher resolution diffraction setup. Furthermore, the purity of the samples could be compared to samples grown in a setup with a crucible using sensitive mass spectrometry techniques. As is often the case in research, we have answered the question of what is possible concerning containerless crystal growth via $\mathrm{EML}$, while raising twice as many questions on how we might continue. As said, every house is built on a foundation. A foundation that is constructed safely and correctly makes the house last for a long time, while also providing a well-defined base for easy and efficient construction of the house itself. We hope the setup we constructed, together with this thesis, will serve as a well-defined base for easy and efficient future research on containerless metal single-crystal growth via electromagnetic levitation. 


\section{Bibliography}

[1] G. Dhanaraj, K. Byrappa, V. Prasad, and M. Dudley. Springer Handbook of Crystal Growth. Springer Berlin Heidelberg, 2010.

[2] P. Capper. Springer Handbook of Electronic and Photonic Materials, pages 269-291. Springer International Publishing, Cham, 2017.

[3] J.L. Schmehr and S.D. Wilson. Active crystal growth techniques for quantum materials. Annual Review of Materials Research, 47(1):153-174, 2017. DOI: 10.1146/annurev-matsci-070616124006.

[4] J. Czochralski. Ein neues Verfahren zur Messung der Kristallisationsgeschwindigkeit der Metalle. Zeitschrift für Physikalische Chemie, 92:219-221, 1918.

[5] P.W. Bridgman. Certain physical properties of single crystals of yungsten, antimony, bismuth, tellurium, cadmium, zinc, and tin. In Proceedings of the American Academy of Arts and Sciences, volume 60, pages 305-383, 1925.

[6] D.C. Stockbarger. The production of large single crystals of lithium fluoride. Review of Scientific Instruments, 7(3):133-136, 1936. DOI: 10.1063/1.1752094.

[7] M.C. Schubert, J. Schön, F. Schindler, W. Kwapil, A. Abdollahinia, B. Michl, S. Riepe, C. Schmid, M. Schumann, S. Meyer, and W. Warta. Impact of impurities from crucible and coating on mcsilicon quality - The example of iron and cobalt. IEEE Journal of Photovoltaics, 3(4):1250-1258, 2013. DOI: 10.1109/JPHOTOV.2013.2279116.

[8] G.D. Patra, S.G. Singh, D.G. Desai, S. Pitale, M. Ghosh, and S. Sen. Effect of OH content in the quartz crucible on the growth and quality of Csl single crystals and remedies. Journal of Crystal Growth, 544:125710, 2020. DOI: 10.1016/j.jcrysgro.2020.125710.

[9] F. Sturm, M. Trempa, S. Schwanke, K. Schuck, C. Kranert, C. Reimann, and J. Friedrich. Solid state diffusion of metallic impurities from crucible and coating materials into crystalline silicon ingots for PV application. Journal of Crystal Growth, 540:125636, 2020. DOI: 10.1016/j.jcrysgro.2020.125636.

[10] T.B. Reed and R.E. Fahey. Resistance heated crystal puller for operation at $2000^{\circ} \mathrm{C}$. Review of Scientific Instruments, 37(1):59-61, 1966. DOI: 10.1063/1.1719951.

[11] O.A. Louchev, S. Kumaragurubaran, S. Takekawa, and K. Kitamura. Thermal stress inhibition in double crucible Czochralski large diameter crystal growth. Journal of Crystal Growth, 274(12):307-316, 2005. DOI: 10.1016/j.jcrysgro.2004.10.027.

[12] H.S. Fang, S. Wang, L. Zhou, N.G. Zhou, and M.H. Lin. Influence of furnace design on the thermal stress during directional solidification of multicrystalline silicon. Journal of Crystal Growth, 346(1):5-11, 2012. DOI: 10.1016/j.jcrysgro.2012.02.032.

[13] T.P. Nguyen, Y.T. Hsieh, J.C. Chen, C. Hu, and H.B. Nguyen. Effect of crucible and crystal rotations on the convexity and the thermal stress in large size sapphire crystals during Czochralski growth. Journal of Crystal Growth, 468:514-525, 2017. DOI: 10.1016/j.jcrysgro.2016.11.045. 
[14] H. Huang and S. Liang. Thermal-stress reduction for a Czochralski grown single crystal. Journal of Engineering Mathematics, 59(1):1-23, 2007. DOI: 10.1007/s10665-006-9117-3.

[15] T. Tsukada, M. Hozawa, and N. Imaishi. Effect of a radiation shield on thermal stress field during Czochralski crystal growth of silicon. Journal of chemical engineering of Japan, 23(2):186-191, 1990. DOI: 10.1252/jcej.23.186.

[16] M. Plate, A. Krauze, and J. Virbulis. Three-dimensional modelling of thermal stress in floating zone silicon crystal growth. In IOP Conference Series: Materials Science and Engineering, volume 355, page 012005. Institute of Physics Publishing, 2018.

[17] D.M. Herlach and D.M. Matson. Solidification of containerless undercooled melts. Wiley-VCH, 1st edition, 2012.

[18] J. Yu, N. Koshikawa, Y. Arai, S. Yoda, and H. Saitou. Containerless solidification of oxide material using an electrostatic levitation furnace in microgravity. Journal of Crystal Growth, 231(4):568-576, 2001. DOI: 10.1016/S0022-0248(01)01431-2.

[19] S.I. Bakhtiyarov and D.A. Siginer. Electromagnetic levitation part III: Thermophysical property measurements in microgravity. Fluid Dynamics and Materials Processing, 5(1):1-22, 2009.

[20] D. Li and D.M. Herlach. Containerless solidification of germanium by electromagnetic levitation and in a drop-tube. Journal of Materials Science, 32(6):1437-1442, 1997. DOI: 10.1023/A:1018593615171.

[21] E.H. Brandt. Levitation in Physics. Science, 243(4889):349-355, 1989. DOI: 10.1126/science.243.4889.349.

[22] M.Z. Bradley. Harper's encyclopedia of mystical \& paranormal experience. HarperCollins Publishers, New York, 1991.

[23] W. Rhim, S.K. Chung, D. Barber, K.F. Man, G. Gutt, A. Rulison, and R.E. Spjut. An electrostatic levitator for high-temperature containerless materials processing in 1-g. Review of Scientific Instruments, 64(10):2961-2970, 1993. DOI: 10.1063/1.1144475.

[24] H. Hwang, Y.C. Cho, S. Lee, T.M. Choi, S.H. Kim, and G.W. Lee. Real-time monitoring of colloidal crystallization in electrostatically-levitated drops. Small, 16:1907478, 2020. DOI: $10.1002 / \mathrm{smll} .201907478$.

[25] S. Klein, D. Holland-Moritz, and D.M. Herlach. Crystal nucleation in undercooled liquid zirconium. Physical Review B, 80(21):212202, 2009. DOI: 10.1103/PhysRevB.80.212202.

[26] K. Yono, P. Paradis, T. Ishikawa, and S. Yoda. Method for producing barium titanium oxide single-crystal piece using containerless processing, 2005.

[27] E.C. Okress, D.M. Wroughton, G. Comenetz, P.H. Brace, and J.C.R. Kelly. Electromagnetic levitation of solid and molten metals. Journal of Applied Physics, 23(5):545-552, 1952. DOI: $10.1063 / 1.1702249$.

[28] M.G. Frohberg. Thirty years of levitation melting calorimetry - a balance. Thermochimica Acta, 337:7-17, 1999. DOI: 10.1016/s0040-6031(99)00159-8. 
[29] G. Lohöfer. Electrical resistivity measurement of liquid metals. Measurement Science and Technology, 16(2):417-425, 2005. DOI: 10.1088/0957-0233/16/2/012.

[30] G. Pottlacher, K. Boboridis, C. Cagran, T. Hüpf, A. Seifter, and B. Wilthan. Normal spectral emissivity near $680 \mathrm{~nm}$ at melting and in the liquid phase for 18 metallic elements. AIP Conference Proceedings, 1552:704-709, 2013. DOI: 10.1063/1.4819628.

[31] L. Gao, Z. Shi, D. Li, G. Zhang, Y. Yang, A. McLean, and K. Chattopadhyay. Applications of electromagnetic levitation and development of mathematical models: A review of the last 15 years (2000 to 2015). Metallurgical and Materials Transactions B, 47:537-547, 2016. DOI: 10.1007/s11663-015-0522-8.

[32] M. Adachi, S. Hamaya, Y. Yamagata, A.J. Loach, J.S. Fada, L.G. Wilson, R.H. French, J.L.W. Carter, and $\mathrm{H}$. Fukuyama. In-situ observation of AIN formation from Ni-Al solution using an electromagnetic levitation technique. Journal of the American Ceramic Society, 103:2389-2398, 2020. DOI: $10.1111 /$ jace.16960.

[33] Z. Jian, K. Kuribayashi, and W. Jie. Crystallization of spherical single crystal of silicon from undercooled droplet under containerless processing. Materials Science Forum, 475-479:2603-2606, 2005. DOI: 10.4028/www.scientific.net/msf.475-479.2603.

[34] K. Kuribayashi and T. Aoyama. Containerless crystallization of silicon. Journal of Crystal Growth, 237-239(Part 3):1840-1843, 2002. DOI: 10.1016/S0022-0248(01)02105-4.

[35] O. Muck. German Pat. No. 422004, 1923.

[36] E. Fromm and $\mathrm{H}$. Jehn. Electromagnetic forces and power absorption in levitation melting. British Journal of Applied Physics, 16(5):653-663, 1965. DOI: 10.1088/0508-3443/16/5/308.

[37] N. El-Kaddah and J. Szekely. The electromagnetic force field, fluid flow field, and temperature profiles in levitated metal droplets. Metallurgical Transactions B, 14(3):401-410, 1983. DOI: $10.1007 / B F 02654359$.

[38] Z.L. Royer, C. Tackes, R. LeSar, and R.E. Napolitano. Coil optimization for electromagnetic levitation using a genetic like algorithm. Journal of Applied Physics, 113(21):214901, 2013. DOI: $10.1063 / 1.4807788$.

[39] S. Roberts, S. Kok, J. Zietsman, and H. Inglis. Electromagnetic levitation coil design using gradient-based optimization Suzanne. In 11th World Congress on Structural and Multidisciplinary Optimization, Sydney, 2015.

[40] Z.A. Moghimi, M. Halali, and M. Nusheh. An investigation on the temperature and stability behavior in the levitation melting of nickel. Metallurgical and Materials Transactions $B$, 37(6):997-1005, 2006. DOI: 10.1007/BF02735022.

[41] A. Kermanpur, M. Jafari, and M. Vaghayenegar. Electromagnetic-thermal coupled simulation of levitation melting of metals. Journal of Materials Processing Technology, 211(2):222-229, 2011. DOI: 10.1016/j.jmatprotec.2010.09.008.

[42] L. Feng and W.-Y. Shi. The influence of eddy effect of coils on flow and temperature fields of molten droplet in electromagnetic levitation device. Metallurgical and Materials 
Transactions B: Process Metallurgy and Materials Processing Science, 46(4):1895-1901, 2015. DOI: 10.1007/s11663-015-0360-8.

[43] L. Feng and W.-Y. Shi. Influence of coil angle arrangement on dynamic deformation and stability of molten droplet in electromagnetic levitation system. ISIJ International, 56(1):50-56, 2016. DOI: 10.2355/isijinternational.ISIJINT-2015-431.

[44] L. Feng and W.-Y. Shi. The influence of Marangoni effect on flow and deformation of an electromagnetically levitated molten droplet under static magnetic fields. International Journal of Heat and Mass Transfer, 101:629-636, 2016. DOI: 10.1016/j.ijheatmasstransfer.2016.05.088.

[45] L. Feng and W.-Y. Shi. Numerical investigation on frequency shift of an electromagnetically levitated molten droplet. International Journal of Heat and Mass Transfer, 122:69-77, 2018. DOI: 10.1016/j.ijheatmasstransfer.2018.01.104.

[46] I. Egry and D. Holland-Moritz. Levitation methods for structural and dynamical studies of liquids at high temperatures. The European Physical Journal Special Topics, 196(1):131-150, 2011. DOI: 10.1140/epjst/e2011-01424-1.

[47] R.P. Feynman, R.B. Leighton, and M. Sands. The Feynman Lectures on Physics: The New Millennium Edition: Mainly Electromagnetism and Matter. The Perseus Books Group, New York, 2011.

[48] D.H. Menzel. Fundamental formulas of physics. Prentice-Hall, Inc., New York, 1955.

[49] W.R. Smythe. Static and dynamic electricity. McGraw-Hill Book Company Inc., New York, 1950.

[50] P.R. Rony. The electromagnetic levitation of metals. Lawrence Radiation Laboratory, Berkeley, 1964.

[51] J.P. Holman. Heat Transfer. McGraw-Hill, Inc., New York, 1990.

[52] S. Spitans, E. Baake, A. Jakovics, and H. Franz. Large scale electromagnetic levitation melting of metals. International Journal of Applied Electromagnetics and Mechanics, 53:S61-S66, 2016. DOI: $10.3233 /$ jae-162238.

[53] J.P. Witteveen, M.A.B. Vrielink, R. van Gastel, A. van Houselt, and H.J.W. Zandvliet. Containerless metal single-crystal growth via electromagnetic levitation. Review of Scientific Instruments, 92:105105, 2021. DOI: 10.1063/5.0064486.

[54] J.P. Witteveen, R. van Gastel, A. van Houselt, and H.J.W. Zandvliet. 3D modeling of electromagnetic levitation coils. Current Applied Physics, 32:45-49, 2021. DOI: 10.1016/j.cap.2021.09.016.

[55] Z. Galazka, R. Uecker, and R. Fornari. A novel crystal growth technique from the melt: Levitation-assisted self-seeding crystal crowth method. Journal of Crystal Growth, 388:61-69, 2014. DOI: 10.1016/j.jcrysgro.2013.11.049.

[56] D. Fort. An ultrahigh vacuum Czochralski crystal growth system using either hot or cold crucibles. Review of Scientific Instruments, 64(11):3209-3214, 1993. DOI: 10.1063/1.1144330.

[57] N.F. Mott. The resistance of liquid metals. Proceedings of the Royal Society of London. Series A, Containing Papers of a Mathematical and Physical Character, 146(857):465-472, 1934. DOI: 10.1098/rspa.1934.0166. 
[58] C. Cagran, C. Brunner, A. Seifter, and G. Pottlacher. Liquid-phase behaviour of normal spectral emissivity at $684.5 \mathrm{~nm}$ of some selected metals. High Temperatures-High Pressures, 34(6):669-679, 2002. DOI: 10.1068/htjr067.

[59] W.H. Hofmeister, R.J. Bayuzick, and M.B. Robinson. Dual purpose pyrometer for temperature and solidification velocity measurement. Review of Scientific Instruments, 61(8):2220-2223, 1990. DOI: 10.1063/1.1141393.

[60] J. Priede and G. Gerbeth. Stability analysis of an electromagnetically levitated sphere. Journal of Applied Physics, 100(5):054911, 2006. DOI: 10.1063/1.2344810.

[61] S. Spitans, E. Baake, B. Nacke, and A. Jakovics. Numerical modeling of free surface dynamics of melt in an alternate electromagnetic field. Part II: Conventional electromagnetic levitation. Metallurgical and Materials Transactions B: Process Metallurgy and Materials Processing Science, 47(1):522-536, 2016. DOI: 10.1007/s11663-015-0515-7.

[62] G. Wouch, E.C. Okress, R.T. Frost, and D.J. Rutecki. Electromagnetic levitation facility incorporating electron beam. Review of Scientific Instruments, 46(8):1122-1123, 1975. DOI: $10.1063 / 1.1134368$.

[63] W. Brisley and B.S. Thornton. Electromagnetic levitation calculations for axially symmetric systems. British Journal of Applied Physics, 14(10):682-686, 1963. DOI: 10.1088/05083443/14/10/320.

[64] V. Bojarevics, K. Pericleous, and M. Cross. Modeling the dynamics of magnetic semilevitation melting. Metallurgical and Materials Transactions B: Process Metallurgy and Materials Processing Science, 31(1):179-189, 2000. DOI: 10.1007/s11663-000-0143-7.

[65] V. Bojarevics and K. Pericleous. Modelling electromagnetically levitated liquid droplet oscillations. ISIJ International, 43(6):890-898, 2003. DOI: 10.2355/isijinternational.43.890.

[66] P. Yan, G. Zhang, Y. Yang, and A. McLean. Numerical investigation of the position and asymmetric deformation of a molten droplet in the electromagnetic levitation system. Metallurgical and Materials Transactions B, 51:247-257, 2019. DOI: 10.1007/s11663-019-01723-9.

[67] W.M. Haynes. CRC Handbook of Chemistry and Physics. CRC Press, Boca Raton, 97th edition, 2016.

[68] S. Zinn and S.L. Semiatin. Coil design and fabrication: basic design and modifications. Heat treating, pages 32-41, 1988.

[69] T. Takaghi, K. Miya, H. Yamada, and T. Takagi. Theoretical and experimental study on the magnetomechanical behavior of superconducting helical coils for a fusion reactor. Nuclear Engineering and Design. Fusion, 1(1):61-71, 1984. DOI: 10.1016/0167-899X(84)90022-3.

[70] M. Liu, P.H. Tuovinen, Y. Kawasaki, M.A. Yedeas, Y. Saitoh, and M. Sekino. Electromagnetic and mechanical characterization of a flexible coil for transcranial magnetic stimulation. AIP Advances, 9(3):035335, 2019. DOI: 10.1063/1.5080148.

[71] A. Bauer, A. Neubauer, W. Münzer, A. Regnat, G. Benka, M. Meven, B. Pedersen, and C. Pfleiderer. Ultra-high vacuum compatible induction-heated rod casting furnace. Review of Scientific Instruments, 87(6):1-5, 2016. DOI: 10.1063/1.4954926. 



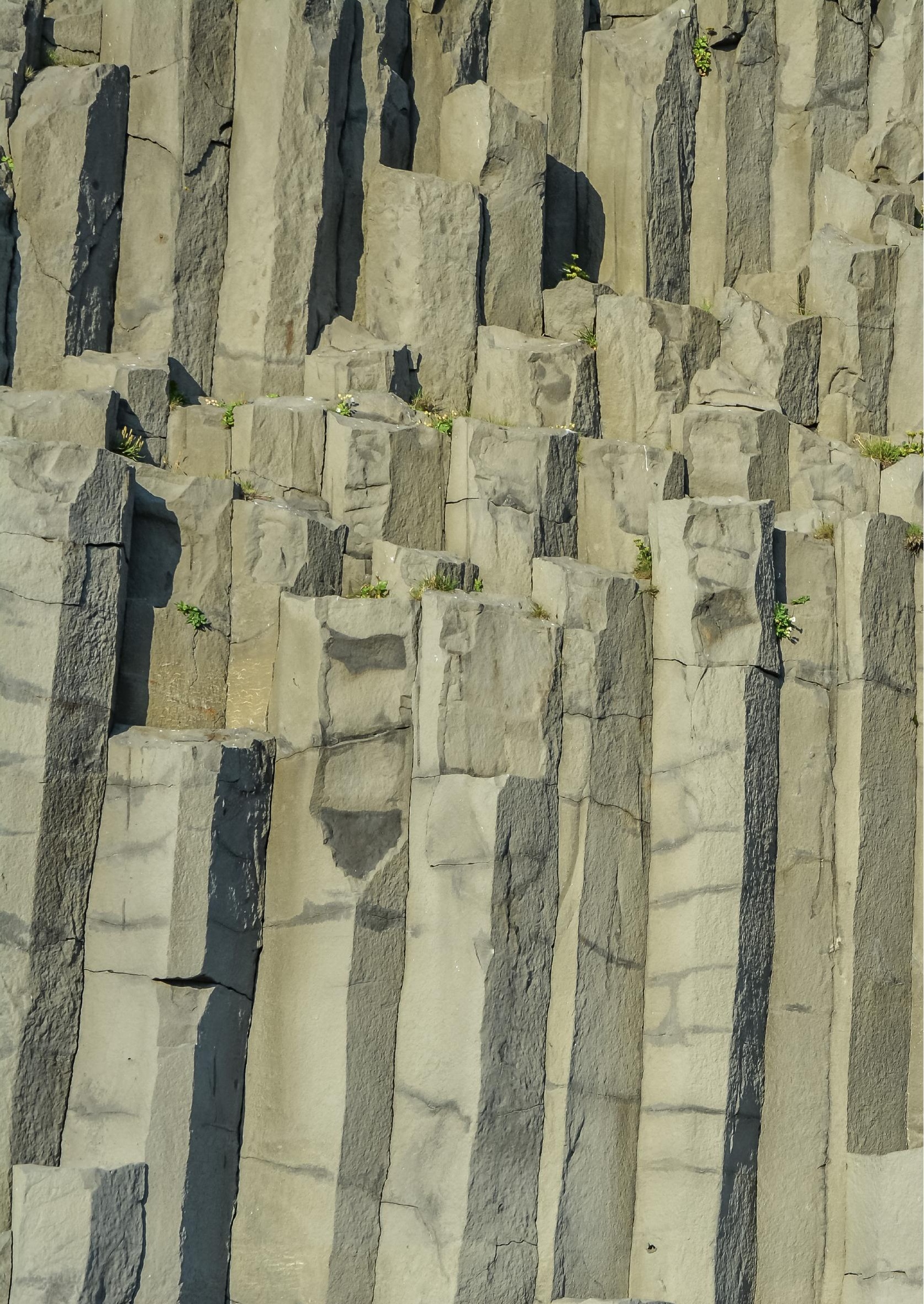




\section{Technical details}

In this extension of Chapter 3, we show photographs of several interesting details of the experimental levitating crystal growth setup. We provide the technical schematic of the watercooling and vacuum system and the schematic of the electronic control system. Lastly, we show a number of screenshots of the custom software that monitors and controls the setup.

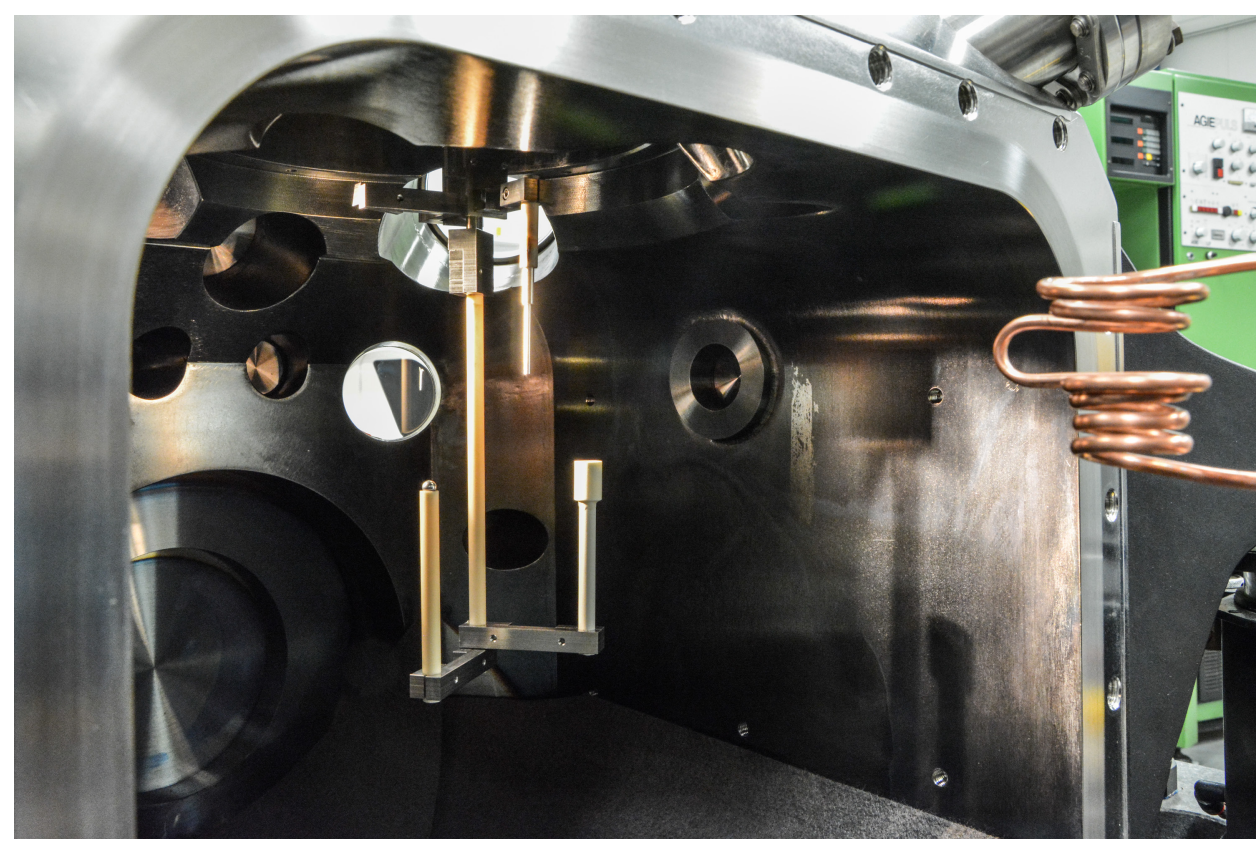

Figure A.1: Inside view of the vacuum chamber. An aluminum seed is suspended in the seed holder carousel. A spherical aluminum sample lies on top of an aluminum oxide rod in the sample carousel. The bottom of the chamber is covered in carbon felt. 


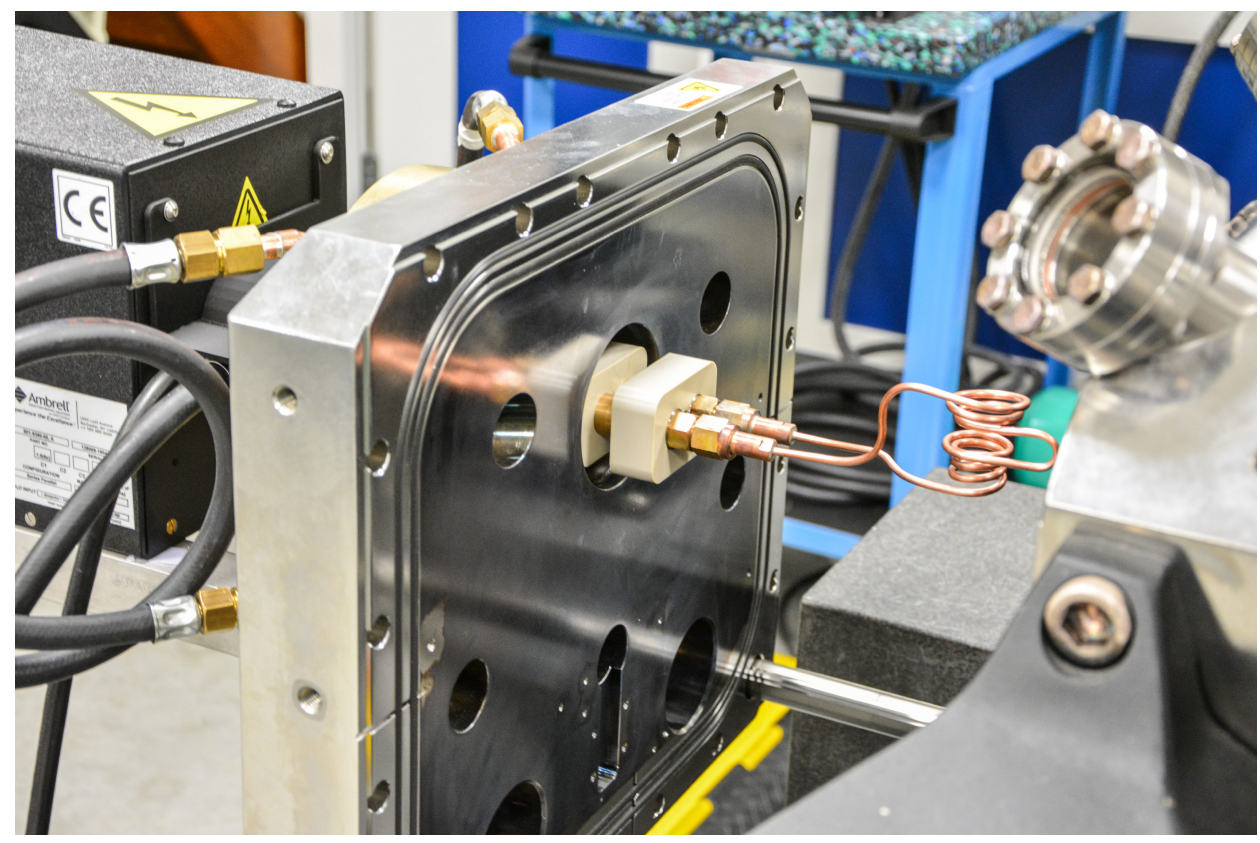

Figure A.2: The door of the vacuum chamber and the levitation coil. The current-carrying rods are fixed by several PEEK spacers.

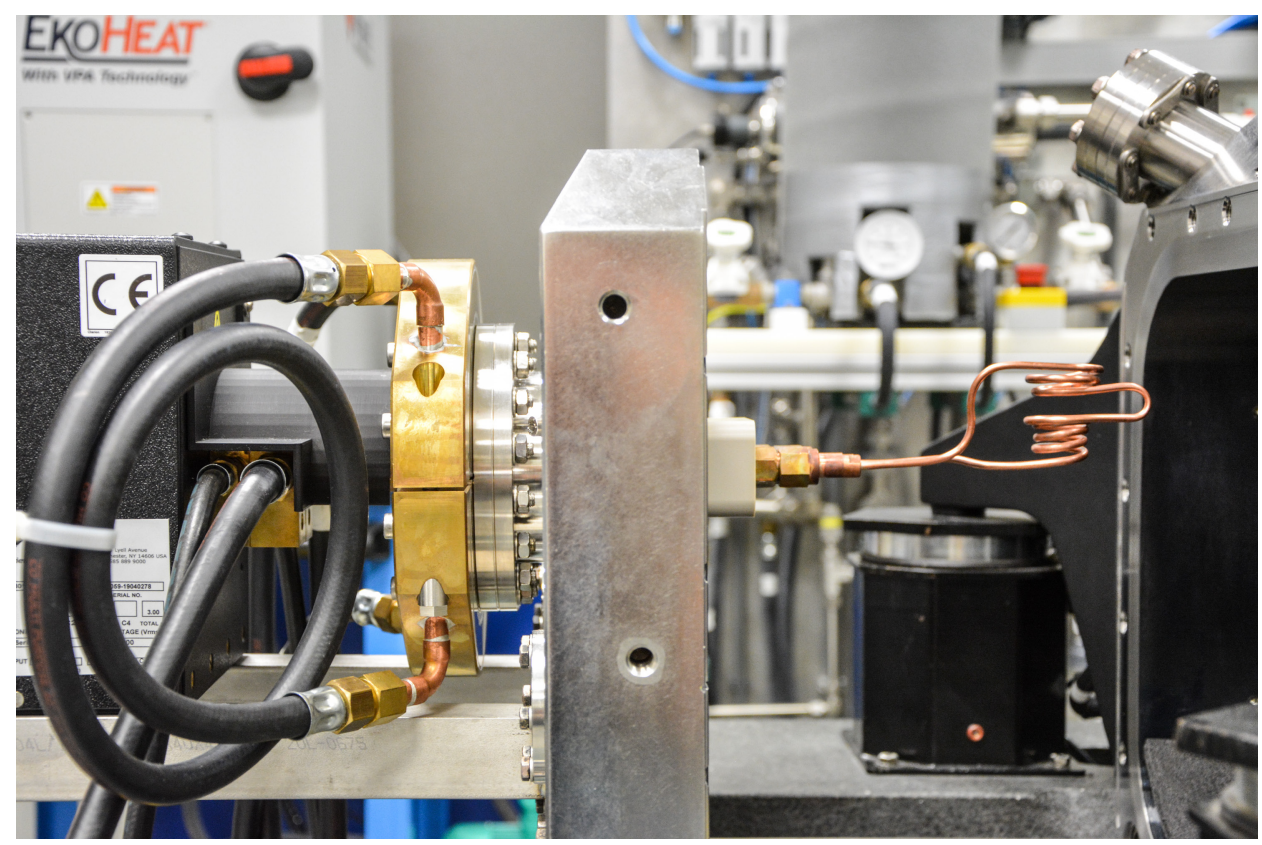

Figure A.3: Sideview of the coil, door, and watercooled vacuum feedthrough. 


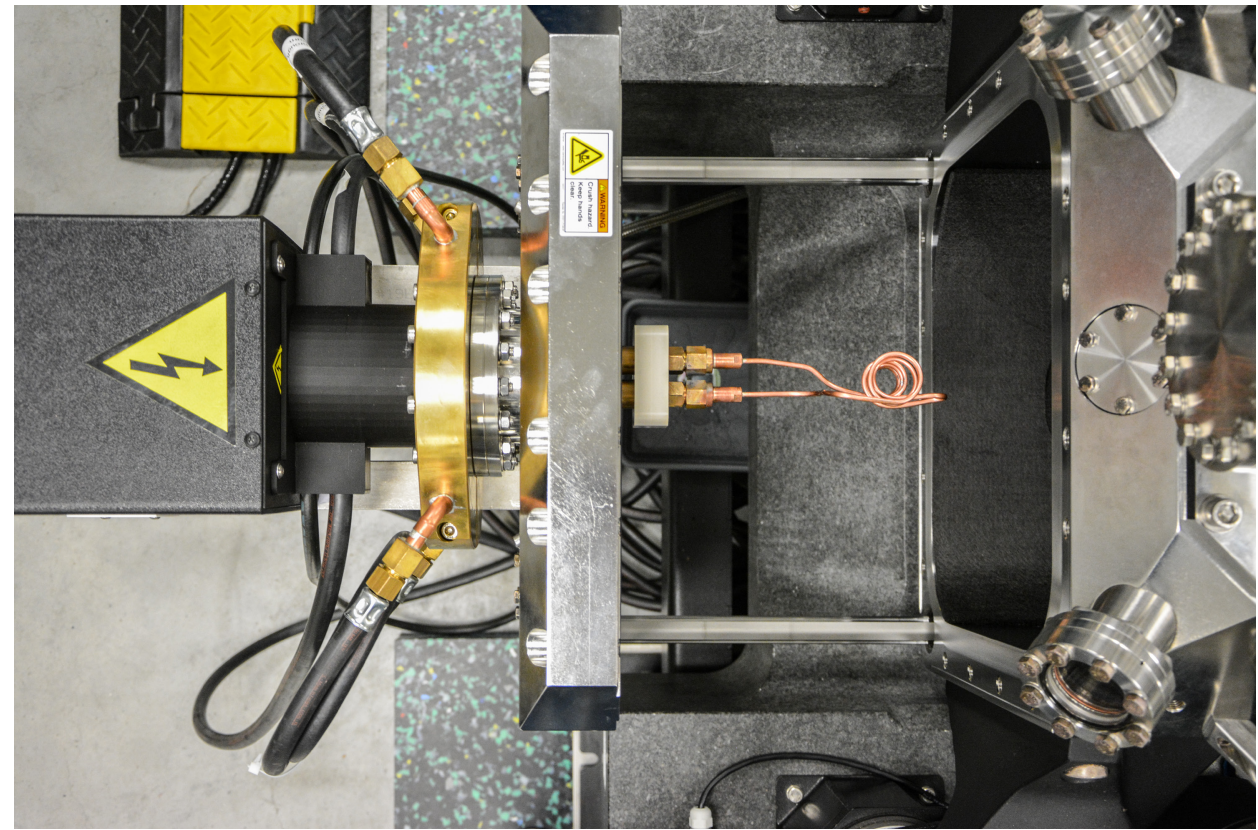

Figure A.4: Topview of the coil, door, and watercooled vacuum feedthrough.

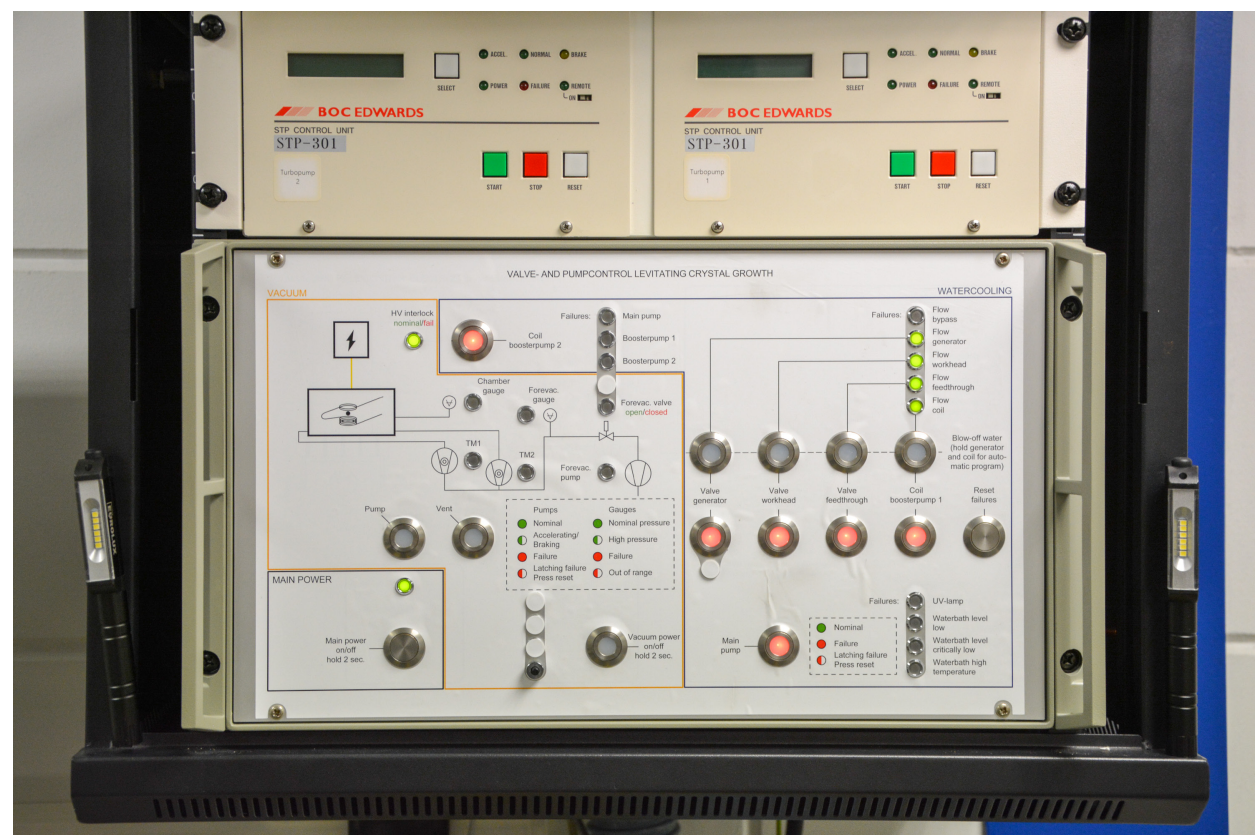

Figure A.5: The control cabinet for the watercooling and vacuum system. 


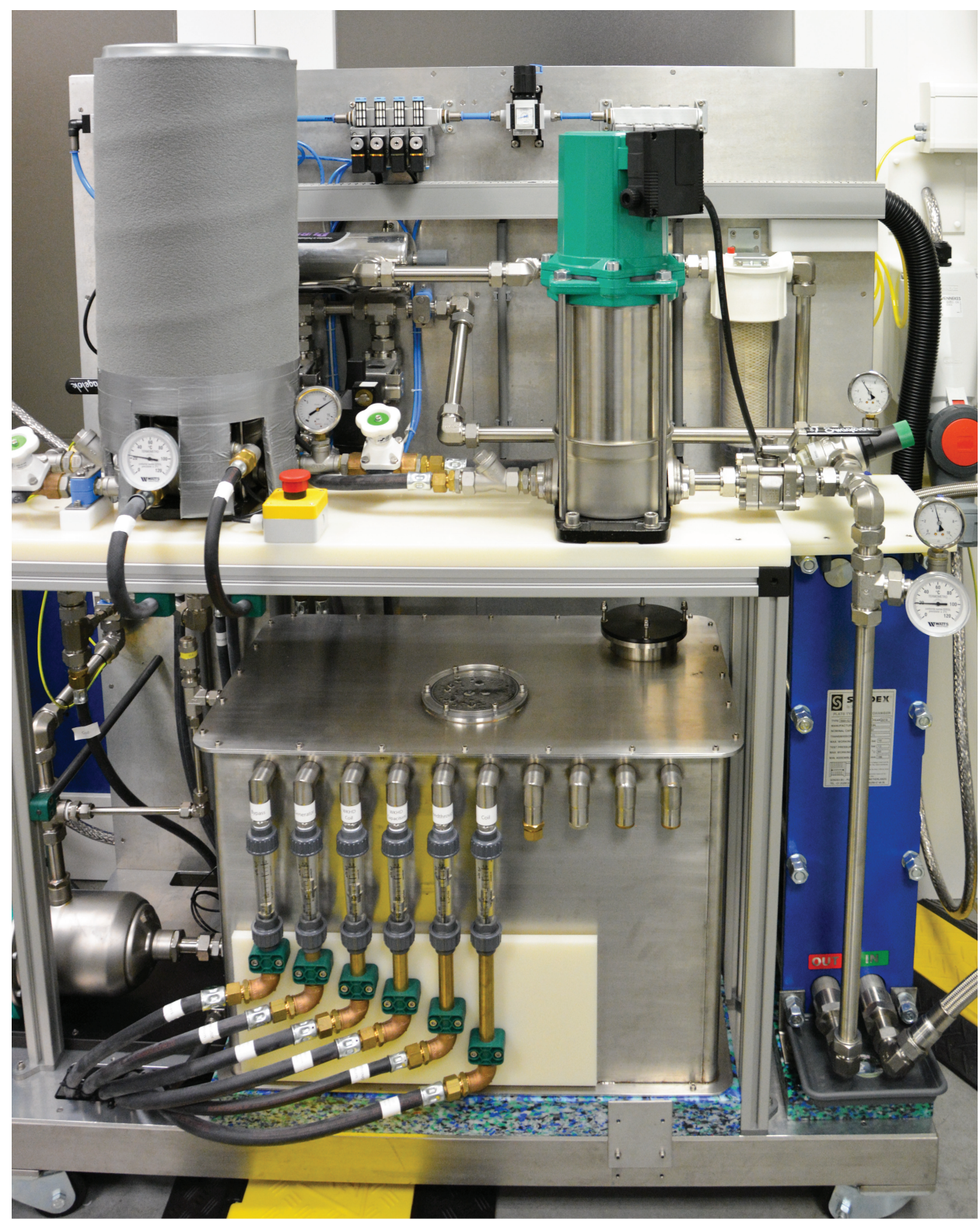

Figure A.6: The watercooling system. Water is pumped from the bath through a UV filter and two particle filters. It is passed through a heat exchanger to cool down, before being sent to the different components of the power source. The water going through the coil flows through two additional pumps to increase the pressure to at least 20 bar. The system can be monitored through digital and analog waterlevel, pressure, flow, and temperature sensors. 


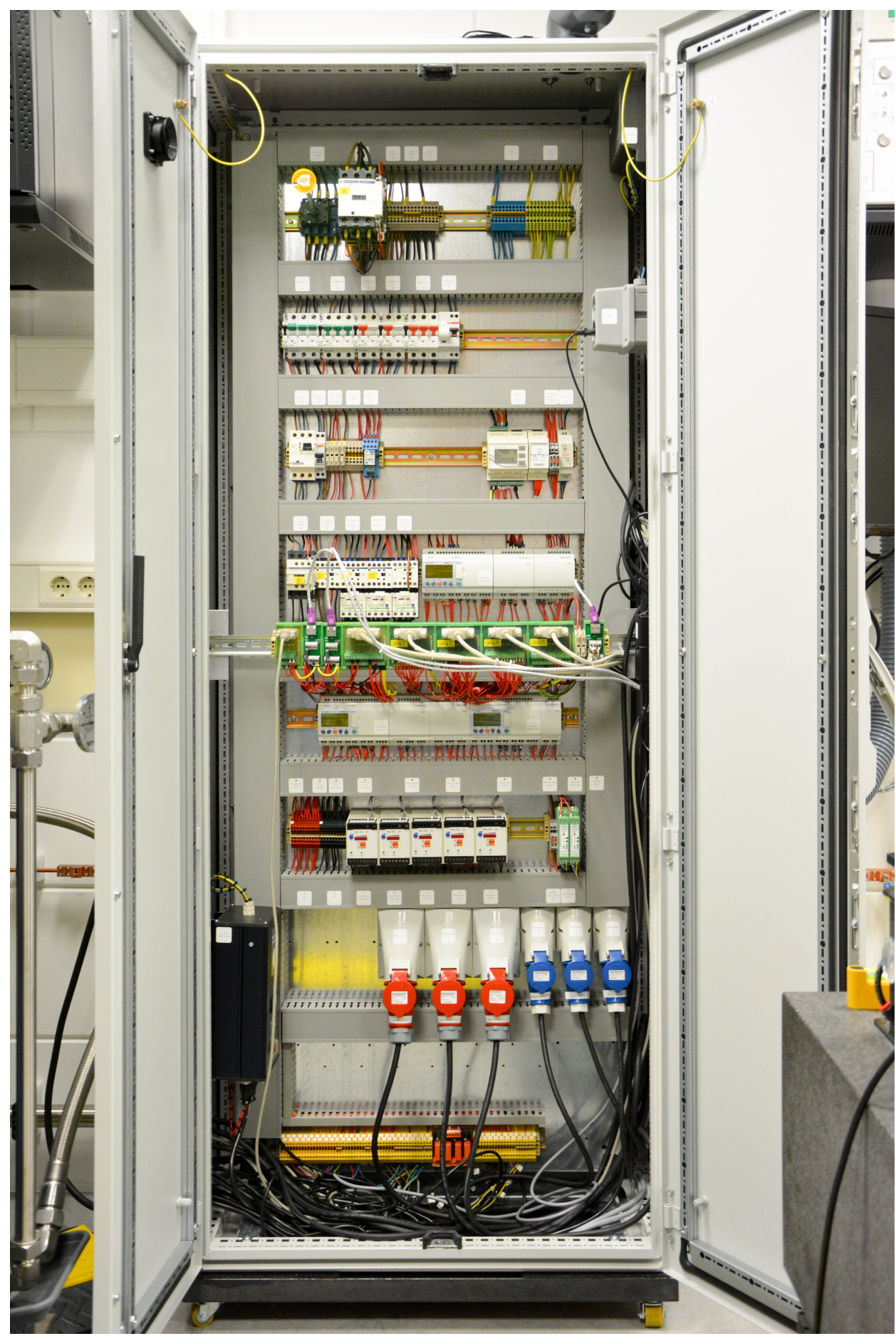

Figure A.7: The cabinet housing the electronics of the setup. It contains circuit breakers, relays, microcontrollers, flow and temperature sensor controllers, pump overheat protection, power outlets, and connections to all individual components of the setup. 


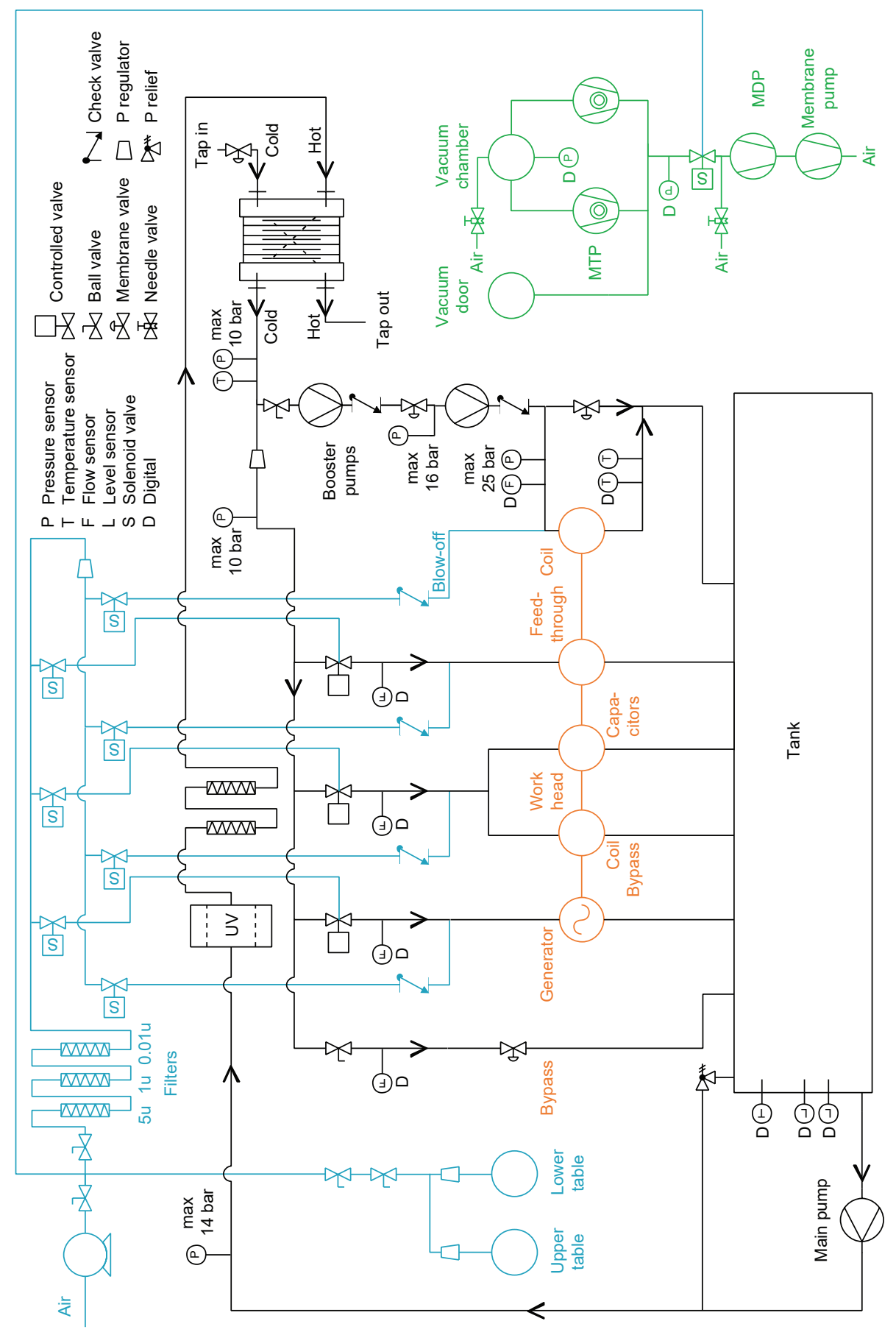

Figure A.8: Schematic diagram of the watercooling and vacuum system. 


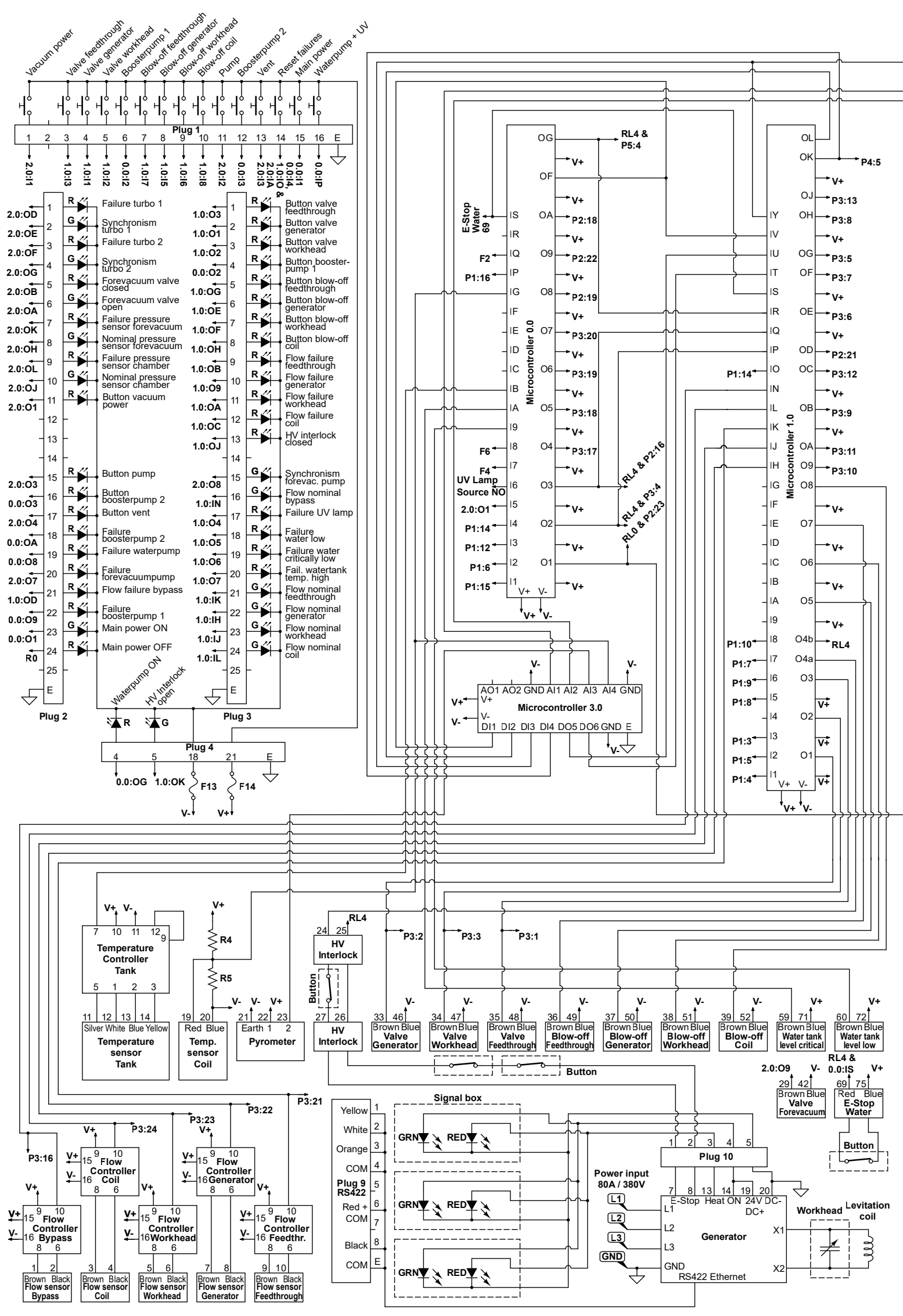



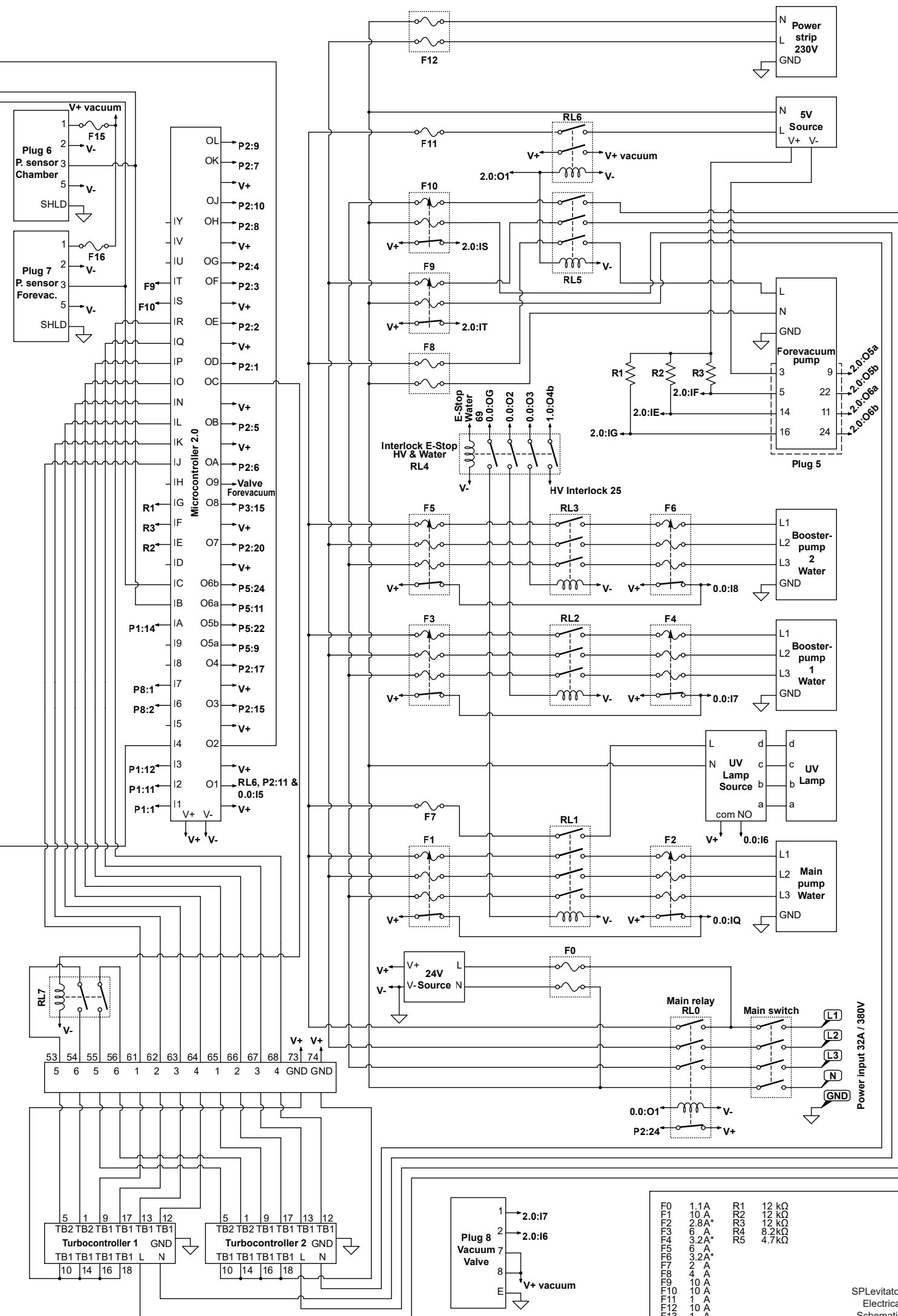

Figure A.9: Schematic diagram of the electronic control system. 
Chapter A Technical details

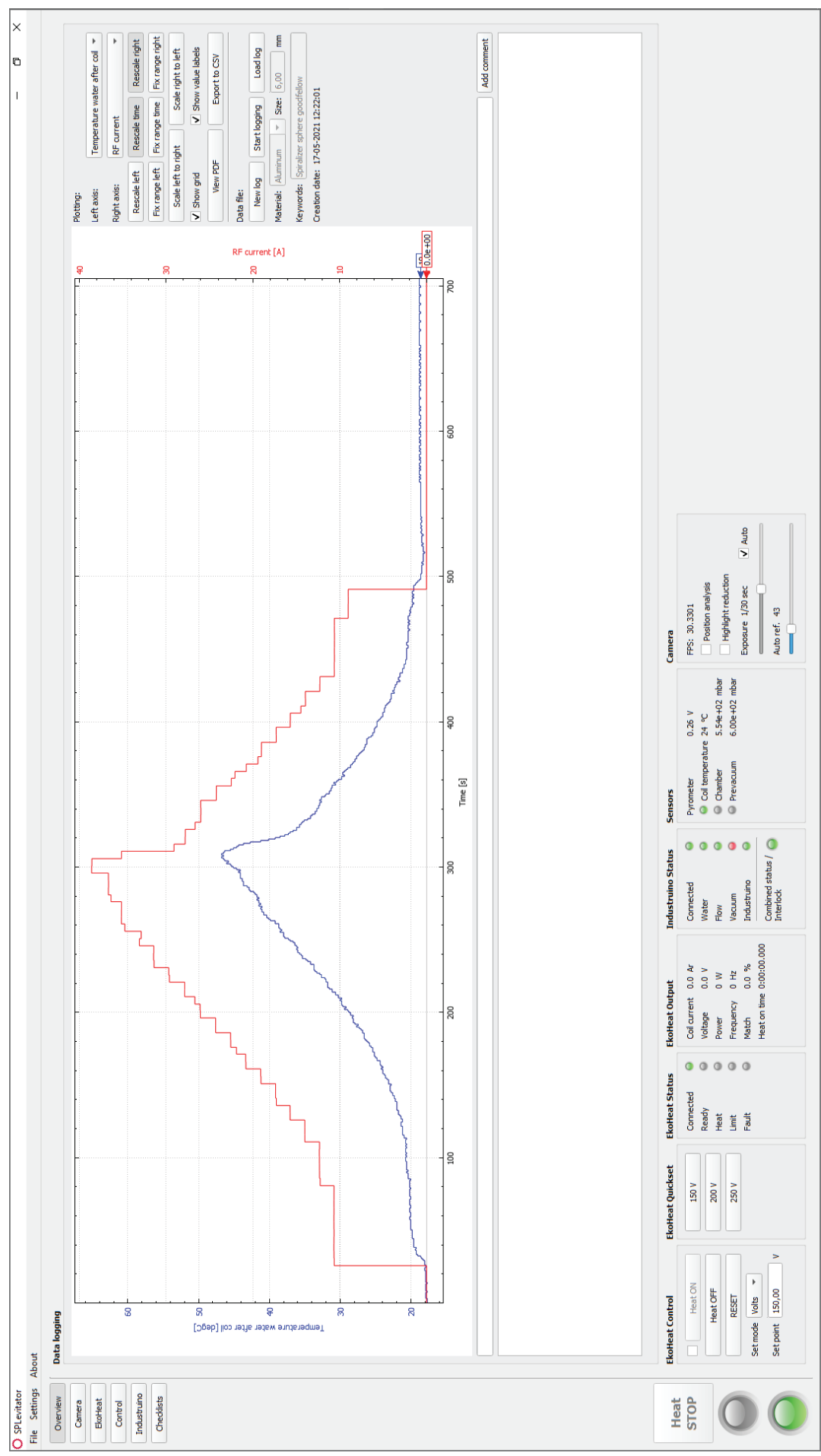

Figure A.10: Main control window which enables data logging and viewing, control of the power source, and control of the camera. 


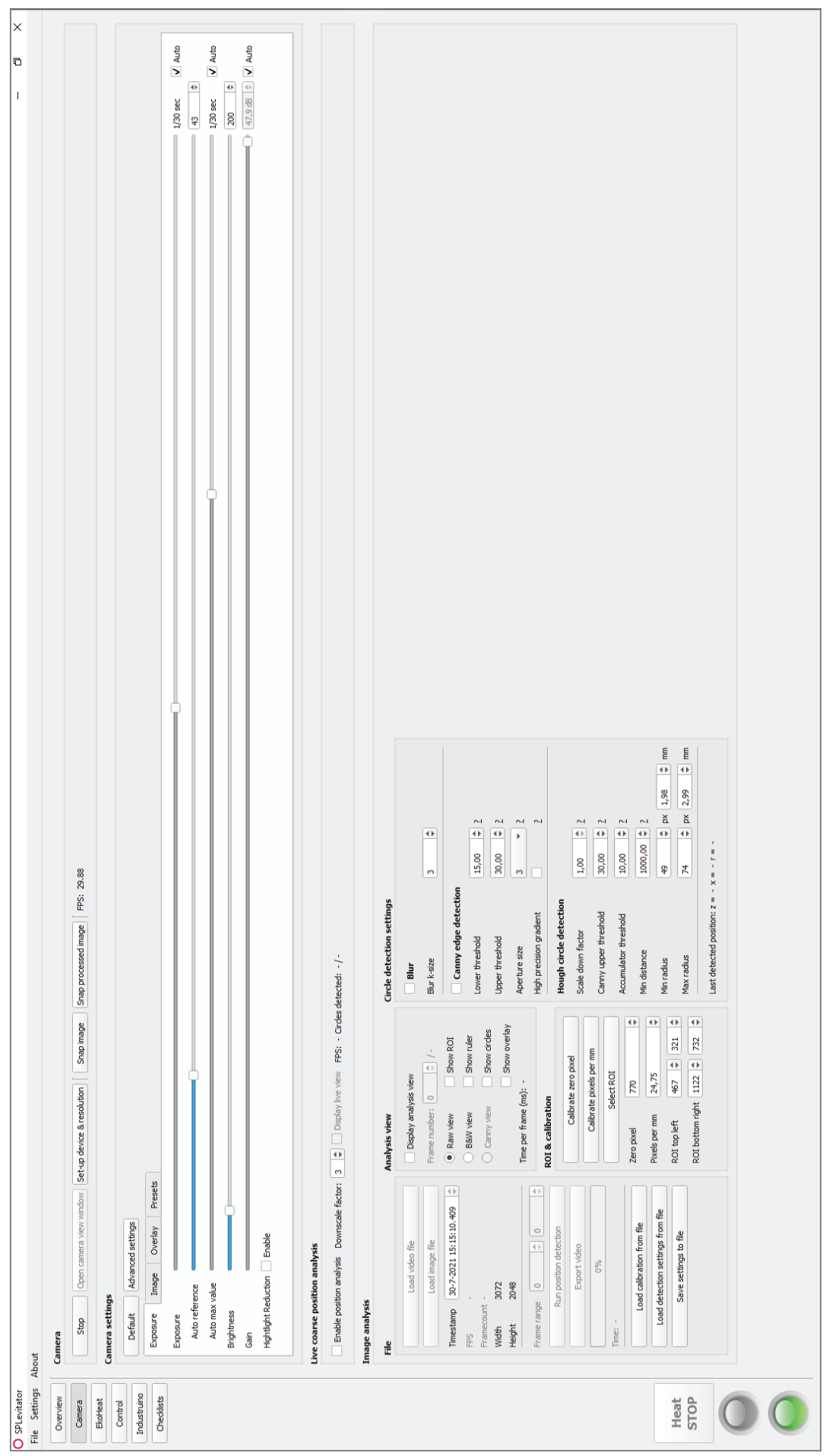

Figure A.11: Camera control window which gives more extensive control over the camera. It also features the control panel for both real-time and post-processing sample detection. 


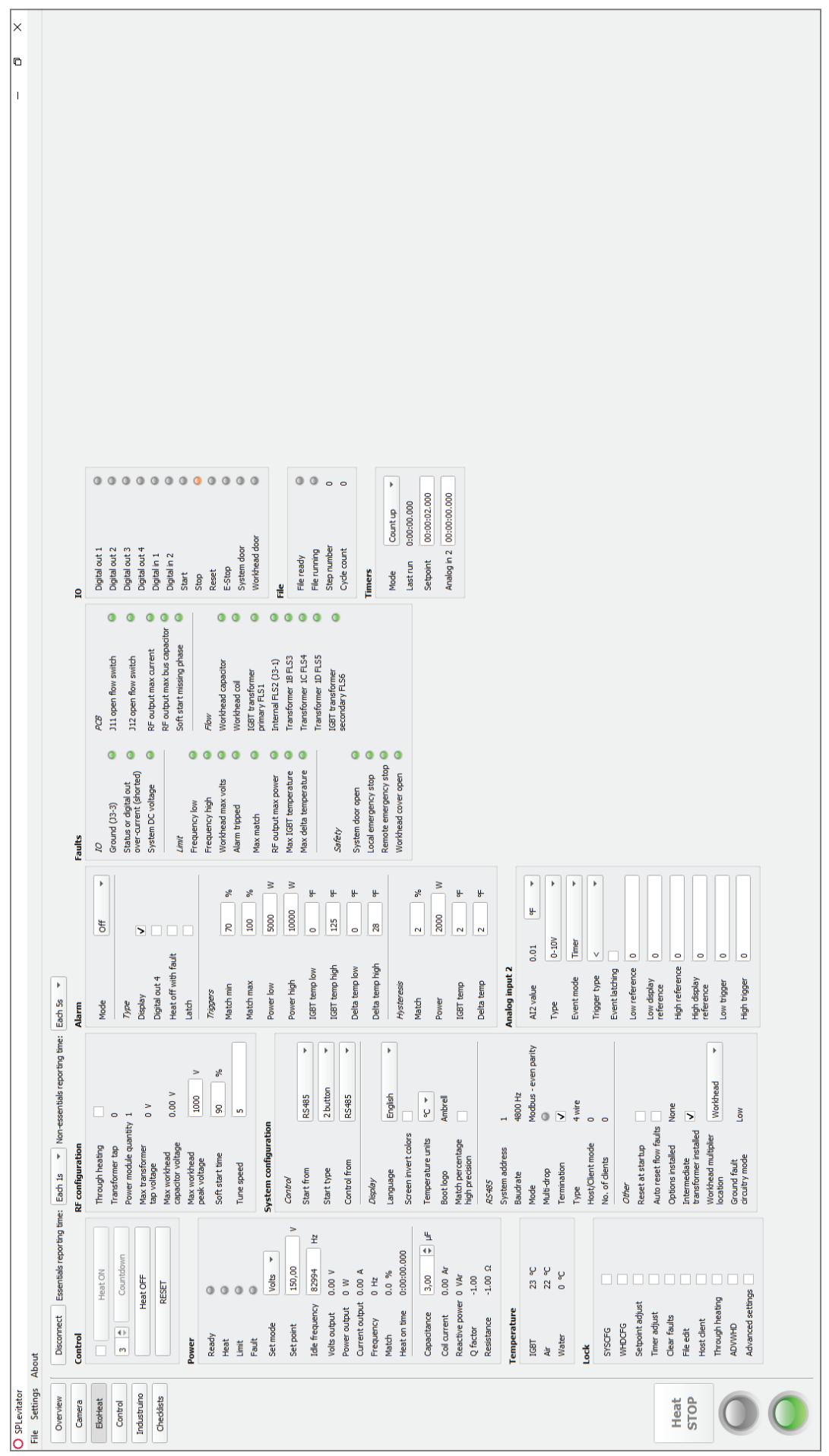

Figure A.12: Control window which gives more extensive control over the power source. 


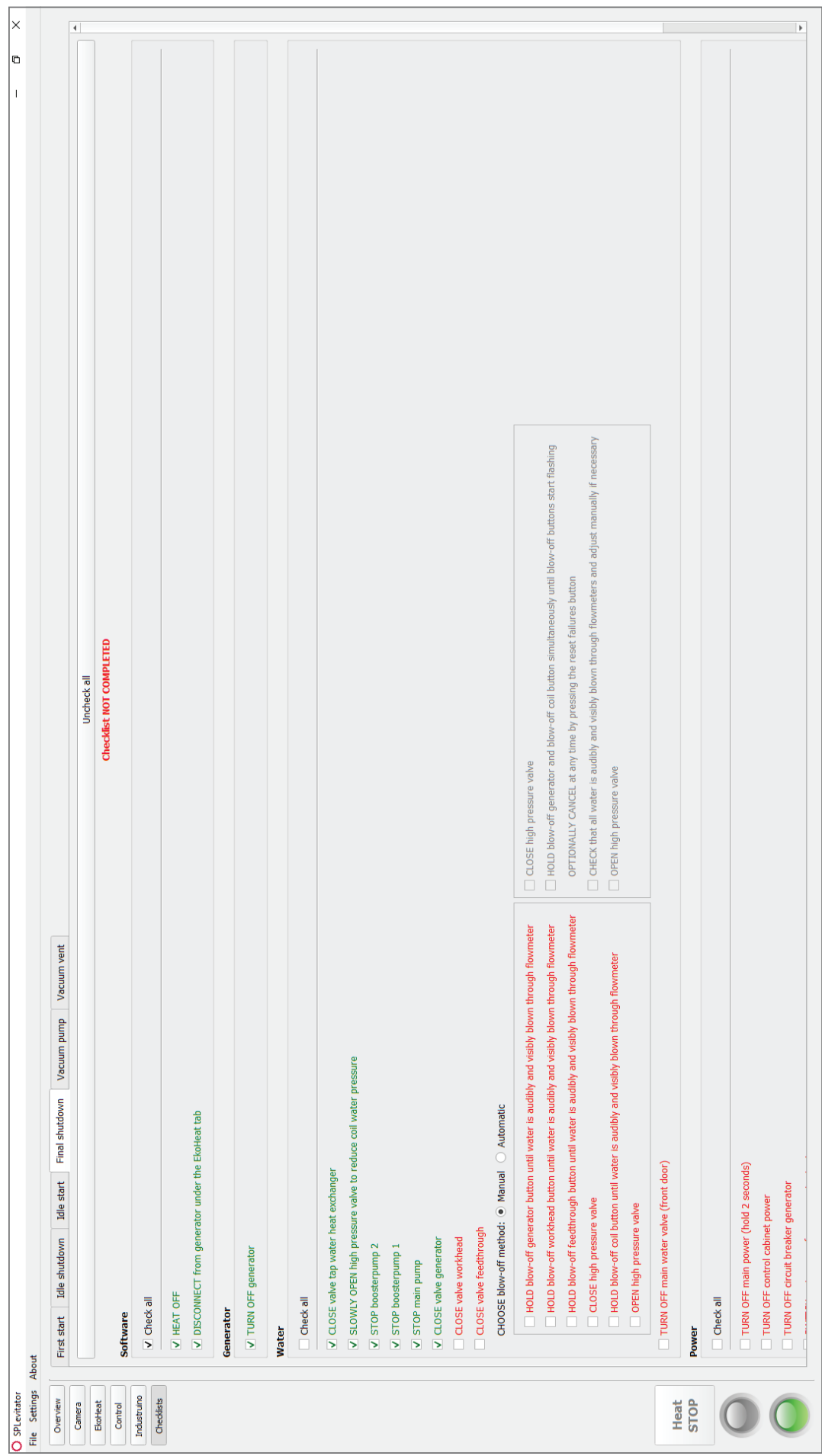

Figure A.13: Window with checklists for start, pause, and stop procedures for all components of the experimental setup. 


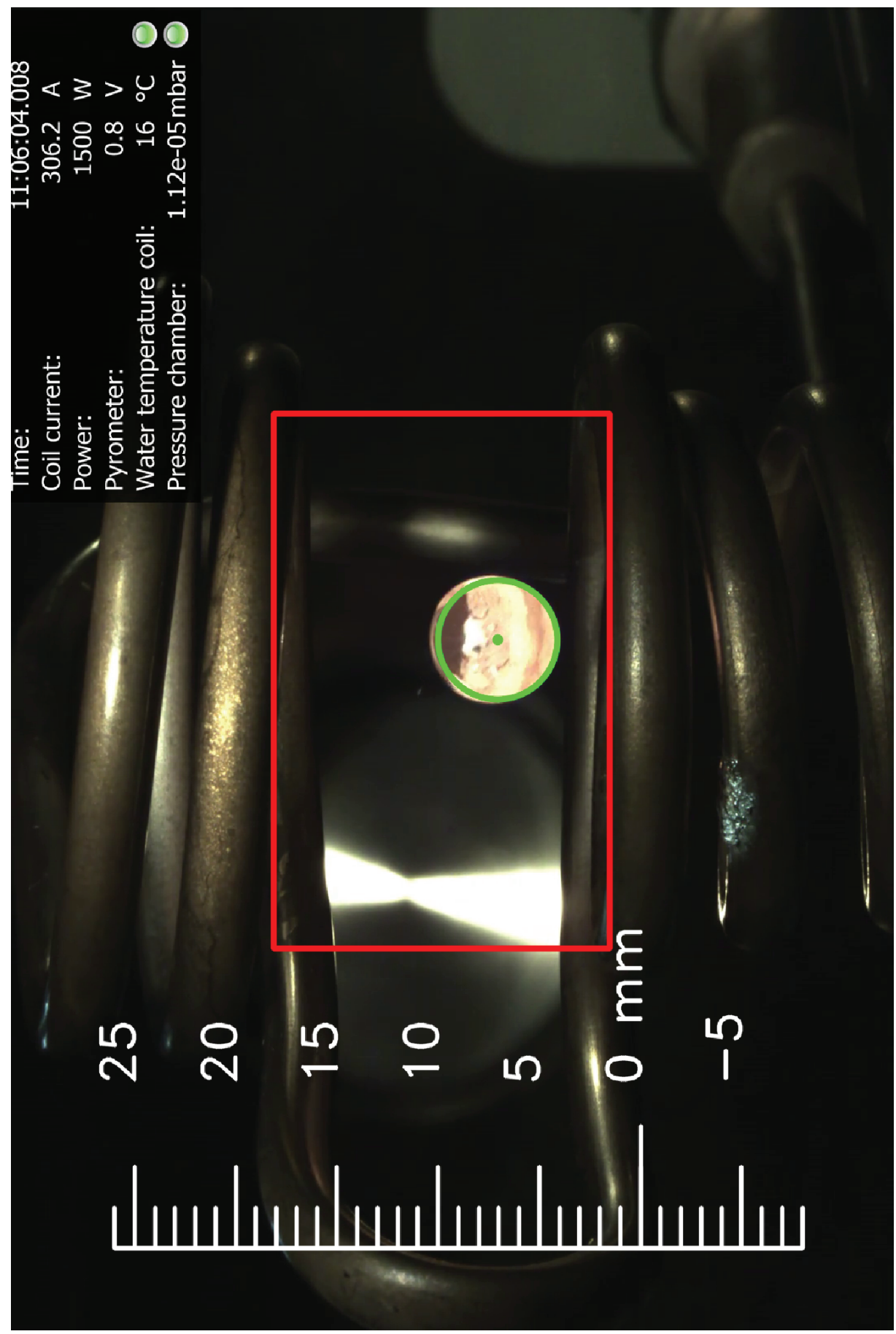

Figure A.14: Analysis view of the camera, which displays several power source parameters such as the current, a calibrated scale, the region of interest for sample tracking and the current detected sample position. 



\section{Summary of experiments with}

\section{various metals}

In this appendix, we show several figures that summarize the results of multiple levitation and crystal growth experiments for various metals.

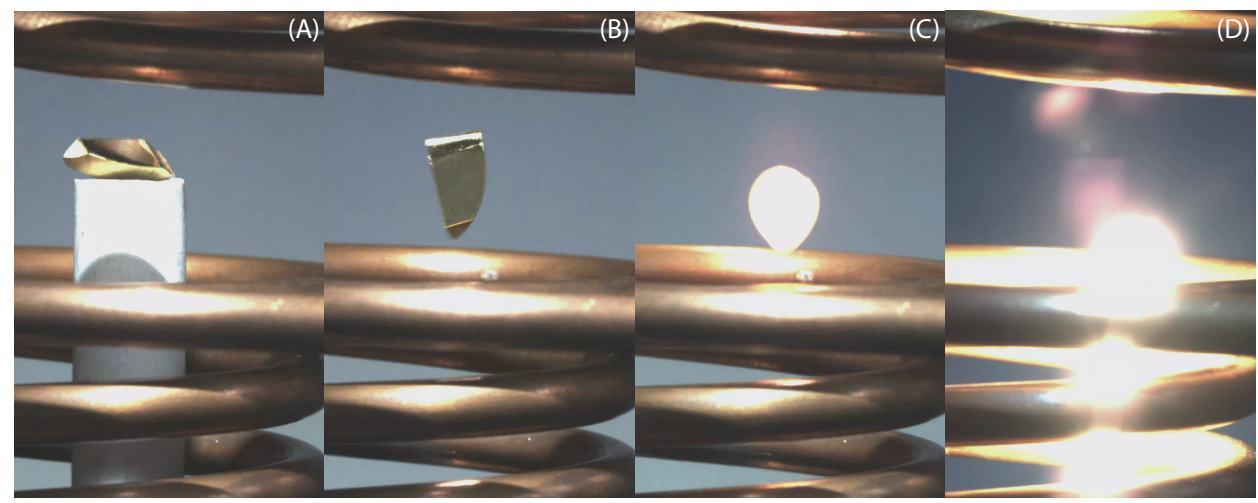

Figure B.1: Gold levitating in air at $1079 \mathrm{~A}$ and $108.9 \mathrm{kHz}$, each still is taken 10 seconds apart. (A) The power is turned on and the sample starts to levitate. (B) The solid sample levitates and descents in the coil as it heats. (C) The sample has molten and has formed a droplet, it descents in the coil as it heats. (D) A jet of small liquid droplets of gold is ejected from the levitating droplet.

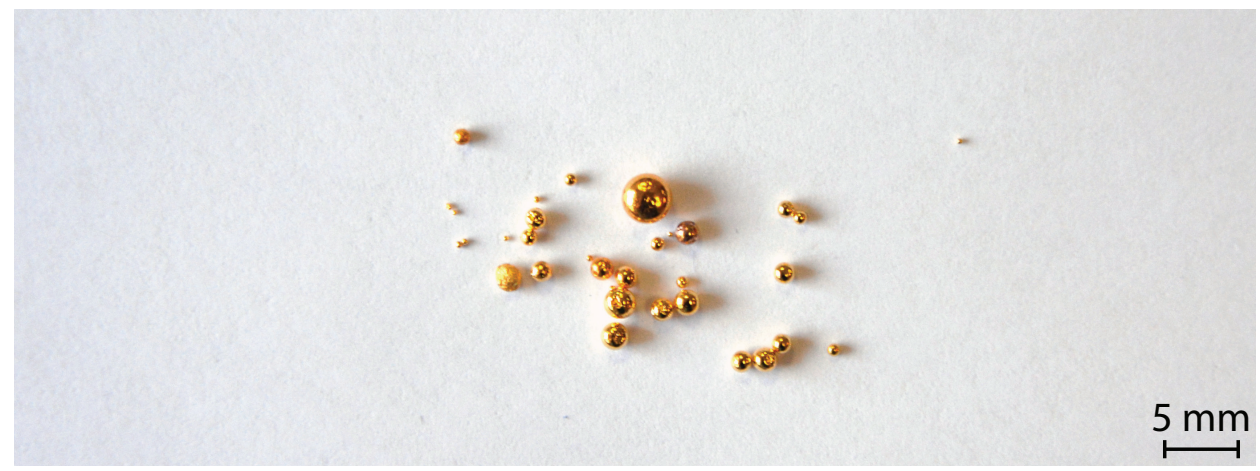

Figure B.2: The jet of gold droplets has solidified into single-crystals up to $3 \mathrm{~mm}$ in size. 


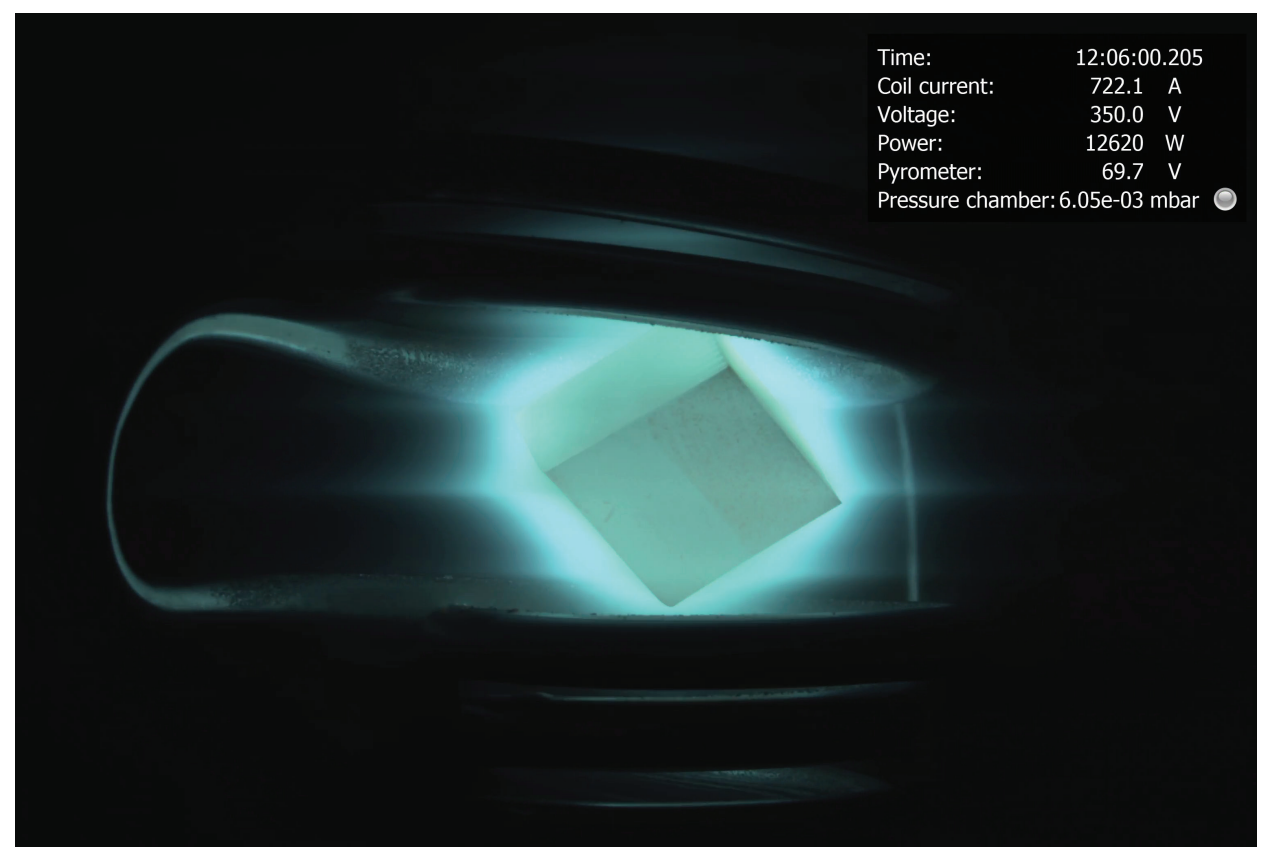

Figure B.3: A levitating cubic sample of chromium, with sides of $12 \mathrm{~mm}$. Due to the low vapor pressure of chromium, the material sublimates as it heats. This increased the pressure in the chamber from $8 \cdot 10^{-6} \mathrm{mbar}$ to $6 \cdot 10^{-3} \mathrm{mbar}$, at which point a plasma ignited.

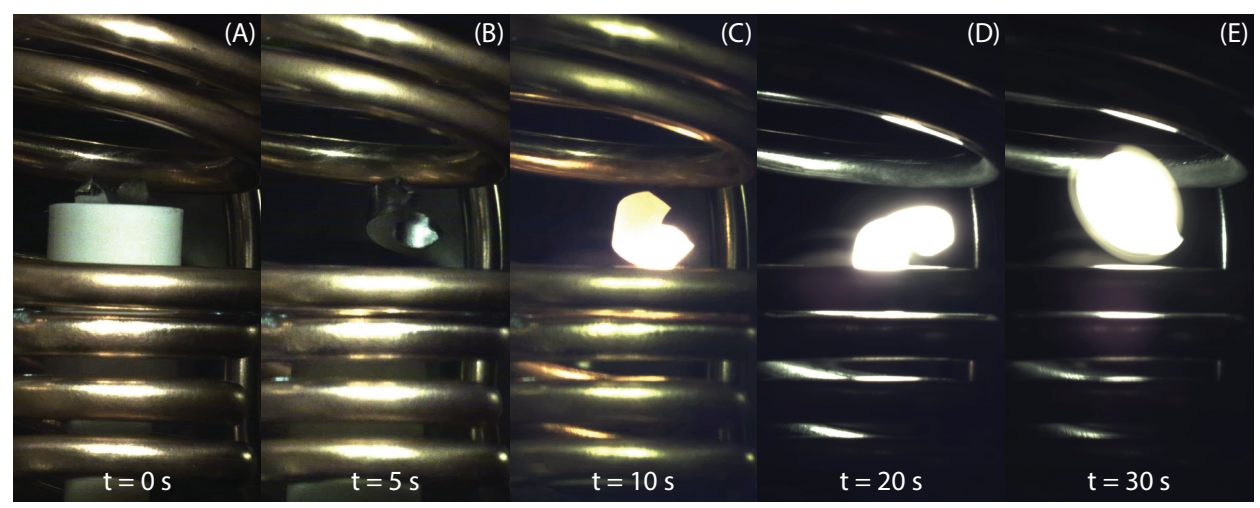

Figure B.4: Vanadium levitating at $1440.5 \mathrm{~A}$ and $109.5 \mathrm{kHz}$ with a pressure of $6.6 \cdot 10^{-6} \mathrm{mbar}$. (A) Start of the experiment, the power is turned on. (B) The sample levitates. (C) The sample heats as it descends in the coil due to increased resistivity. (D) The sample starts to melt. (E) The sample is molten the shape changes to a droplet. It starts to oscillate and spin uncontrollably, so the experiment is aborted. 


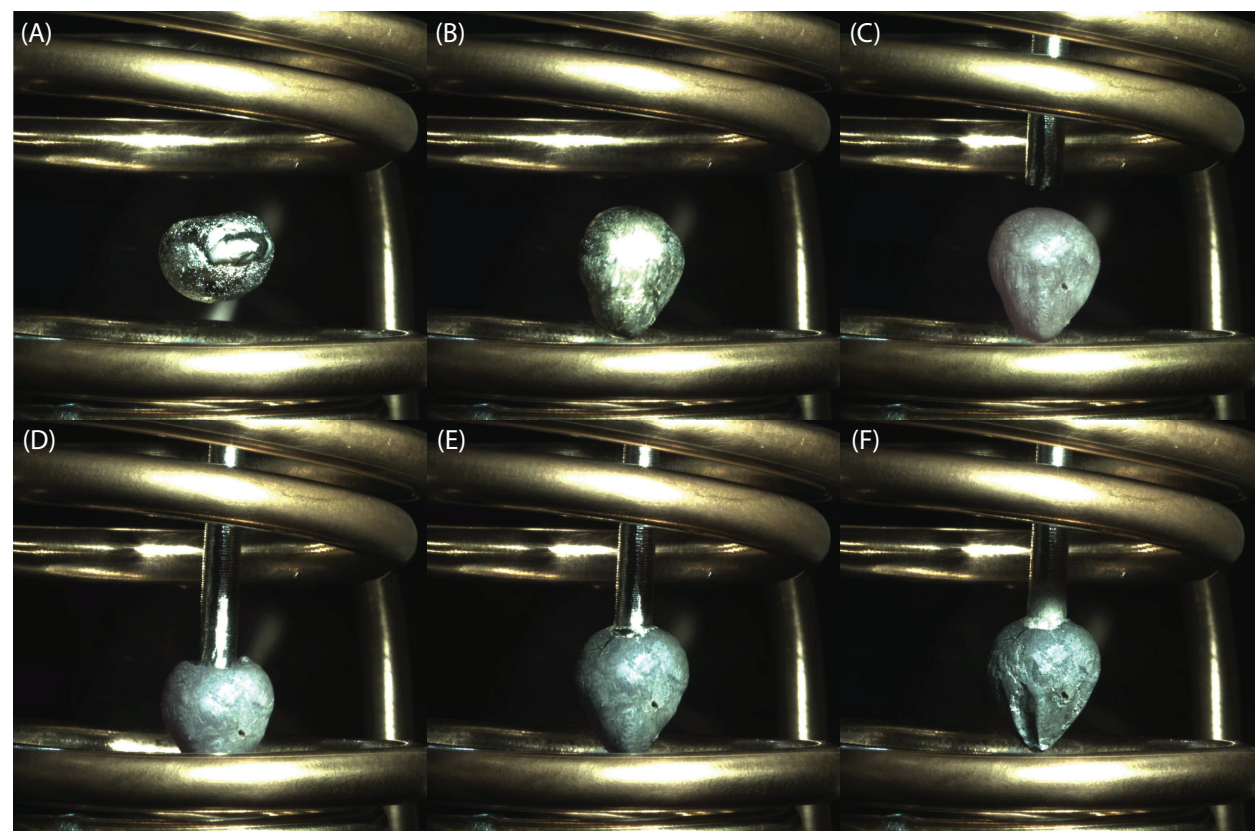

Figure B.5: Aluminum levitating at $308.7 \mathrm{~A}$ and $109.2 \mathrm{kHz}$ in a 1 bar argon environment. (A) The levitating solid sample. (B) The sample is molten, an oxide layer forms on the surface. (C) We lower the seed crystal. (D) The seed cannot penetrate the oxide layer, the sample is pushed down in the coil. (E) We increase the current to $319 \mathrm{~A}$, the oxide layer opens and the sample jumps back to its initial position. (F) As the sample is now further away from the coil, and in contact with the seed, the temperature decreases and the sample solidifies.

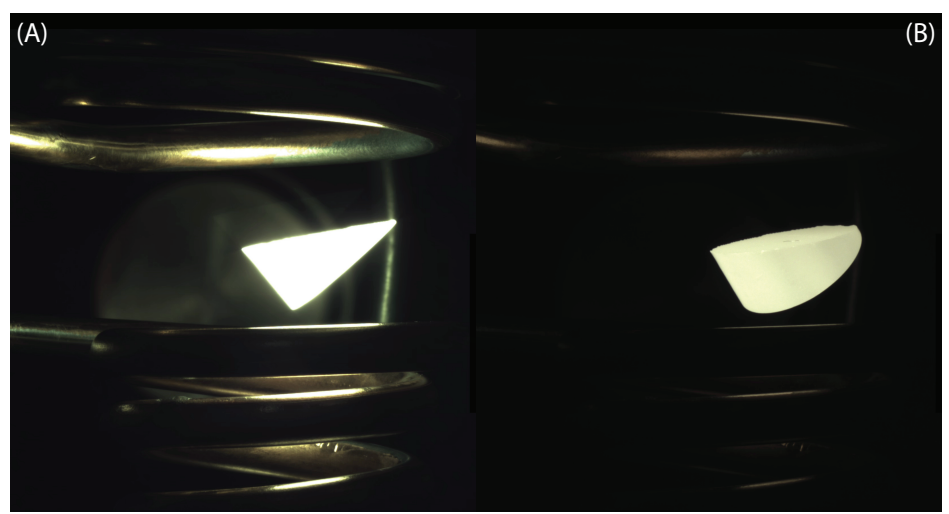

Figure B.6: Tungsten levitating at $904.5 \mathrm{~A}$ and $108.9 \mathrm{kHz}$ with a pressure of $1.3 \cdot 10^{-5} \mathrm{mbar}$. Stable levitation was possible indefinitely, and we could control the temperature, as observed by the pyrometer, by changing the current. However, the temperature did not reach the melting point. (A) High exposure image. (B) Low exposure image. 



\section{Summary}

A single-crystal is a solid object in which an orderly three-dimensional arrangement of the atoms is repeated throughout the entire volume. A polished single-crystal makes for a very well-defined substrate. Therefore, crystals are used extensively in surface physics, catalytic chemistry, and the investigation of material properties. Improvements in singlecrystal fabrication have historically enabled leaps in technological advancements and opened new paradigms of scientific understanding. For example, crystalline silicon forms the base of the modern semiconductor industry. The quality of a crystal is determined by the fabrication method. For a long time, the development of crystal growth techniques stayed well ahead of the development of crystal characterization techniques. Recently, the characterization techniques improved so much that the shortcomings of the traditional crystal growth methods started to surface. The demand from the industry for even higher purity and quality metal single-crystals is growing every day. Thus, this thesis aims to develop an apparatus to grow metal crystals of superior quality and purity.

The growth of elemental metal single-crystals is usually achieved through classic growth techniques such as the Czochralski or floating zone methods. Drawbacks of these techniques are the susceptibility to contamination from the crucible and thermal stressinduced defects due to contact with the ambient. These drawbacks can be mitigated by growing in a containerless environment, which can be achieved by using electromagnetic levitation (EML). EML relies on the Lorentz force that acts between a levitation coil and the metal sample. A high-frequency alternating current in the coil generates a magnetic field that is counterbalanced by another magnetic field arising from eddy currents induced in the metal sample. During levitation, the gravitational force is balanced by the Lorentz force. In addition to generating a Lorentz force, the induced eddy currents cause Joule heating of the sample. Through careful coil design, the coupling between levitation and heating can be controlled to create a comfortable temperature window suitable for crystal growth.

A quantitative understanding of EML is desired to develop a crystal growth apparatus that employs electromagnetic levitation to grow metal crystals of high quality and purity. Chapter 2 looks at the mathematical models available in the literature that have two different approaches: The magnetic flux density approach and the mutual inductance approach. The mutual inductance approach is most suitable for developing the crystal growth apparatus because it can accurately predict the levitation forces, stable levitation position, and the sample temperature for a given coil geometry, sample size, material, 
and power source setting. Most importantly, the fast computation times make it possible to quickly optimize coil designs to find a melting and solidifying procedure for many different metals. A MATLAB implementation of the model is used to find a coil geometry that requires the minimum possible current to levitate a copper sample. In this coil geometry it is possible to levitate samples of 15 different materials if the power source can deliver at least $880 \mathrm{~A}$ at $61 \mathrm{kHz}$.

In Chapter 3 we report on the development of a novel crystal growth apparatus that employs electromagnetic levitation in a vacuum to grow metal single-crystals of superior quality and purity. This apparatus enables two growth modes: containerless undercooled crystallization and levitation-based Czochralski growth. The system can levitate a wide variety of metals while having precise control over the sample temperature in both the liquid and solid state within $1 \mathrm{~K}$. The entire process occurs in a self-leveling vacuum chamber with soft carbon felt at the bottom to protect falling samples. A manipulator allows the insertion of samples and seed crystals from a carousel to the coil. A camera with sample tracking software and a pyrometer provide the operator with information on the sample stability and temperature. An automated water cooling system cools the coil, vacuum feedthrough, capacitor bank, and power source, capable of delivering currents in the order of $1500 \mathrm{~A}$ with a frequency of 50 to $150 \mathrm{kHz}$. As a proof of concept, we show the successful containerless growth of copper single-crystals. These crystals are at least equal in quality to commercially available single-crystals grown using the traditional Czochralski technique. As such, we made an essential contribution towards improving the currently available state-of-the-art crystals.

EML coil design is currently based on two-dimensional (2D) mathematical models combined with empirical data and experience. In Chapter 4, we propose that employing a truly 3D model enables a more accurate and rational coil design. This approach shows significant differences in the magnetic field and the resulting lift and heating properties when comparing a 2D and a 3D coil. A 3D coil, resembling the geometry of a 2D coil, requires more current to generate the same lift. Reversing the situation, a 3D coil producing the exact same magnetic field as a 2D coil has a vastly different design. Furthermore, we show that the assumption that the magnetic field is homogeneous in the axial plane within the sample volume is invalid, even for small samples, in the upper and lower regions of the coil. Using a 3D model, we design a coil capable of levitating and melting an iridium sphere with a diameter of $6 \mathrm{~mm}$.

In Chapter 5, we show that the same Lorentz forces that make electromagnetic levitation possible also induce a deformation in the levitation coil itself. In an experiment, the current is increased from 0 to $1000 \mathrm{~A}$. The levitated sample displaces by $4 \mathrm{~mm}$, while the 
top and bottom part of the levitation coil separate by almost $2 \mathrm{~mm}$. We present a FEM model in COMSOL that qualitatively predicts the coil deformation for direct current but with an amplitude that is too small by two orders of magnitude. For a high-frequency current, resulting in an inhomogeneous eddy current distribution within the coil, we find an amplitude in better agreement with experiments but with incorrect qualitative bending behavior. The coil bending seems to have little effect on the levitation height in our experiments, but it does cause stability problems at high currents. Additional research is required to make a definitive conclusion on the influence of self-induced bending of EML coils on the levitation parameters such as sample temperature.

In general, we have achieved the containerless single-crystal growth via electromagnetic levitation of metal samples using the theory, models, and setup described in this thesis. Still, each material has its own behavior, peculiarities, advantages, and challenges. This makes it difficult to develop a single machine that can produce crystals for all materials. In the future development of the setup, we recommend focusing on a single metal or a group of similar metals. The mathematical model, coil, and setup design can then be optimized for this focus metal. 



\section{Samenvatting}

Een eenkristal is een vaste stof waarin de ordelijke driedimensionale rangschikking van de atomen door translatie door het gehele kristal wordt beschreven. Een gepolijst eenkristal biedt een zeer goed gedefinieerde ondergrond. Daarom worden kristallen op grote schaal gebruikt in oppervlaktefysica, katalyse onderzoek en in de bepaling van materiaaleigenschappen. Door verbeteringen in de productie van eenkristallen zijn grote sprongen in technologische vooruitgang mogelijk gemaakt en nieuwe wetenschappelijke onderzoeksvelden gecreëerd. Zo stond en staat monokristallijn silicium aan de basis van de moderne halfgeleiderindustrie. De kwaliteit van een kristal wordt bepaald door de fabricagemethode. Lange tijd bleef de ontwikkeling van kristalgroeitechnieken de ontwikkeling van kristalkarakteriseringstechnieken ver vooruit. Onlangs zijn de karakteriseringstechnieken zo sterk verbeterd, dat tekortkomingen van de traditionele kristalgroeimethoden aan het licht komen. Vanuit de industrie groeit elke dag de vraag naar een nog hogere zuiverheid en betere kwaliteit van metalen eenkristallen. Dit proefschrift heeft daarom als doel een instrument te ontwikkelen dat metaalkristallen van superieure kwaliteit en zuiverheid kan groeien.

De groei van elementaire metalen eenkristallen wordt meestal bereikt door middel van klassieke groeitechnieken zoals de Czochralski of de smeltende zone methode. Deze technieken hebben echter een hoge gevoeligheid voor verontreinigingen uit de smeltkroes en defecten veroorzaakt door grote gradiënten in de temperatuur tijdens het kristalliseren als gevolg van contact met de omgeving. Deze nadelen kunnen worden voorkomen door te groeien zonder smeltkroes, wat kan worden bereikt met elektromagnetische levitatie (EML). EML is gebaseerd op de Lorentzkracht die werkt tussen een levitatiespoel en het metalen sample. Een hoogfrequente wisselstroom in de spoel genereert een magnetisch veld dat wordt gecompenseerd door een ander magnetisch veld dat voortkomt uit foucaultstromen die in het metalen sample worden geïnduceerd. De Lorentzkracht compenseert de zwaartekracht tijdens het leviteren. Naast het genereren van de Lorentzkracht, genereren de geïnduceerde foucaultstromen ook warmte in het sample door middel van het Joule-effect. Een zorgvuldig spoelontwerp kan zorgen voor de (ont)koppeling tussen levitatie en verwarming zodat een geschikt temperatuurvenster voor kristalgroei ontstaat.

Een kwantitatief begrip van EML is nodig om een kristalgroei opstelling te ontwikkelen waarin via elektromagnetische levitatie metaalkristallen van hoge kwaliteit en zuiverheid gegroeid kunnen worden. In Hoofdstuk 2 worden de twee wiskundige modellen die in 
de literatuur beschikbaar zijn, de magnetische fluxdichtheidsbenadering en de wederzijdse inductiebenadering, besproken. Van deze twee verschillende benaderingen is de wederzijdse inductiebenadering het meest geschikt voor het ontwikkelen van een kristalgroei opstelling omdat het nauwkeurig de levitatiekrachten, stabiele levitatiepositie en de sampletemperatuur kan voorspellen voor een bepaalde spoelgeometrie, samplegrootte, materiaal en stroombroninstelling in een relatief korte rekentijd. Daardoor kunnen snelle optimalisatierondes gemaakt worden om geschikte spoelen te ontwerpen voor het smelten en vervolgens gecontroleerd weer stollen van diverse metalen. Dit in MATLAB geïmplementeerde model wordt gebruikt om een spoelgeometrie te vinden waarin zo min mogelijk stroom wordt gebruikt om een kopersample te laten zweven. In deze spoelgeometrie is het volgens dit model mogelijk om samples van 15 verschillende materialen te laten zweven als de stroombron minimaal $880 \mathrm{~A}$ met $61 \mathrm{kHz}$ kan leveren.

In Hoofdstuk 3 rapporteren we over de ontwikkeling van een nieuw kristalgroeiapparaat dat gebruik maakt van elektromagnetische levitatie in een vacuüm om metalen eenkristallen van superieure kwaliteit en zuiverheid te groeien. Dit apparaat beschikt over twee groeimodi: onderkoelde kristallisatie zonder smeltkroes en op levitatie gebaseerde Czochralski-groei. Het systeem kan een grote verscheidenheid aan metalen laten zweven en geeft binnen $1 \mathrm{~K}$ nauwkeurige controle over de sampletemperatuur in zowel vloeibare als vaste toestand. Het hele proces vindt plaats in een gestabiliseerde vacuümkamer met zacht koolstofvilt aan de onderkant om vallende samples te beschermen. Een manipulator maakt het mogelijk om samples en kiemkristallen uit een carrousel in de spoel in te brengen. Een camera met sample tracking software en een pyrometer geven de operator informatie over de stabiliteit en temperatuur van het sample. Een geautomatiseerd waterkoelsysteem koelt de spoel, vacuümdoorvoer, condensatorbank en stroombron, die stromen kan leveren rond de $1500 \mathrm{~A}$ met een frequentie van 50 tot $150 \mathrm{kHz}$. Als concept demonstratie laten we de succesvolle groei van koperen eenkristallen zien met behulp van de op levitatie gebaseerde Czochralski-groei. Deze kristallen hebben minstens dezelfde kwaliteit als commercieel verkrijgbare eenkristallen die zijn gegroeid door middel van de traditionele Czochralski-techniek. Dit is een veelbelovende techniek voor de verdere verbetering van de huidige productiemethoden van eenkristallen.

Het ontwerp van EML-spoelen is momenteel gebaseerd op tweedimensionale (2D) wiskundige modellen in combinatie met empirische gegevens en ervaring. In Hoofdstuk 4 stellen we dat het gebruik van een echt 3D-model een nauwkeuriger en rationeler spoelontwerp mogelijk maakt. Bij het vergelijken van een $2 \mathrm{D}$ - en een $3 \mathrm{D}$ spoel vinden we significante verschillen in het magnetische veld en de resulterende lift- en verwarmingseigenschappen. Een 3D-spoel, die zoveel mogelijk lijkt op een gegeven geometrie van een 2D-spoel, vereist meer stroom om dezelfde lift te genereren als de mathematische 2D 
spoel. Omgekeerd heeft een 3D-spoel die exact hetzelfde magnetische veld produceert als een 2D-spoel een totaal andere geometrie. Verder laten we zien dat de aanname dat het magnetische veld homogeen is in het axiale vlak binnen het samplevolume ongeldig is, zelfs voor kleine samples, in de bovenste en onderste gedeeltes van de spoel. Met behulp van het 3D-model ontwerpen we een spoel die een iridiumbol met een diameter van $6 \mathrm{~mm}$ kan laten zweven en smelten.

In Hoofdstuk 5 tonen we dat dezelfde Lorentzkrachten die elektromagnetische levitatie mogelijk maken, ook een vervorming in de levitatiespoel zelf veroorzaken. In een experiment wordt de stroom opgevoerd van 0 naar $1000 \mathrm{~A}$. Het zwevende sample verplaatst zich met $4 \mathrm{~mm}$, terwijl het bovenste en onderste deel van de levitatiespoel bijna $2 \mathrm{~mm}$ van elkaar worden weggeduwd. We presenteren een FEM-model in COMSOL dat kwalitatief de spoelvervorming voorspelt voor gelijkstroom, maar een amplitude heeft die twee ordes van grootte te klein is. Voor een hoogfrequente stroom, resulterend in een inhomogene foucaultstroom verdeling in de spoel, vinden we een amplitude die beter overeenkomt met experimenten maar een onjuist kwalitatief buiggedrag heeft. De spoelbuiging lijkt in onze experimenten weinig effect te hebben op de levitatiehoogte, maar veroorzaakt wel stabiliteitsproblemen bij hoge stromen. Aanvullend onderzoek is nodig om een definitieve conclusie te trekken over de invloed van zelfgeïnduceerde buiging van EML-spoelen op de levitatieparameters zoals sampletemperatuur.

Kortom, we hebben zwevende eenkristalgroei via elektromagnetische levitatie van metaalsamples bereikt met behulp van de theorie, modellen en experimentele opstelling die in dit proefschrift worden beschreven. Desondanks heeft elk materiaal zijn eigen gedrag, eigenaardigheden, voordelen en uitdagingen. Dit maakt het moeilijk om één instrument te ontwikkelen waarmee kristallen van uiteenlopende metalen kunnen worden geproduceerd. Voor de toekomstige ontwikkeling van de opstelling raden we aan om te concentreren op een enkel metaal of op een groep vergelijkbare metalen. Het wiskundige model, de spoel en het ontwerp van de opstelling kunnen vervolgens worden geoptimaliseerd naar de eisen van dit metaal. 



\section{Scientific output}

\section{Thesis publications}

- J.P. Witteveen, A. van Houselt, R. van Gastel, and H.J.W. Zandvliet. "Zwevende kristalgroei: Gecontroleerde groei van metalen éénkristallen via elektromagnetische levitatie" NEVAC blad, 59(1):7-11, 2021. (Chapter 3)

- J.P. Witteveen, M.A.B. Vrielink, R. van Gastel, A. van Houselt, and H.J.W. Zandvliet. "Containerless metal single-crystal growth via electromagnetic levitation." Review of Scientific Instruments, 92:105105, 2021. DOI: 10.1063/5.0064486 (Chapter 3)

- J.P. Witteveen, R. van Gastel, A. van Houselt, and H.J.W. Zandvliet. "3D modeling of electromagnetic levitation coils." Current Applied Physics, 32:45-49, 2021. DOI: 10.1016/j.cap.2021.09.016 (Chapter 4)

\section{Other publications}

- P. Bampoulis, J.P. Witteveen, E.S. Kooij, D. Lohse, B. Poelsema, and H.J.W. Zandvliet. "Structure and Dynamics of Confined Alcohol-Water Mixtures." ACS Nano, 10(7):6762-6768, 2016. DOI: 10.1021/acsnano.6b02333

- M. Kataja, F. Freire-Fernández, J.P. Witteveen, T.K. Hakala, P. Törmä, and S. van Dijken. "Plasmon-induced demagnetization and magnetic switching in nickel nanoparticle arrays."

Applied Physics Letters, 112(7):072406, 2018. DOI: 10.1063/1.5012857

- H. Qin, S.J. Hämäläinen, K. Arjas, J.P. Witteveen, and S. van Dijken. “Propagating spin waves in nanometer-thick yttrium iron garnet films: Dependence on wave vector, magnetic field strength, and angle."

Physical Review B, 98(22):224422, 2018. DOI: 10.1103/PhysRevB.98.224422 


\section{Oral presentations}

- J.P. Witteveen, R. van Gastel, A. van Houselt, and H.J.W. Zandvliet. "3D modeling of electromagnetic levitation coils (for containerless single crystal growth)." Physics@ Veldhoven, Veldhoven, The Netherlands, January 2021.

\section{Poster presentations}

- J.P. Witteveen, R. van Gastel, R.J.I.M. Koper, A. van Houselt, and H.J.W. Zandvliet. "Levitating metal crystals"

Physics@ Veldhoven, Veldhoven, The Netherlands, January 2018.

- J.P. Witteveen, R. van Gastel, J.W.M. van Dorsselaer, R.J.I.M. Koper, A. van Houselt, and H.J.W. Zandvliet. "Levitating metal crystal growth" Physics @ Veldhoven, Veldhoven, The Netherlands, January 2019.

- J.P. Witteveen, R. van Gastel, J.W.M. van Dorsselaer, R.J.I.M. Koper, A. van Houselt, and H.J.W. Zandvliet. "Levitating metal crystal growth"

Physics @ Veldhoven, Veldhoven, The Netherlands, January 2020. 


\section{Curriculum vitae}

\begin{tabular}{|c|c|}
\hline Name & Jorn Witteveen \\
\hline Date of birth & September 12, 1994 \\
\hline Place of birth & $\begin{array}{l}\text { Vlissingen (Zeeland), } \\
\text { the Netherlands }\end{array}$ \\
\hline Website & www.jpwitteveen.com \\
\hline Email address & connect@jpwitteveen.com \\
\hline
\end{tabular}

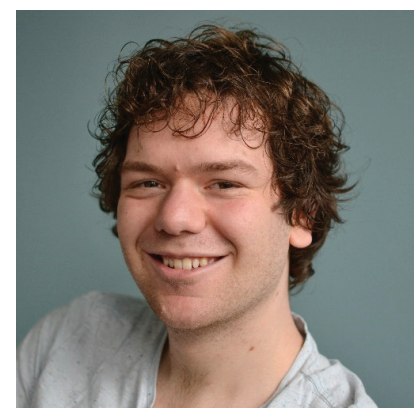

\begin{tabular}{lr} 
Education & \\
PhD in Applied Physics & University of Twente \\
Oct 2017-Dec 2021 & Surface Preparation Laboratory \\
Master in Nanotechnology & University of Twente \\
Sep 2015 - Sep 2017 & University of Twente \\
Bachelor in Advanced Technology & \\
Sep 2012 - Aug 2015 & \\
\hline
\end{tabular}

\footnotetext{
(17) Work experience

PhD in Applied Physics

Oct 2017 - Dec 2021

University of Twente Surface Preparation Laboratory I have designed, built, tested and implemented a device that can levitate and melt metal in a vacuum to fabricate very pure metal crystals.

\section{Internship}

Aalto University

Aug 2016 - Jan 2017

Research in the NanoSpin group on spin wave manipulation via plasmonic nano-heating.

University assistant

University of Twente

Sep 2013 - Jul 2017

Lecturing and guiding students on electrodynamics (including three trips to CERN), error analysis, MATLAB, modelling, general statics, dynamics and network analysis.
} 



\section{Dankwoord - Acknowledgments}

Beste lezer, bedankt voor het op zijn minst lezen van dit dankwoord. Blader ook eens door de rest van dit boek, het is een mix van mooie foto's uit IJsland en gave plaatjes van vliegend gesmolten metaal. Elke letter die je extra leest zie ik als een leuke bonus. Mocht je naast de afbeeldingen hier en daar een stukje wetenschappelijk onderzoek tegenkomen dan kun je je afvragen of ik dat allemaal alleen heb gedaan. Er staat immers maar één naam op de voorkant. Toch is dit boek niet voor niets in de wij-vorm geschreven. Daarom bedank ik hier iedereen die in enige vorm heeft bijgedragen aan de totstandkoming van deze thesis.

Harold, nadat je me aan een bacheloropdracht en een stageplek had geholpen stond ik in januari 2017 bij je in de kamer voor een masteropdracht. Die had je wel, op voorwaarde dat ik zou blijven hangen voor een promotietraject. Een traject dat mij de komende vijf jaar bezig zou blijven houden. Toen ik 24 uur later je aanbod accepteerde was jij wellicht nog wel blijer dan ik op dat moment. Ik had namelijk nog geen idee wat en wie ik in Zaandam zou gaan aantreffen. Wel had ik het vertrouwen dat jij wist welk project de perfecte match zou zijn voor mij. Dat vertrouwen bleek gegrond. Dit avontuur was een gezonde mix tussen de academische wereld en de industrie, met genoeg uitdaging in de natuurkunde en vooral ook de engineering. Al tijdens de masteropdracht heb je mij heel veel zelfstandigheid gegeven, wat ik erg waardeer. Tijdens de promotie heb je altijd vol achter mij en mijn werk gestaan en je enthousiasme bleef onverminderd, zelfs na afwijzing op afwijzing van mijn eerste artikel. Bedankt voor alles.

Arie, bedankt voor de begeleiding vanuit Enschede. Je was altijd beschikbaar voor een overleg, het zoeken van een onderdeel uit de voorraadkasten daar, of het doorlezen van al mijn schrijfwerk. Het was fijn hoe jij meedacht over de communicatie naar de journals, met uiteindelijk een positief resultaat. Ik kijk met veel plezier terug op onze gezamenlijke begeleiding van Bram en Maarten, dat was een hele prettige samenwerking!

I would like to thank prof. Abelmann, dr. Dhallé, prof. Huijben, prof. Otte, and prof. Palasantzas for spending their time to read this thesis and for being a part of my graduation committee. I thank prof. Juurlink, dr. Weststrate, prof. Otte, and dr. Schuddeboom for the fruitful discussions during the user committee meetings.

Rene, net afgestudeerd en met een hoofd vol gedachtes drukte jij een moersleutel in mijn hand. Eerst maar eens de hele vacuümketel demonteren, schoonmaken en weer monteren. Dankzij jou heb ik me enorm ontwikkeld in de praktische kant; hoe kom je van een idee tot een werkbaar iets? Ik heb genoten van onze tijd waarin we aan het koelrek 
en de ketel sleutelden, de water- en elektra infrastructuur plaatsten en de spoelen bogen en soldeerden. Los daarvan waren er zo veel gezellige etentjes dat ik de tel ben kwijt geraakt. Bedankt voor deze mooie jaren bij SPL!

Raoul, bij jou kon ik juist terecht voor alle natuurkunde en wetenschap. Alhoewel je je niet te veel probeerde te bemoeien met hoe Rene en ik de opstelling bouwden kwam je toch regelmatig met een goede ingeving. Toen we uiteindelijk begonnen met experimenteren had ik je graag aan mijn zijde. Vier ogen zien nou eenmaal meer dan twee. Bedankt ook voor alle goede gesprekken aan de koffiewatertafel en de gezellige 6-minuten-kletspraatjes.

Jessika, it seems so long ago that we celebrated your birthday on a conference in Bulgaria. A shame we didn't get to travel to other places. Thanks for the cooperation with building the open air setup and the experiments. Best of luck to you with the remainder of your research!

Randall, bedankt voor de leuke en gezellige tijd tijdens mijn eerste jaren bij SPL. Je zorgde altijd voor veel vrolijkheid en mooie verhalen over je belevenissen aan de andere kant van de oceaan. Gracias amigo!

Joop, menig idee is door jou uitgewerkt tot een prachtige technische tekening. Hierdoor konden we snel nieuwe onderdelen realiseren als we weer eens tegen een probleem aan liepen. Bovendien scheelde het mij zeeën van tijd, bedankt daarvoor!

Bram, een paar weken nadat jij bij mij was begonnen brak de coronapandemie uit. Het was even zoeken naar een goede werkvorm voor ons. Gelukkig kan je heel zelfstandig werken en ben je ijzersterk in simuleren. Het DC COMSOL model uit hoofdstuk 5 is grotendeels jouw verdienste. Bedankt voor de prettige samenwerking!

Maarten, in de 13 maanden waarin we hebben samengewerkt hebben we elkaar goed leren kennen. Los van het feit dat je een uitstekende experimentator bent, heb ik erg genoten van onze gezamenlijke lunches en gesprekken. Je zorgde altijd voor een goede portie enthousiasme en wat reuring. Je vele scherpe vragen prikkelden mij om ook voor mezelf goed op een rijtje te zetten waarom we nou deden wat we deden en de fysica is zoals die is. Als kers op de taart staat ook jouw naam boven het artikel dat in dit boek een groot deel van hoofdstuk 3 vult. Heel erg bedankt!

Dear PIN collegues, although I only showed my face on the university about once per month, I have always felt connected and included by everyone. This only grew stronger when we started meeting online for our Monday morning sessions. Thanks for all the great discussions, support and small talk. 
Kees en Bernhard, bedankt voor jullie steun als paranimfen. Maar bovenal bedankt voor de steun tijdens het hele promotietraject, de vele uitsmijters in de Gallery, en de logeerplek die altijd beschikbaar was als ik vroeg in Enschede moest zijn. Ik hoop dat we met Rob en Ineke nog een hoop leuke dingen en zaken mogen beleven!

Ik bedank al mijn vrienden van de studie voor de gezellige tijd! Martijn, ik hoop dat we nog lang random technische berichten in de CloudCatcher app blijven sturen. Lisette, bedankt voor alle diepe en luchtige gesprekken. Koen, Tom, Wout en de rest van de AT club, bedankt voor de leuke uitstapjes naar binnen- en buitenland en de all-round gezelligheid.

Thanks for filling my playlist, Gareth Emery, Above \& Beyond, Lane 8, and Ben Böhmer. Uiteraard wil ik ook mijn familie bedanken. Mijn ouders, Fred en Arianne, bedankt voor alle liefde en steun. Birrit en Mats, bedankt voor alle ontspannen en gezellige weekendjes in Zeeland tussen de drukte door. En tot slot mijn oma, Koos, ondanks dat dit één van de weinige zinnen in dit boek is die je zult snappen spreek je altijd vol trots over mijn werk.

Lieve Freija, ík verliet joú toen ik naar Finland vertrok. Vervolgens was ik ook de eerste die besloot in Amsterdam te gaan werken. Jij had je maar weer te schikken aan mijn plannen, wat je zonder enige vorm van mopperen deed. De afgelopen jaren hebben we allebei mogen ervaren wat het is om PhD-er te zijn, daardoor wist je maar al te goed hoe je mij kon steunen. Bedankt voor het aanhoren van mijn geklaag, mijn frustraties, maar ook voor het luisteren naar de mooie momenten en het delen van mijn enthousiasme. Bedankt voor het organiseren van de prachtige reizen die we hebben gemaakt. Bedankt voor de kleine momentjes die we pakten tijdens het thuiswerken. Maar bovenal bedankt dat je er altijd voor me bent! 

